\title{
Biochemical and clinical factors in rhegmatogenous retinal detachment
}

Citation for published version (APA):

Diederen, R. M. H. (2007). Biochemical and clinical factors in rhegmatogenous retinal detachment.

[Doctoral Thesis, Maastricht University]. Universiteit Maastricht. https://doi.org/10.26481/dis.20070405rd

Document status and date:

Published: 01/01/2007

DOI:

10.26481/dis.20070405rd

Document Version:

Publisher's PDF, also known as Version of record

\section{Please check the document version of this publication:}

- A submitted manuscript is the version of the article upon submission and before peer-review. There can be important differences between the submitted version and the official published version of record.

People interested in the research are advised to contact the author for the final version of the publication, or visit the DOI to the publisher's website.

- The final author version and the galley proof are versions of the publication after peer review.

- The final published version features the final layout of the paper including the volume, issue and page numbers.

Link to publication

\footnotetext{
General rights rights.

- You may freely distribute the URL identifying the publication in the public portal. please follow below link for the End User Agreement:

www.umlib.nl/taverne-license

Take down policy

If you believe that this document breaches copyright please contact us at:

repository@maastrichtuniversity.nl

providing details and we will investigate your claim.
}

Copyright and moral rights for the publications made accessible in the public portal are retained by the authors and/or other copyright owners and it is a condition of accessing publications that users recognise and abide by the legal requirements associated with these

- Users may download and print one copy of any publication from the public portal for the purpose of private study or research.

- You may not further distribute the material or use it for any profit-making activity or commercial gain

If the publication is distributed under the terms of Article $25 \mathrm{fa}$ of the Dutch Copyright Act, indicated by the "Taverne" license above, 


\section{Biochemical and clinical factors in rhegmatogenous retinal detachment}

Roselie M.H. Diederen 


\section{Biochemical and clinical factors in rhegmatogenous retinal detachment}

Roselie M.H. Diederen

ISBN/EAN: 978-90-9021705-5

Layout: $\quad$ Jook van der Snel

Cover Painting Alan Davie, Draak- puzzel Nr 2; 1970

All rights reserved. No part of this publication may be reproduced in any material form (including photocopying or storing in any medium by electronic means) without the written permission of the authors and other copyright owner(s).

Applications for the copyright owner's permission to reproduce any part of this publication should be addressed to the publisher.

Disclaimer: Whilst the authors, editor and publisher have tried to ensure the accuracy of this publication, the publisher, authors and editors cannot accept responsibility for any errors, omissions, misstatements, or mistakes and accept no responsibility for the use of the information presented in this work.

\section{(C) 2007 R.M.H. Diederen}




\title{
Biochemical and clinical factors in rhegmatogenous retinal detachment
}

\author{
PROEFSCHRIFT \\ TER VERKRIJGING VAN DE GRAAD VAN DOCTOR \\ AAN DE UNIVERSITEIT MAASTRICHT, \\ op geZag VAn DE ReCtor Magnificus, Prof. Mr. G.P.M.F. Mols \\ VOLGENS Het BESLUIT VAN HET COLLEGE VAN DECANEN, \\ IN HET OPENBAAR TE VERDEDIGEN
}

OP DONDERDAG 5 APRIL OM 14:00 UUR

DOOR

ROSELIE MARIA HELENA DIEDEREN 


\section{Promotor:}

Prof. dr. F. Hendrikse

Co-promotores:

Dr. E. C. La Heij

Dr. J. De Vente

\section{Beoordelingscommissie:}

Prof. dr. H.W.M. Steinbusch

Prof. dr. J.C. Van Meurs (Erasmus Universiteit Rotterdam)

Prof. dr. F.C.S. Ramaekers

Prof. dr. P.J. Ringens (Vrije Universiteit Amsterdam)

Dr. C.A.B. Webers 


\section{CONTENTS}

Chapter 1 General Introduction

Chapter 2 Scleral buckling surgery after macula-off retinal detachment; worse visual outcome after more than six days

Chapter 3 Pre-operative factors influencing visual outcome and anatomic success after retinal detachment without macular involvement

Chapter 4 Increased glutamate levels in the vitreous of patients with retinal detachment

Chapter 5 Increased nitric oxide (NO) pathway metabolites in the vitreous fluid of patients with rhegmatogenous retinal detachment or diabetic traction retinal detachment.

Chapter 6 Cyclic GMP synthesis by human retinal pigment epithelial cells is mainly mediated via the particulate guanylyl cyclase pathway.

Chapter 7 Two autocrine pathways to regulate cGMP synthesis in cultured human RPE cells

Chapter 8 Selective blockade of Phosphodiesterases Types 2, 5 and 9 results in cGMP accumulation in Retinal Pigment Epithelium Cells

Chapter 9 Cyclic GMP in the pig vitreous and retina after experimental retinal detachment

Chapter 10 General discussion

Summary / Samenvatting

Curriculum vitae

Acknowledgements / Dankwoord

Publications and Presentations 


\section{ABBREVIATIONS}

ANP

BNP

cGMP

CNP

DMEM

EAA

GABA

GC

GS

GTP

HPLC

IBMX

ILM

iNOS

IPL

NMDA

NO

NOS

nNOS

OPL

PDR

PVD

PVR

PDE

RPE

RRD

SNP

TBS atrial natriuretic peptide

brain-type natriuretic peptide

3',5' - guanosine monophosphate

c-type natriuretic peptide

dulbecco's modified Eagle's medium

Exacitatory amino acid

gamma-aminobutyric acid

guanylyl cyclase

glutamine synthetase

guanosine '5-triphophate

high pressure liquid chromatography

3 - isobutyl -1 - methylxanthine

inner limiting membrane

inducible nitric oxide synthetase

inner plexiform layer

$N$-methyl-D-aspartatic acid

nitric oxide

nitric oxide synthetase

neuronal nitric oxide synthetase

outer plexiform layer

proliferative diabetic retinopathy

posterior vitreous detachment

proliferative vitroretinopathy

phosphodiesterase

retinal pigment epithelium

rhegmatogenous retinal detachment

sodium nitroprusside

tris buffered saline 


\section{CHAPTER I}

\section{General introduction}

Biochemical and clinical factors in

rhegmatogenous retinal detachment

Roselie M.H. Diederen 



\section{THE RETINA AND VITREOUS}

\section{Neurosensory Retina}

The retina is an approximately $0.5 \mathrm{~mm}$ thick multi-layered sensory tissue that lines the back of the eye. All vertebrate retinas are composed of three layers of nerve cell bodies and two layers of synapses.

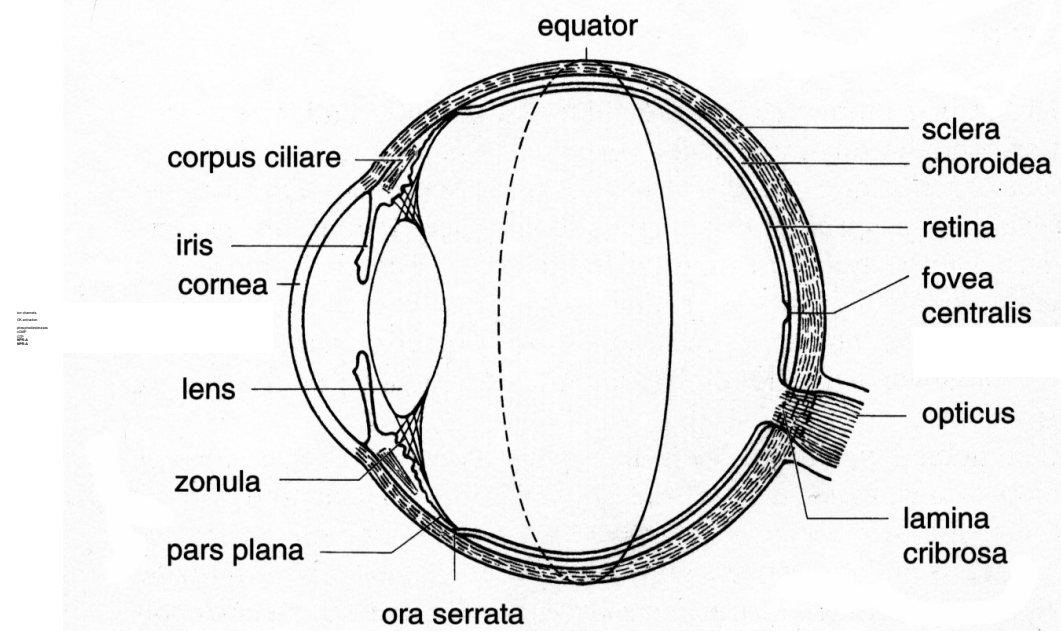

Figure 1. The eye. Adapted from Praktische Oogheelkunde, Bohn Stafleu Van Loghum, 1996. With permission.

The outer nuclear layer contains cell bodies of the photoreceptor cells. There are two types of photoreceptors in the retina: rods and cones. The middle nuclear layer contains cell bodies of the bipolar, horizontal and amacrine cells and the inner cell layer contains cell bodies of ganglion and displaced amacrine cells. Dividing these nerve cell layers there are two regions where synaptic contacts between cells occur. The first region is the outer plexiform layer (OPL) where connections between rod and cones, and vertically running bipolar cells and horizontally oriented horizontal cells occur. Cone photoreceptors have a one to-one synapse with bipolar cells whereas more than one rod, and sometimes more than 100 rods converge to each bipolar cell. The second region of synaptic contact, is the inner plexiform layer (IPL), where the bipolar cells connect to the ganglion cells. In addition, amacrine cells interact in further networks to influence and integrate the ganglion cell signals. Light striking the retina must travel through the full thickness of the retina to reach the photoreceptors. The visual information is transmitted from the retina to the brain along the optic nerve. The inner limiting membrane (ILM), situated between the retina and the vitreous is the innermost layer of 


\section{Chapter I}

the retina. The ILM is formed by the footplates of Müller cells, which is contiguous with the most posterior aspect to the vitreous.

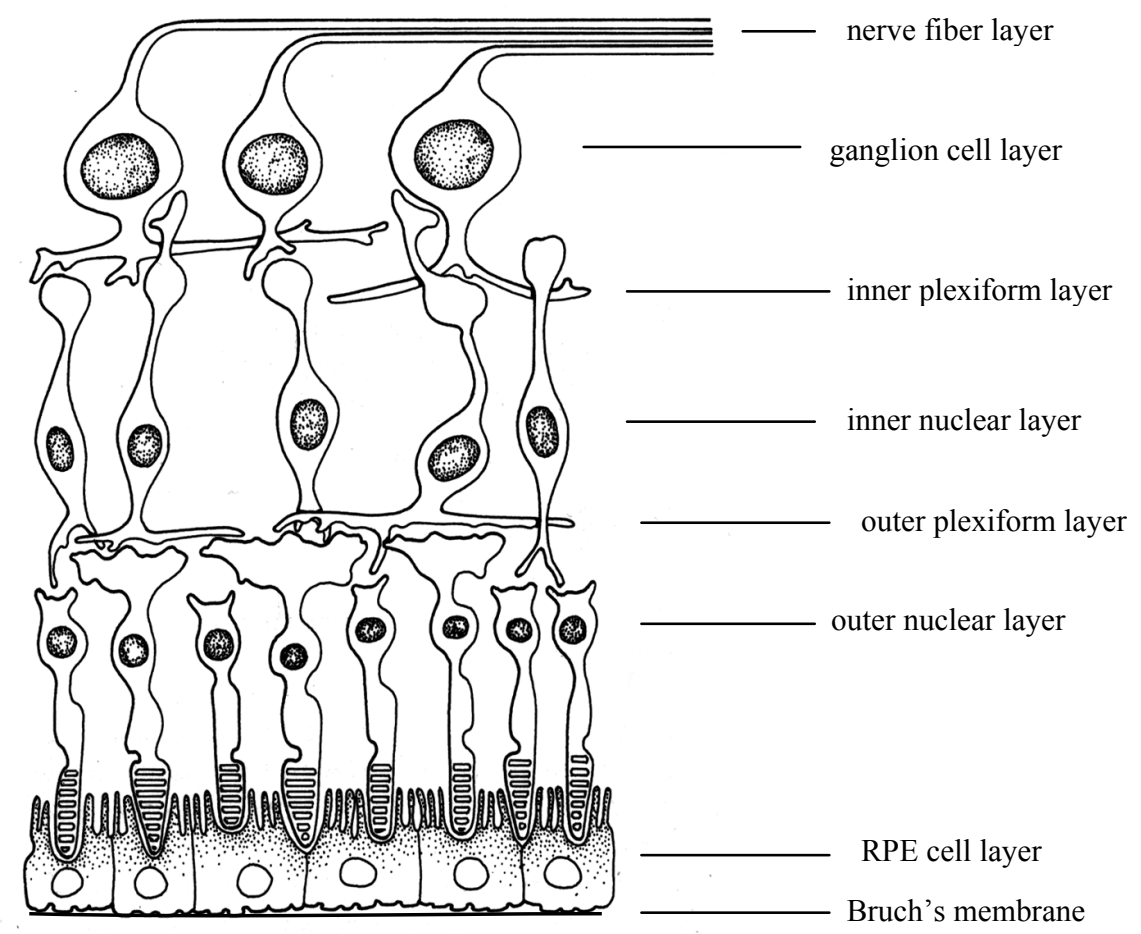

Figure 2. The retina. Adapted from Praktische Oogheelkunde, Bohn Stafleu Van Loghum, 1996. With permission.

The human retina contains approximately 6 million cones. Cones function best in bright light and allow us to distinguish color. The cones are concentrated in the area defined as the macula lutea or yellow spot. The macula contains xanthophyll (yellow) pigment that is visible through an ophthalmoscope. This area is 5-6 $\mathrm{mm}$ in diameter and defines the center of the retina. The central $1.5 \mathrm{~mm}$ within the macula is occupied by the fovea, which is the region of highest visual acuity. In the fovea, the ratio of ganglion cells to photoreceptors is the highest in the eye. In addition, at the fovea all of the other cell types squeeze out of the way to allow a maximum of light to hit the cones. This makes the fovea visible microscopically, appearing as a pit in the retina. No retinal blood vessels are present in and around the fovea. This structural specialization maximizes visual acuity at the fovea. There are approximately 125 million rods. They are spread throughout the peripheral retina and have their greatest density about $20^{\circ}$ from fixation. Rods function best in dim lighting and are responsible for peripheral and night vision. 


\section{Retinal Pigment Epithelium}

The retinal pigment epithelium (RPE) is a monolayer of cuboidal cells situated between Bruch's membrane and the retina. These RPE cells perform a variety of functions including inhibition of light scattering (as a result of their pigmentation) and endocytosis and breakdown of disk membranes that are shed by the photoreceptor cells on a diurnal basis. RPE cells also participate in the visual cycle by generating 11-cis-retinaldehyde that is used in the activation of rhodopsin in the photoreceptors. As a result of light absorption, transretinaldehyde is formed by bleaching of rhodopsin. This is reduced to all-trans-retinol which is then moved back to the RPE cells where 11-cis-retinol is regenerated.

RPE cells also play an essential role in maintaining the integrity of the blood-retinal barrier and thereby control access of blood-borne molecules to the neural retina. ${ }^{1}$ In addition, RPE cells are involved in absorption of subretinal fluid, which is part of the mechanism keeping the photoreceptor layer in close contact with the RPE cells. ${ }^{2}$ Because RPE cells are in such close contact with the photoreceptor cells they are able to facilitate the supply of necessary substrates, including oxygen to the photoreceptor cells. Together, RPE cells are critical to the functioning of the eye and are involved in many eye diseases, such as age-related macular degeneration, Stargardt disease and proliferative vitreoretinopathy (PVR).

\section{The Vitreous}

The vitreous is a clear matrix, occupying the posterior segment of the globe. The vitreous body is composed of water (99\%), a small amount of collagen and hyaluronic acid. Vitreous humor transmits light, supports the posterior surface of the lens, contributes to the intraocular pressure and holds the neural retina tightly against the pigment epithelial cells. It is bound anteriorly by the posterior segment of the lens capsule and posteriorly it is in close contact with the retina, and attached to the optic disc and vitreous base. With ageing, particularly in myopic eyes, the central vitreous undergoes liquefaction or syneresis. This causes the vitreous to shrink and ultimately detach from the retina and optic disc. This process is called posterior vitreous detachment (PVD). Symptoms of PVD include photopsias (flashing of light), caused by the physical stimulus of vitreoretinal traction on the retina and floaters. Many patients do not report acute symptoms when a PVD occurs.

\section{RHEGMATOGENOUS RETINAL DETACHMENT (RRD)}

\section{Pathophysiology}

Because the vitreous gel remains attached at the base, traction caused by spontaneous or traumatic PVD can cause retinal breaks. Approximately 15\% of all patients with acute symptomatic PVD are found to have one or more 


\section{Chapter I}

retinal breaks. ${ }^{4}$ Retinal breaks in symptomatic eyes have a high risk of causing rhegmatogenous (rhegma means break in Greek) retinal detachment (RRD). RRD is caused by liquefied vitreous passing through a retinal break into the potential subretinal space between the photoreceptor layer and the RPE (Figure 3). When situated in the subretinal space, the fluid is called subretinal fluid. The retina will then start to detach from the underlying tissue. Since most tears occur in the peripheral retina, the detachment will first cause loss of the peripheral visual field. The patient may remark a curtain or dark shadow. As the detachment extends towards the macula, the shadow will also enlarge. An acute drop in (central) visual acuity will occur when the macula detaches. Without surgical repair, most rhegmatogenous detachments will eventually involve the entire retina and lead to blindness of the affected eye.

If a retinal break is discovered before a detachment occurs, it can be treated to prevent the retina from detaching. Usually photocoagulation (laser) is used to treat a retinal break. The laser creates a series of burns surrounding the break which eventually scar and seal the retina to the underlying tissue. This prevents fluid (liquid vitreous) from passing through the break and detaching the retina.
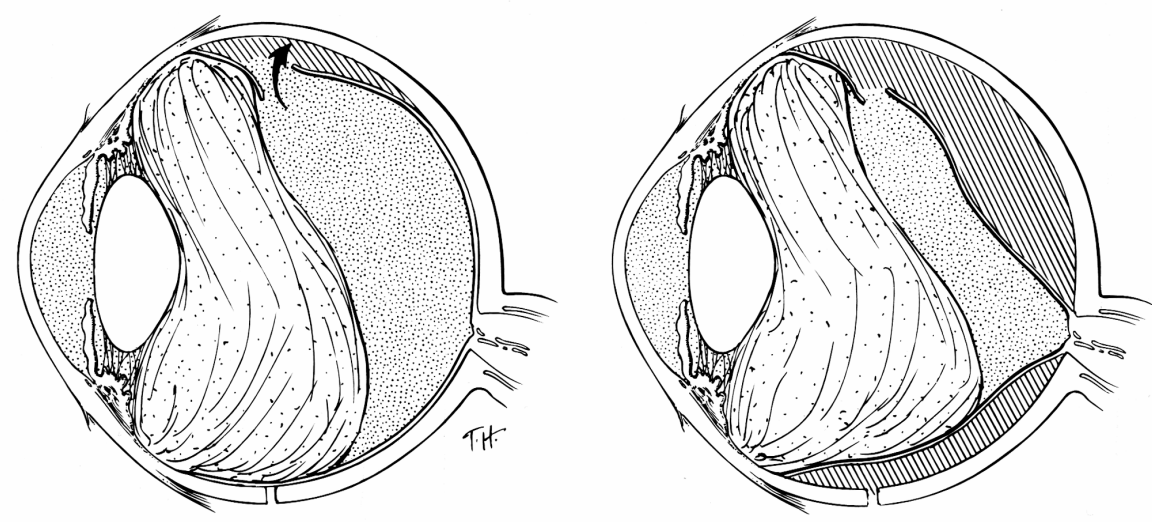

Figure 3. Rhegmatogenous retinal detachment (RRD). Left: liquefied vitreous passing through a retinal break into the potential subretinal space between the photoreceptor layer and the RPE (arrow). Right: more advanced rhegmatogenous retinal detachment. Adapted from. With permission.

\section{Epidemiology}

The incidence of retinal detachment is approximately 1:10.000 a year. ${ }^{3}$ Exact figures for the Netherlands are not known. Most retinal detachments occur between the ages of 50 and 65 years. The prevalence of RRD is $0.07 \%{ }^{3}$ The prevalence of retinal detachment during childhood and adolescence was 
studied by Rosner et al., and was found to be $0.028 \%$; $61.5 \%$ of these had traumatic retinal detachment, and $23.1 \%$ had high myopia without a history of trauma. ${ }^{4}$

Risk factors for RRD are: myopia, trauma, cataract surgery, family history, inflammatory disease, diabetes and retinal detachment in the fellow eye. The differential diagnosis of retinal detachment includes retinoschisis, choroidal tumors and retinal elevation secondary to a detachment of the choroid.

\section{Treatment}

Currently, there are different surgical approaches in repairing a RRD; most often a scleral buckle procedure or a vitrectomy are performed

Scleral buckle: In most clinics, uncomplicated cases of retinal detachment are operated on with scleral buckling surgery. This surgical procedure, first introduced in 1949 by Dr. Custodies, ${ }^{5}$ is commonly used for rhegmatogenous retinal detachments, especially when there are no complicating factors. The procedure involves localizing the position of all the retinal breaks, treating retinal breaks with the cryoprobe or laser, and supporting all the retinal breaks with a scleral buckle. The buckle is usually a piece of silicone sponge or solid silicone. The type and shape of the buckle varies depending on the location, and the type and number of retinal breaks. The buckle is sewn onto the outer wall of the eyeball (sclera) to create an indentation or buckle effect inside the eye. The buckle is positioned so that it pushes the underlying RPE, choroid and scleral wall to the retinal break so that it effectively closes the break. Once the break is closed, the fluid under the retina (subretinal fluid) will usually spontaneously resolve over 1-2 days. Often surgeons will also drain subretinal fluid at the time of surgery. A scleral buckle procedure may be performed under local or general anesthesia and as same day surgery (in and out of the hospital on the same day).

Vitrectomy: More complicated cases of RRD (like RRD complicated with severe preoperative proliferative vitreoretinopathy (PVR), a giant tear or vitreous hemorrhage) are operated on with a vitrectomy. The initial step in this procedure is usually the removal of the vitreous gel through very small incisions $(2-3 \mathrm{~mm})$ in the sclera, hence the name "vitrectomy". The vitreous is removed with a miniature handheld cutting device and replaced with a special saline solution similar to the liquid being removed from the eye. A high intensity fiber optic light source is used to illuminate the inside of the eye while the surgeon operates. The surgeon uses a specialized operating microscope and contact lenses or a wide field viewing system, which allows a clear view of the vitreous cavity and retina at various magnifications. Depending on the severity of the pathology, the estimated length of the surgery and the patients preference, the vitrectomy is performed under local or general anesthesia. 


\section{Chapter I}

Currently, about $90 \%$ of retinal detachments can be successfully repaired with a single procedure. ${ }^{3,6}$ Proliferative vitreoretinopathy (PVR) is the most common cause of failure of RRD surgery. ${ }^{3}$ PVR is caused by the proliferation of retinal pigment epithelial (RPE) cells, glial cells and other cells forming membranes on the inner and occasionally outer retinal surface. As the membrane formation progresses, traction at the surface of the retina creates fixed retinal folds, equatorial traction, detachment of the nonpigmented epithelium of the pars plana and generalized retinal shrinkage. This may cause the initial retinal breaks to reopen, new breaks to occur or tractional detachments to develop.

\section{Postoperative visual acuity}

A retinal detachment can cause permanent damage to the vision if left untreated. The status of the macula (whether it was detached and for how long) is the most important pre-operative determinant for postoperative visual acuity. After a macula-off rhegmatogenous retinal detachment (RRD) recovery of central vision commonly remains compromised, due to permanent functional damage to the photoreceptor cells in the macular region after detachment. ${ }^{7-9}$ Even when reattachment surgery is successful, a reattached retina rarely regains normal sensitivity or acuity. ${ }^{9-11}$

Patients with rhegmatogenous retinal detachment (RRD) without macular involvement represent a distinct category because they generally have good preoperative central visual acuity. Although final visual outcome of successfully reattached macula-on retinal detachments is usually expected to be good, postoperative visual acuity may occasionally be disappointing. In 10\% $-15 \%$ of the patients with a successfully repaired macula-on retinal detachment, visual acuity does not return to the preoperative level. ${ }^{4}$

\section{Experimental animal models of retinal detachment}

Several animal models of retinal detachment have been described. These models enable scientists to get a better understanding of the pathogenesis of retinal detachment and ultimately develop new treatment strategies. Most studies involving experimental retinal detachment models in animals have been done in cats, mainly by the group of Lewis and Fisher at the Neuroscience Research institute from the University of California in Santa Barbara. ${ }^{9,12-14}$ Other animal species have also been used as experimental models for human retinal detachment, including rabbit, dog, and primate. ${ }^{15-17}$ The eyes of each of these animal species have differences from human eyes, such as the size of the globe and lens, photoreceptor type and distribution and scleral rigidity. ${ }^{18}$ In this thesis we used a pig model for retinal detachment since porcine eyes resemble human eyes quite well. Not only are the globe and lens size similar to human eyes, also the scleral rigidity, retinal circulation and photoreceptor density are comparable. ${ }^{19-21}$ 


\section{Biochemical factors in Rhegmatogenous Retinal Detachment}

In addition to the duration of macular detachment, biochemical factors may further deteriorate functional outcome after RD repair. These factors may have a protective or toxic effect on the retina, and may thereby influence visual outcome after retinal detachment. As mentioned above, subretinal fluid is often drained during scleral buckling surgery and vitreous fluid is removed while performing a vitrectomy. Instead of discarding these fluids, they are stored and used for various research purposes after the patients give their informed consent. Because the Department of Ophthalmology of the University Hospital Maastricht collects so many intraocular fluid samples, we were able to determine the concentration of some potentially toxic biochemical factors in the eye after retinal detachment.

\section{GLUTAMATE TOXICITY}

\section{Glutamate}

Glutamate is believed to be the major excitatory neurotransmitter in the retina. Glutamate is classified as an excitatory amino acid (EAA) because glutamate binding onto postsynaptic receptors typically stimulates, or depolarizes, the postsynaptic cells. In the retina, photoreceptors, bipolar cells, and ganglion cells are glutamate immunoreactive. ${ }^{22-27}$ Some horizontal and/or amacrine cells can also display weak labeling with glutamate antibodies. ${ }^{22,23,26,27}$ However, these neurons are believed to release GABA in stead of glutamate as their neurotransmitter, ${ }^{28}$ suggesting the weak glutamate labeling reflects the pool of metabolic glutamate used in the synthesis of GABA.

After glutamate is released from neurons it is cleared from the extracellular environment via uptake by Müller cells (Figure 4). Müller cells subsequently transform glutamate into glutamine by the enzyme glutamine synthetase (GS), which is then exported from glial cells and incorporated into surrounding neurons (Figure 4). ${ }^{29}$ Neurons can then synthesize glutamate from glutamine. $^{29,30}$

Overproduction of glutamate may occur when glutamate is generated in excess or when the glutamate re-uptake is ineffective, as may happen in ischemia. ${ }^{31}$ Glutamate toxicity is considered to be caused by an excessive activation of the $N$-methyl-d-aspartate (NMDA)-type glutamate receptor and hence excessive $\mathrm{Ca}^{2+}$ influx through the receptor's associated ion channel. ${ }^{32} \mathrm{Ca}^{2+}$, which may cause cell death trough apoptosis when present in abundance, can stimulate the enzyme nitric oxide synthetase (NOS) to produce nitric oxide (NO). Under normal circumstances, NO is an important intracellular signalling molecule (see next paragraph), however, overproduction of NO can lead to cell death through a variety of mechanisms, e.g. trough DNA damage, 


\section{Chapter I}

apoptosis and decreased energy production by inhibition of mitochondrial function. ${ }^{31}$

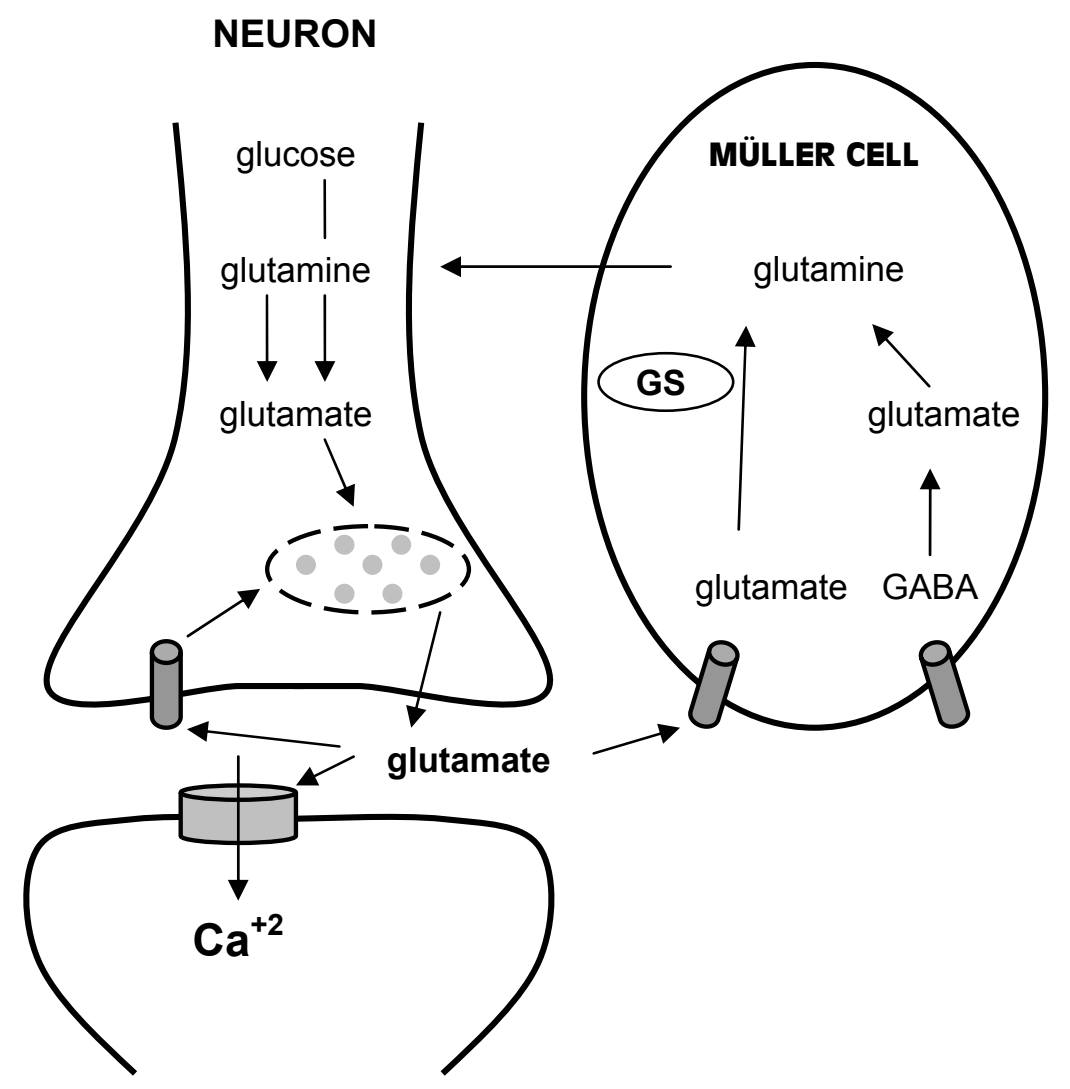

Figure 4. Glutamate metabolism. GS (glutamine synthetase).

There are several animal studies implicating the role of glutamate in experimental retinal detachment. In cat eyes with experimental retinal detachment, a marked decrease in the expression of glutamine synthetase (GS) activity has been found, suggesting that the clearance capacity of glutamate by Müller cells may be lost after retinal detachment. ${ }^{12}$ Also, there is evidence for large shifts in intracellular glutamate concentrations in the retina following experimental retinal detachment. ${ }^{33}$ In human eyes, glutamine synthetase activity was significantly higher in subretinal fluid from patients with RRD compared to control patients, and an increased level of glutamine synthetase correlated with a longer duration of the retinal detachment. ${ }^{34}$ In experimental intervention studies, it has been shown that glutamate receptor (NMDA) antagonists were able to decrease retinal damage after experimentally induced retinal ischemia. ${ }^{35-37}$ 


\section{Nitric Oxide}

Nitric oxide (NO) is an important mediator of cell-cell interactions and homeostatic processes in the eye, such as regulation of aqueous humour dynamics, retinal neurotransmission and phototransduction. ${ }^{38,39} \mathrm{NO}$ is produced when the semi-essential amino acid 1-arginine is converted to l-citrulline and NO by nitric oxide synthase (NOS) enzymes. ${ }^{40} \mathrm{NO}$ then diffuses into nearby target cells to elevate cyclic GMP levels and thereby triggers different cell functions. NOS exists in three major isoforms: neuronal, endothelial and inducible NOS. In the retina, neuronal NOS is thought to be responsible for producing NO in photoreceptors and bipolar cells, whereas inducible NOS, is found in Müller cells and in the retinal pigment epithelial (RPE) cell layer. ${ }^{41,13}$ Neuronal and endothelial NOS are constitutively expressed and activated in a calcium/calmodulin dependent way by glutamate or vasodilatators. ${ }^{39}$ Expression of inducible NOS is activated by endotoxin and cytokines. As stated earlier, excess NO can be toxic. ${ }^{42}$

High levels of NO have been implicated in the pathogenesis of a variety of eye diseases, including glaucoma, proliferative diabetic retinopathy, cataract and uveitis. ${ }^{43-46}$

\section{CYCLIC GMP}

\section{Cyclic GMP function in the retina}

Cyclic 3', 5'-guanosine monophosphate (cGMP), regulates the activity of neurons throughout the whole central nervous system, controlling processes like electrical signaling and synaptic physiology. In the eye, cGMP is a central molecule in the phototransduction cascade and is also involved in a number of other physiological processes in the retina. ${ }^{47,48}$ In experimental retinal detachment, cGMP analogues were shown to increase the rate of fluid absorption from the subretinal space by $33 \%{ }^{48}$ It has also been shown that cGMP analogues or NO donors reduce the gap-junction coupling of amacrine cells with cone bipolar cells. ${ }^{49}$ In RPE cells, cGMP has been implicated in stimulation of $\mathrm{Cl}$ - transport, suppression of hypoxia-associated vascular endothelial growth factor (VEGF) gene expression, and phagocytosis of rod outer segments. ${ }^{50-52}$ The increased rate of fluid absorption from the subretinal space indicates a possible role for cGMP in the clearance of subretinal fluid after retinal detachment. The involvement of cGMP in retinal detachment was furthermore suggested by a previous study, in which we observed a decreased level of cGMP in vitreous and subretinal fluid of patients with retinal detachment. ${ }^{53}$ Moreover, a significant decrease was found in the mean subretinal cGMP levels when the retinal detached existed longer. Thus, it appears that cGMP can modulate several aspects of retinal physiology, besides its role in phototransduction. In the retina, cGMP gated chan- 


\section{Chapter I}

nels were found in photoreceptors, ganglion cells, bipolar cells and Müller cells. ${ }^{54-56}$

\section{Cyclic GMP synthesis}

Two different enzymes catalyze the conversion of the substrate guanosine '5-triphosphate (GTP) into cGMP (Figure 5). These enzymes are called particulate (membrane-bound) or soluble (cytosolic) cyclases based on their general structure and cellular distribution. There are several isoforms known of each type. Soluble guanylyl cyclase is activated by nitric oxide (NO), and is expressed in neurons of the inner retina. ${ }^{57}$ The enzyme soluble GC is a heterodimeric protein consisting of two different subunits, the so-called $\alpha-$ and $\beta$ subunit. ${ }^{58}$ Stimulation of soluble guanylyl cyclase by NO occurs through binding of NO to the prosthetic heme group which can lead to an up to 100-200 fold stimulation of the enzyme. ${ }^{59}$ Increasing tissue levels of NO, by incubation with sodium nitroprusside (SNP) as an NO donor, results in increased cGMP immunoreactivity in amacrine, ganglion and bipolar cells. ${ }^{60-63}$

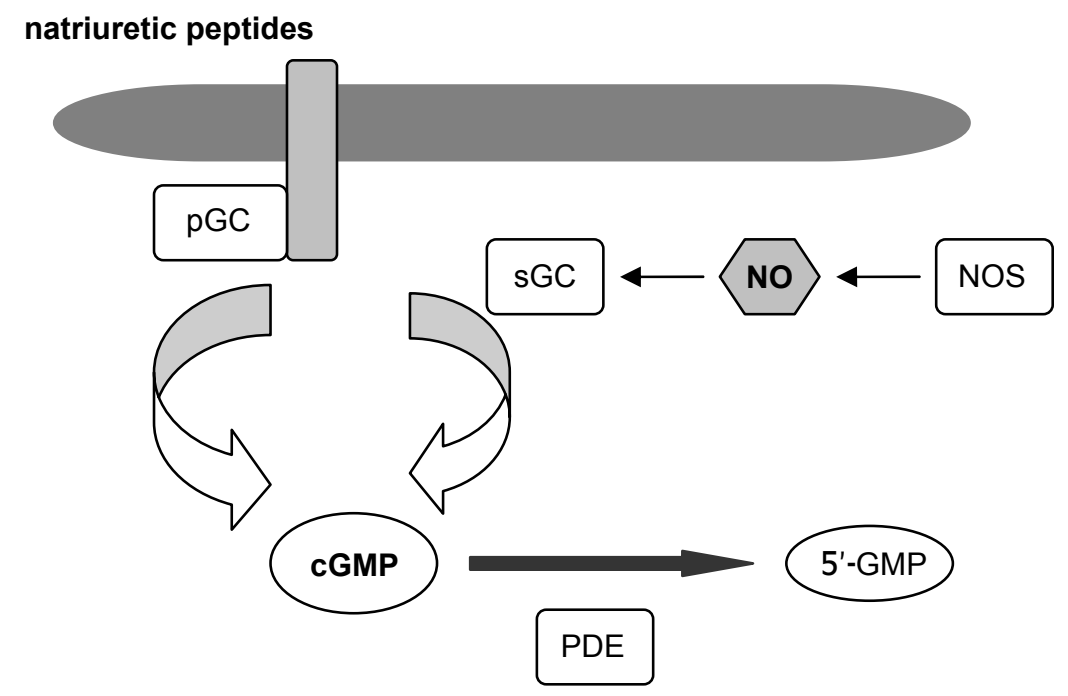

Figure 5. cGMP synthesis and breakdown. pGC (particulate guanylyl cyclase), ${ }_{s G C}$ (soluble guanylyl cyclase), NOS (nitric oxide synthase), NO (nitric oxide), PDE (phosphodiesterases)

Membrane bound or particulate guanylyl cyclases produce cGMP, after activation by natriuretic peptides such as atrial natriuretic peptide (ANP), braintype natriuretic peptide (BNP) and C-type natriuretic peptide (CNP). ${ }^{64} \mathrm{Par}-$ ticulate guanylyl cyclases are either ligand-activated receptors (e.g. natriuretic factors) or calcium-regulated, integral membrane proteins. ${ }^{65}$ In turtle retina, stimulation with exogenous natriuretic peptides increased total retinal cGMP levels. ${ }^{42}$ Reports comparing both enzymatic pathways involved in the 
cGMP production in the rat retina show that the NO-cGMP pathway (via soluble guanylyl cyclase) exists dominantly in the inner nuclear layer and the ANP-cGMP pathway (via particulate guanylyl cyclase) exists dominantly in the rod photoreceptor. ${ }^{57,65-67}$

ANP is a circulating peptide and has been detected in different cell layers of the rat and rabbit retina. Also in the RPE cell layer of the human retina strong ANP immunolabeling has been previously shown. ${ }^{68}$ In addition, mRNA of NPR-A and NPR-B, both ANP receptors, has been demonstrated in cultured rabbit RPE cells. ${ }^{69}$ Histochemical and molecular cloning studies have also revealed the presence of the NPR-A and NPR-B in the human and turtle retina. ${ }^{59,60,63}$ ANP is furthermore involved in controlling the extracellular fluid homeostasis. Also in RPE cells it has been shown that ANP stimulates $\mathrm{Cl}$ - transport. ${ }^{50}$

\section{Phosphodiesterases}

Intracellular concentrations of cGMP represent the net balance between synthesis by guanylyl cyclases and breakdown by 3', 5'- cyclic nucleotide phosphodiesterases (PDEs). ${ }^{70,71}$ PDE activity was already discovered in 1958 by Sutherland et al. ${ }^{72}$ PDEs comprise a large group of enzymes that hydrolyze cAMP and cGMP to their inactive 5' -derivates. The major function for PDEs in the cell is to terminate the amplitude and duration of the cyclic nucleotide second messenger signal. ${ }^{71}$ Eleven different subfamilies of PDE isozymes (PDE1 - PDE11) have been classified. The classification is based on their affinities for cGMP and cAMP, and a number of proteomic and genomic characteristics. ${ }^{73}$ PDE2, PDE5, PDE6, PDE9 and PDE10 are the major cGMP-degrading enzymes. ${ }^{74-78}$ From these PDE families, PDE10 (which hydrolyzes both cAMP and cGMP) has never been demonstrated in the eye and PDE6 is known to be only present in retinal photoreceptor cells. ${ }^{71,79}$ PDE5 has been implicated in the control of vascular resistance. ${ }^{71}$ Also in the retina PDE5 has been shown to have a possible role in the regulation of retinal blood flow. ${ }^{80}$ Because PDE9 has the highest affinity for cGMP of all the mammalian PDEs this enzyme could play a fundamental role in keeping intra ocular cGMP at a low basal level. ${ }^{75}$

\section{PDE inhibitors}

The classification of the eleven PDE families is among other things based on their affinity towards a large number of PDE inhibitors. PDE inhibitors are well known in medical practice and used to treat a variety of diseases, like depression, asthma, pulmonary hypertension, cardiovascular disease, and male impotence. The compound Bay $60-7550$ is a highly selective inhibitor of PDE2 and more potent than erythro-9-(2-hydroxy-3-nonyl) adenine (EHNA) which is generally used as a PDE2 inhibitor. ${ }^{81}$ In addition, in contrast to EHNA, Bay $60-7550$ is devoid of adenosine deaminase activity. ${ }^{81}$ Sildenafil, known as a drug used for male impotence, is a relatively selective 


\section{Chapter I}

inhibitor for PDE5. Sildenafil however also weakly inhibits PDE6, an enzyme involved in the process of phototransduction, with an efficacy of $10 \%$ of that for PDE5. ${ }^{82}$ A single oral dose of $100 \mathrm{mg}$ sildenafil has been shown to cause impaired photoreceptor function which is being attributed to weak inhibition of PDE6 by sildenafil. ${ }^{83,84}$ Sch51866 is a somewhat selective inhibitor of PDE9 as it also weakly inhibits PDE5, with an efficacy of 1/15 of that for PDE9. ${ }^{85}$

\section{Questions and hypotheses addressed in this thesis}

As stated earlier, even after successful surgery of a macular detachment, a reattached macula seldom regains its former sensitivity or acuity. ${ }^{9-11}$ A delay in surgery may result in a less favorable visual outcome in patients with a macula-off retinal detachment. ${ }^{8,86}$ Rapid changes in the detached retina, like a massive efflux of glutamate found in experimental retinal detachment, ${ }^{33}$ indicate that the retina should be re-attached as soon as possible to prevent further damage to the retinal cells. Therefore a retinal detachment of recent onset is generally considered to be a surgical emergency, especially when the macula is involved. Looking at the disadvantages of emergency surgery, the question rises: does a short delay result in diminished visual acuity after surgery for patients with a detached macula? To answer this question we did a large observational case series to determine the effect of duration of macular detachment on recovery of post operative visual acuity, as described in Chapter 2.

Because most patients with a macula-on retinal detachment have good visual acuities before surgery, keeping up this visual acuity postoperatively is important to meet the patients' expectations. Knowing the risk factors associated with re-detachment and/or a worse visual outcome after macula-on scleral buckling surgery may therefore be valuable information that can be used for pre-operative counseling. Therefore the aim of our retrospective study, outlined in Chapter 3, was to identify preoperative clinical variables associated with re-detachment and/or a worse visual outcome in patients with rhegmatogenous retinal detachment (RRD) without macular involvement after scleral buckling surgery.

Ischemia of the retina leads to changes in the localization of the retinal amino acid neurotransmitters glutamate and GABA as well as to accumulation of glutamate and GABA in Müller cells. ${ }^{87,88}$ Experimental models have also implicated glutamate in the irreversible damage to retinal cells following retinal detachment. Because experiments detecting changes in neurotransmitter levels after retinal detachment have mostly been performed in animal models,${ }^{13}$ the role of neurotransmitters in human retinal detachment is not yet known. We hypothesized that glutamate toxicity may have a role in causing a diminished visual acuity after retinal detachment surgery. Therefore we hypothesized that levels of glutamate and other amino acid 
neurotransmitters may be increased in the vitreous fluid of patients suffering from a retinal detachment compared to the levels in control patients. This hypothesis was tested in the study described in Chapter 4.

One way through which excessive glutamate levels can cause neurotoxicity is via prolonged stimulation of NOS and overproduction of NO. ${ }^{42}$ High levels of NO have been implicated in the pathogenesis of a variety of ocular disorders, including glaucoma, proliferative diabetic retinopathy, cataract and uveitis. ${ }^{43-46}$ However no clinical study has been done previously to investigate whether NO is involved in retinal detachment. When increased NO synthesis has a role in RRD, it is to be expected that metabolites of the NO pathway (arginine, citrulline, nitrite e.g.) are upregulated in the vitreous fluid of RRD patients. This hypothesized was tested in the experiments described in Chapter 5.

Cyclic GMP stimulates the absorption of subretinal fluid by activating the retinal pigment epithelium (RPE) cell pump. ${ }^{2,89}$ Recently we found that retinal detachment was associated with a decrease in the cGMP concentration in the subretinal fluid as compared to controls. ${ }^{53}$ Moreover, a significant decrease was found in the mean subretinal cGMP levels when the retinal detached existed longer. ${ }^{53}$ Chapter 6 focuses on the mechanisms involved in cGMP metabolism in the RPE cells because those cells are known for their role in keeping the retina attached. We found that human RPE cells are capable of producing cGMP and that most cGMP is generated following stimulation of the particulate guanylyl cyclase pathway with ANP. Previously, also the inducible isoform of nitric oxide synthase (iNOS) has been demonstrated in RPE cells. ${ }^{90,91}$ However, the relation between NO-synthesis and cGMP synthesis in the cultured RPE cells has not been investigated. As also ANP stimulates cGMP synthesis in RPE cells, we hypothesized that continuous synthesis of NO by iNOS results in a low level of cGMP synthesis in RPE cells, and that ANP stimulated cGMP synthesis might occur in (a) different compartment(s). The aim of the study described in Chapter 7 was therefore to investigate the role of two separate enzymatic pathways (soluble versus particulate guanylyl cyclase) in the synthesis of cGMP in cultured human RPE cells with special focus on the role of ANP and iNOS and their interaction. Next, we questioned which PDE isoforms are involved in the cGMP breakdown in RPE cells and could so be responsible for the decreased cGMP concentration after retinal detachment. To answer this question we performed a series of experiments described in Chapter 8.

The mechanisms causing decreased cGMP levels in RRD and the biological significance are unknown. We hypothesized that because of energy and oxygen deprivation due to the separation of the retina, the number of cells expressing cGMP may be reduced after retinal detachment. This hypothesis was tested by analyzing the presence of cGMP in retinal cells and vitreous 


\section{Chapter I}

fluid from pig eyes with an experimental retinal detachment as described in Chapter 9.

In Chapter 10, the findings of this thesis are discussed and suggestions for future research are presented. 


\section{LITERATURE}

1 Zinn K. Anatomy of the human retinal pigment epithelium. Cambridge: Harvard University Press, 1979.

2 Marmor MF, Negi A. Pharmacologic modification of subretinal fluid absorption in the rabbit eye. Arch Ophthalmol. 1986; 104, 1674-1677.

3 Basic and clinical science course. Retina and Vitreous. San Francisco: American academy of Ophthalmology 2005; 273.

4 Rosner M, Treister G, Belkin M. Epidemiology of retinal detachment in childhood and adolescence. J Pediatr Ophthalmol Strabismus. 1987; 24:42-44.

5 Michiels RG, Wilkinson CP, Rice TA. Retinal detachment. St Louis, CV Mosby, 1990.

6 Sharma R, Hagannadh KC, Ravishamkar KV, Mruesan R. Scleral buckling for retinal detachment. Predictors of anatomic failure. Retina 1994; 14:338-43.

7 Burton TC. Recovery of visual acuity after retinal detachment involving the macula. Trans Am Ophthalmol Soc 1982; 80:475-497.

8 Sabates NR, Sabates FN, Sabates R, Ledd KY, Ziemianski MC. Macular changes after retinal detachment surgery. American Journal of Ophthalmology 1989; 108:22-29.

9 Mervin K Valter K, Maslim J, Lewis G, Fisher S, Stone J. Limiting photoreceptor death and deconstruction during experimental retinal detachment: the value of oxygen supplementation. American Journal of Ophthalmology 1999; 128:155-164.

10 Michels R, Wilkinson C, Rice T. Results of retinal reattachment surgery. In: Retinal detachment. St Louis: CV Mosby 1990:917-938.

11 Liem AT, Keunen JE, Meel van GJ, Norren van D. Serial foveal densitometry and visual function after retinal detachment surgery with macular involvement. Ophthalmology 1994; 101:1945-52.

12 Lewis GP, Erickson PA, Guèrin CJ, Anderson DH, Fisher SK. Changes in the expression of specific Müller cell proteins during long-term retinal detachment. Exp Eye Res. 1989; 49:93-111.

13 Marc RE, Murry RF, Fisher SK, Linberg KA, Lewis GP. Amino acid signatures in the detached cat retina. Invest Ophthalmol Vis Sci 1998; 39(9):1694-702.

14 Lewis GP, Talaga KC, Linberg KA, Avery RL, Fisher SK. The efficacy of delayed oxygen therapy in the treatment of experimental retinal detachment. Am J Ophthalmol. 2004; 1085-95.

15 Dalma-Wiszhaus J, Blumenkranz M, Hartzer M, Hernandez E. Intraocular extracellular cyclic nucleotide concentrations: the influence of vitreous surgery. Graefe's Arch Clin Exp Ophthalmol. 1993; 231:184-186.

16 Fraunfelder FT, Potts AM. An experimental study of retinal detachment. Am J Ophthalmol. 1966; 62:561-568.

17 Machemer R, Noron EW. Experimental retinal detachment in the owl monkey. Am J Ophthalmol. 1968; 66:388-396.

18 Jackson TL, Hillenkamp J, Williamson TH, Clarke KW, Almubarak AI, Marshall J. An experimental model of rhegmatogenous retinal detachment: surgical results and glial cell response. IOVS 2003; 44:4026-34.

19 Hendrickson A, Hicks D. Distribution and density of medium- and short-wavelength selective cones in the domestic pig retina.Exp Eye Res. 2002; 74(4):435-44.

20 Jocobs GH, Calderone JB, Sakai T, Lewis GP, Fisher SK. An animal model for studying cone function in retinal detachment. Doc Ophthalmol. 2002; 104(1):119-32.

21 Chandler MJ, Smith PJ, Samuelson DA, MacKay EO. Photoreceptor density of the domestic pig retina. Vet Ophthalmol. 1992; 2:179-184.

22 Ehinger B, Ottersen OP, Storm-Mathisen J, Dowling JE. Bipolar cells in the turtle retina are strongly immunoreactive for glutamate. Proc Natl Acad Sci U S A. 1988; 85:8321-5.

23 Marc RE, Liu WL, Kalloniatis M, Raiguel SF, van Haesendonck E. Patterns of glutamate immunoreactivity in the goldfish retina. J Neurosci. 1990; 10:4006-34. 


\section{Chapter I}

24 Van Haesendonck E, Missotten L. Glutamate-like immunoreactivity in the retina of a marine teleost, the dragonet. Neurosci Lett. 1990; 111:281-6.

25 Kalloniatis M, Fletcher EL. Immunocytochemical localization of the amino acid neurotransmitters in the chicken retina. J Comp Neurol. 1993; 336:174-93.

26 Yang CY, Yazulla S. Glutamate-, GABA-, and GAD-immunoreactivities co-localize in bipolar cells of tiger salamander retina. Vis Neurosci. 1994; 11:1193-203.

27 Jojich L, Pourcho RG. Glutamate immunoreactivity in the cat retina: a quantitative study. Vis Neurosci. 1996; 13:117-33.

28 Yazulla S. Is GABA the neurotransmitter for some photoreceptors? Nature. 1986; 320:685-6.

29 Pow DV, Crook DK. Direct immunocytochemical evidence for the transfer of glutamine from glial cells to neurons: use of specific antibodies directed against the d-stereoisomers of glutamate and glutamine. Neuroscience. 1996; 70:295-302.

30 Hertz L. Functional interactions between neurons and astrocytes I. Turnover and metabolism of putative amino acid transmitters. Prog Neurobiol. 1979; 13:277-323.

31 Kanai Y, Stelzner M, Nussberger S, Khawaja S, Herbert SC, Smith CP, Hediger MA. The neuronal and epithelial human high affinity glutamate transporter. Insights into structure and mechanism of transport. J Biol Chem. 1994; 269:20599-606.

32 Lipton SA. Failures and Successes of NMDA Receptor Antagonists: Molecular Basis for the Use of Open-Channel Blockers like Memantine in the Treatment of Acute and Chronic Neurologic Insults. Neurorx. 2004 Jan; 1(1):101-110.

33 Sherry DM, Townes-Anderson E. Rapid glutamatergic alterations in the neural retina induced by retinal detachment. IOVS 2000; 41:2779-2790.

34 La Heij EC, Van de waardenburg MPH, Blaauwgeers HG, Kessels AG, de Vente J, Liem AT, Steinbusch H, Hendrikse F. Levels of basic fibroblast growth factor, glutamine synthetase, and interleukin-6 in subretinal fluid from patients with retinal detachment Am J Ophthalmol. 2001 Oct; 132(4):544-50.

35 Vorwerk CK, Lipton SA, Zurakowski D, Hyman BT, Sabel BA, Dreyer EB. Chronic lowdose glutamate is toxic to retinal ganglion cells: toxicity blocked by memantine. Invest Ophthalmol Vis Sci. 1996; 37:1618-1624.

36 Mosinger JL, Price MT, Bai HY, Xiao H, Wozniak DF, Olney JW. Blockage of both NMDA and non-NMDA receptors is required for optimal protection against ischemic neuronal degeneration in the in vivo adult mammalian retina. Exp Neurol. 1991; 113:10-17.

37 YoonYH, Marmor MF. Dextromethorphan protects retina against ischemic injury in vivo. Arch Opthalmol. 1989; 107:409-411.

38 Dawson VL, Dawson TM. Nitric oxide neurotoxicity. J Chem Neuroanat 1996; 10(3-4):179-90.

39 Moncada S, Palmer RM, Higgs EA. Nitric oxide: physiology, pathophysiology, and pharmacology. Pharmacol Rev. 1991; 43(2):109-42.

40 Gharavi N, El-Kadi AO. Measurement of nitric oxide in murine Hepatoma Hepa1c1c7 cells by reversed phase HPLC with fluorescence detection. J Pharm Pharm Sci. 2003; 6(2):302-7.

41 Becquet F, Courtois Y, Goureau O. Nitric oxide decreases in vitro phagocytosis of photoreceptor outer segments by bovine retinal pigmented epithelial cells. J Cell Physiol. 1994; 159(2):256-62.

42 Yoshida A, Pozdnyakov N, Dang L, Orselli SM, Reddy VN, Sitaramayya A. Nitric oxide synthesis in retinal photoreceptor cells. Vis Neurosci 1995; 12(3):493-500.

43 Neufeld AH, Sawada A, Becker B. Inhibition of nitric-oxide synthase 2 by aminoguanidine provides neuroprotection of retinal ganglion cells in a rat model of chronic glaucoma. Proc Natl Acad Sci U S A. 1999; 96(17):9944-8.

44 Tilton RG, Chang K, Corbett JA, Misko TP, Currie MG, Bora NS, Kaplan HJ, Williamson JR. Endotoxin-induced uveitis in the rat is attenuated by inhibition of nitric oxide production. 1994; Invest Ophthalmol Vis Sci. 19941; 35(8):3278-88. 


\section{General introduction}

45 Inomata M, Hayashi M, Shumiya S, Kawashima S, Ito Y. Aminoguanidine-treatment results in the inhibition of lens opacification and calpain-mediated proteolysis in Shumiya cataract rats (SCR). J Biochem (Tokyo). 2000; 128(5):771-6.

46 Goldstein IM, Ostwald P, Roth S. Nitric oxide: a review of its role in retinal function and disease. Vision Res. 1996; 36(18):2979-94.

47 Baylor DA. Photoreceptor signals and vision. Proctor lecture. Invest Ophthalmol Vis Sci. 1987; 28, 34-49.

48 Yamazaki A, Moskvin O, Yamazaki RK. Phosphorylation by cyclin-dependent protein kinase 5 of the regulatory subunit (Pgamma) of retinal cgmp phosphodiesterase (PDE6): its implications in phototransduction. Adv Exp Med Biol. 2002; 514, 131-153.

Mills SC, Massey SL. Differential properties of two gap junctional pathways made by AII amacrine cells. Nature. 1995; 377(6551):734-7.

50 Mikami Y, Hara M, Yasukura T, Uyama M, Minato A, Inagaki C. Atrial natriuretic peptide stimulates Cl- transport in retinal pigment epithelial cells. Curr Eye Res. 1995; 14, 391-397.

51 Ghiso N, Rohan RM, Amano S, Garland R, Ademis AP. Suppression of hypoxiaassociated vascular endothelial growth factor gene expression by nitric oxide via cGMP. Invest Ophthalmol Vis Sci. 1999; 40(6):1033-9.

52 Kogishi JI, Akimoto M, Mandai M, Kuriyama S, Hall MO, Honda Y, Yoshimura N. Nitric oxide as a second messenger in phagocytosis by cultured retinal pigment epithelial cells. Ophthalmic Res. 2000; 32:138-142.

53 La Heij EC, Blaauwgeers HG, de Vente J, Markerink M, Liem AT, Kessels AG, Steinbusch H, Hendrikse F. Decreased levels of cGMP in vitreous and subretinal fluid from eyes with retinal detachment. Br J Ophthalmol. 2003; 87:1409-12. Ahmad I, Leinders-Zufaal R, Kocsis JD, Shepherd GM, Zufall F, Barnstable CJ. Retinal ganglion cells express a cGMP-gated cation conductance activatable by nitric oxide donors. Neuron. 1994; 12:155-165. Nawy S, Jahr E. cGMP-gated conductance in retinal bipolar cells is suppressed by the photoreceptor transmitter. Neuron 1991; 7:677-683. Kusaka S. Dabin I, Barnstable CJ, Puro DG. cGMP mediated effects on the physiology of bovine and human retinal Müller cells. Journal of Physiology 1996; 497:813-824. Ahmad I, Barnstable CJ. Differential laminar expression of particulate and soluble guanylate cyclase genes in rat retina. Exp Eye Res. 1993; 56:51-62.

58 Garbers DL. Purification of soluble guanylate cyclase from rat lung. J Biol Chem. 1979; 254(1):240-3.

59 Stone JR, Marletta MA. Heme stoichiometry of heterodimeric soluble guanylate cyclase. Biochemistry. 1995; 34(45):14668-74.

60 Blute TA, Lee HK, Huffmaster T, Haverkamp S, Eldred WD. Localization of natriuretic peptides and their activation of particulate guanylate cyclase and nitric oxide synthase in the retina. J Comp Neurol 2000; 424:689-700.

61 Gotzes S, de Vente J, Muller F. Nitric oxide modulates cGMP levels in neurons of the inner and outer retina in opposite ways. Vis Neurosci 1998; 15:945-55.

${ }^{62}$ Baldridge WH, Fischer AJ. Nitric oxide donor stimulated increase of cyclic GMP in the goldfisch retina. Vis Neurosci. 2001; 18:849-56.

63 Blute TA, Velasco P, Eldred WD. Functional localization of soluble guanylate cyclase in turtle retina: modulation of cGMP by nitric oxide donors. Vis Neurosci 1998; 15:485-98.

Lucas KA, Pitari GM, Kazerounian S, Ruiz-Stewart I, Park J, Schulz S, Chepenik KP, Waldman SA. Guanylyl cyclases and signaling by cyclic GMP. Pharmacol Rev. 2000; 52:375-414.

65 Shyjan AW, de Sauvage FJ, Gillett NA, Goeddel DV, Lowe DG. Molecular cloning of a retina-specific membrane guanylyl cyclase. Neuron 1992; 9:727-37.

${ }_{66}$ Garbers DL, Lowe DG. Guanylyl cyclase receptors. J Biol Chem.1994; 269:30741-30744.

67 Moriwaki Y, Kamisaki Y, Itoh T, Nagata M, Tamai A. Cyclic 3',5'-Guanosine monophosphate synthesis induced by atrial natriuretic peptide, C-type natriuretic peptide, and nitric oxide in the rat. Jpn J Ophthalmology 1997; 42:269-274. 


\section{Chapter I}

68 Rollin R, Mediero A, Roldan-Pallares M, Fernandez-Cruz A, Fernandez-Durango R. Natriuretic peptide system in the human retina. Mol Vision 2004; 10:15-22.

69 Fujiseki Y, Omori K, Omori K, Mikami Y, Suzukawa J, Okugawa G, Uyama M, Inagaki C. Natriuretic peptide receptors, NPR-A and NPR-B, in cultured rabbit retinal pigment epithelium cells. Jpn J Pharmacol 1999; 79:359-68.

70 Francis SH, Corbin JD. Cyclic nucleotide-dependent protein kinases: intracellular receptors for cAMP and cGMP action. Crit Rev Clin Lab Sci. 1999; 36, 275-328.

71 Beavo JA. Cyclic nucleotide phosphodiesterases: functional implications of multiple isoforms. Physiol Rev. 1995 Oct; 75(4):725-48.

72 Sutherland EW, Rall TW. Fractionation and characterization of a cyclic adenine ribonucleotide formed by tissue particles. J Biol Chem. 1958; 232(2):1077-91.

73 Beavo JA, Conti M, Heaslip RJ. Multiple cyclic nucleotide phosphodiesterases. Mol Pharmacol. 1994; 46, 399-405.

74 Gillespie PG, Beavo JA. Characterization of a bovine cone photoreceptor phosphodiesterase purified by cyclic GMP-sepharose chromatography. J Biol Chem. 1988; 263:8133-41.

75 Thomas MK, Francis SH, Corbin JD. Characterization of a purified bovine lung cGMPbinding cGMP phosphodiesterase. J Biol Chem. 1990; 265:14964-70.

76 Sonnenburg WK, Mullaney PJ, Beavo JA. Molecular cloning of a cyclic GMP-stimulated cyclic nucleotide phosphodiesterase cDNA. Identification and distribution of isozyme variants. J Biol Chem. 1991; 266:17655-61.

77 Fisher DA, Smith JF, Pillar JS, St Denis SH, Cheng JB. Isolation and characterization of PDE9A, a novel human cGMP-specific phosphodiesterase. J Biol Chem. 1998; 19:15559-64.

78 Fujishige K, Kotera J, Michibata H, Yuasa K, Takebayashi S, Okamura K, Omori K. Cloning and characterization of a novel human phosphodiesterase that hydrolyzes both cAMP and cGMP (PDE10A). J Biol Chem. 1999; 274:18438-45.

79 Soderling SH, Bayuga SJ, Beavo JA. Isolation and characterisation of a dual-substrate phosphodiesterase gene family: PDE10A.Proc. Natl. Acad. Sci USA.1999; 96:7071-7076. Pache M, Meyer P, Prünte C, Orgül S, Nuttli I, Flammer J. Sildenafil induces retinal vasodilatation in healthy subjects . British Journal of Ophthalmology 2002; 86:156-158.

81 Boess FGHM, Hendrix M. van der Staay FJ, Erb C, Schreiber R, van Staveren W, De Vente J, Prickaerts J, Blokland A, Konig G. Inhibition of phosphodiesterase 2 increases cGMP neuronal plasticity and memory performance. Neuropharmacoloy. 2004; 47:1081-92.

82 Ballard SA, Gingell CJ, Tang K, Turner LA, Price ME, Naylor AM. Effects of Sildenafil on the relaxation of human corpus cavernosum tissue in vitro and on the activities of cycylic nucleotide phosphodiesterase isozymes. J Urol 1998; 159:2164-71.

83 Vobig MA, Klotz T, Staak M, Bartz-Schmidt KU, Engelman U, Walter P. Retinal sideeffects of Sildenafil. The Lancet. 1999; 353:375.

84 Vobig MA. Retinal side-effects of Sildenafil. The Lancet. 1999; 353:1442.

85 Soderling SH, Bayuga SJ, Beavo JA. Identification and characterization of a novel family of cyclic nucleotide phosphodiesterases. J Biol Chem. 1998; 273(25):15553-8.

86 Burton TC. A predictive model for visual recovery following retinal detachment surgery. Ophthalmology 1978; 85:619-625.

87 Napper GA, Kalloniatis M. Neurochemical changes following postmortem ischemia in the rat retina. Visual Neuroscience. 1999; 16:1169-1180.

88 Napper GA, Pianta MJ, Kalloniatis M. Localization of amino acid neurotransmitters following in vitro ischemia and anoxia in the rat retina. Visual Neuroscience. 2001; 18:413-427.

89 Marmor MF. Control of subretinal fluid: Experimental and clinical studies. Eye. 1990; 4,340-344.

90 Liversidge J, Grabowski P, Ralston S, Benjamin N, Forrester JV. Rat retinal pigment epithelial cells express an inducible form of nitric oxide synthase and produce nitric oxide 
in response to inflammatory cytokines and activated T cells. Immunology. 1994; 83:404-409.

91 Vasilaki A, Papadaki T, Notas G, Kolios G, Mastrodimou N, Hoyer D, Tsilimbaris M, Kouroumalis E, Pallikaris I, Thermos K. Effect of somatostatin on nitric oxide production in human retinal pigment epithelium cell cultures. Invest Ophthalmol Vis Sci. 2004; 45:1499-1506. 



\title{
CHAPTER II
}

\section{Scleral buckling surgery after macula-off retinal detachment; worse visual outcome after more than six days}

Ophthalmology (in press)

\author{
Roselie M.H. Diederen ${ }^{\text {, Ellen C. La Heij }}{ }^{\text {, }}$ \\ Alfons G.H. Kessels ${ }^{2}$, Fleur Goezinne ${ }^{I}$, \\ Albert T.A. Liem ${ }^{l}$ and Fred Hendrikse ${ }^{l}$
}

1 Eye Research Institute Maastricht, Department of Ophthalmology, University Hospital Maastricht, The Netherlands

2 Department of Clinical Epidemiology and Medical Technology Assessment, University Hospital Maastricht, The Netherlands 



\section{ABSTRACT}

The aim of this retrospective, observational case series was to determine the effect of duration of macular detachment (DMD) on visual acuity in patients with macula-off rhegmatogenous retinal detachment. A total of 202 consecutive patients (202 eyes) with primary, uncomplicated, macula-off retinal detachment, a preoperative visual acuity $\leq 10 / 100$, a precise history of when macular function was lost, successful re-attachment surgery and a minimal follow up of 3 months were included. All retinal detachments were repaired with a primary scleral buckling procedure performed by three vitreoretinal surgeons. Main outcome measure was postoperative best corrected visual acuity. Considering all eyes, the cumulative mean of the best corrected postoperative visual acuity (logarithm of the minimum angle of resolution (LogMAR)) as a function of the DMD shows a rapid worsening when DMD exceeds 6 days. Eyes were divided into three groups, corresponding to the following DMD time intervals: immediate (within 10 days), delayed (11 days - 6 weeks) and late (longer than 6 weeks). The mean postoperative visual acuity (in $\log$ MAR) of eyes with DMD up to 10 days was $0.35 \pm 0.31$ (between 20/40 and 20/50 Snellen Equivalent), in the delayed group the mean visual acuity was $0.48 \pm 0.26$ (20/60 Snellen Equivalent), and in the eyes with DMD longer than 6 weeks it was $0.86 \pm 0.30$ ( $8 / 60$ Snellen Equivalent). Our results indicate that the scleral buckling procedure should be done preferably within a 7-day DMD.

\section{INTRODUCTION}

After a macula-off retinal detachment improvement of central vision remains compromised, due to permanent functional damage to the macula after detachment. ${ }^{1-3}$ Even when reattachment surgery is successful, a reattached retina rarely regains normal sensitivity or acuity..$^{3-5}$ A delay in surgery may result in an even worse visual outcome for patients with a detached retina. ${ }^{1,6}$ Therefore a retinal detachment of recent onset is generally considered to be a surgical emergency, especially when the macula is involved. Not only the ophthalmologist but also most patients would like the surgery to be scheduled soon after the onset of detachment.

Detachment of the neural retina from the retinal pigment epithelium (RPE) induces a variety of changes in several cell types throughout the retina. ${ }^{3}$ From experimental animal research it is known that a retinal detachment leads to alterations in the neurotransmitter and metabolic acid content of virtually all neuronal and glial cells in the neural retina. ${ }^{7,8}$ Some of these alterations, like a massive efflux of neuronal glutamate, start to occur within hours after the onset of retinal detachment. ${ }^{9}$ These rapid changes of a detached ret- 


\section{Chapter II}

ina may indicate that the retina should be re-attached as soon as possible to minimize further damage to the retinal cells.

In clinical practice, the question rises: does a short delay result in diminished visual acuity after surgery for patients with a detached macula? To answer this question large observational case series are needed that determine the effect of duration of macular detachment (DMD) on post operative visual acuity.

Although an important article was published on visual recovery of maculaoff retinal detachments as early as in 1982, only a few papers have been published on this topic ever since. In this article Burton et al. showed progressive decline in visual acuity over a 1- to 79-day period. ${ }^{1}$ This paper did not specifically show detailed results about visual acuity after macula-off detachments operated within the first week of macular involvement. Another study was published that showed visual recovery in macula-off rhegmatogenous retinal detachment (RRD) of 7 days' duration or less. ${ }^{10}$ The authors concluded that delay in surgical repair does not adversely affect visual outcome within the first week after development of macula-off retinal detachment. Although a large number of patients were included in this study, no cut-off point in time could be found after which the post operative visual results become significantly worse. This may be due to the fact that only patients with a DMD of 7 days duration or less were included.

Hassan et al. divided the DMD into three different intervals, namely; acute (10 days or less), subacute (11 days - 6 weeks) and chronic (longer than 6 weeks). These authors showed better visual recovery in the acute group compared to the subacute and chronic group. ${ }^{11}$ Due to the small number of patients in the acute group, Hassan et al. were not able to make powerful statistical comparisons within this group of patients with a DMD up to 10 days.

The aim of the current study was to verify the results of Hassan et al. ${ }^{11}$ and additionally to study the visual recovery of patients with a macular detachment operated within 10 days. Our major goal was to determine a cutoff point in DMD after which the post operative visual results become significantly worse.

\section{MATERIALS AND METHODS}

\section{Patients}

We retrospectively reviewed the records of 671 consecutive patients with RRD who were operated on with a scleral buckling (SB) procedure by one of three experienced vitreoretinal surgeons during a 7-year period (1997 2003 ) in our clinic. The study was performed with the agreement of the Uni- 
versity Hospital ethics committee; all patients gave their informed consent prior to inclusion in the study and after the nature of the study had been explained. The study adhered to the tenets of the Declaration of Helsinki. We used extensive inclusion criteria to select the patient database for this series. All eyes of patients that were included suffered from a primary, macula-off RRD with a visual acuity (VA) $\leq 10 / 100$. Only patients who could estimate the time of onset of significant visual loss accurately to a specific 24-hour period were included. DMD was defined as the time between the onset of symptoms of macular detachment (sudden significant visual loss) and the time of surgery. Eyes with vitreous hemorrhage or any other coexistent ocular disease were excluded because poor pre-operative visual acuity could not be attributed solely to macular detachment. When present, proliferative vitreoretinopathy (PVR) was graded according to the classification of RRD. ${ }^{13}$ In our clinic, eyes with RRD with up to PVR grade $\mathrm{C} 1$ are operated with a conventional scleral buckling technique. Eyes with PVR grade C2 and higher are operated on with a primary vitrectomy (as previously described) ${ }^{13}$, and were excluded from this study. In addition, patients who had any prior ocular surgery other than uncomplicated cataract extraction were excluded. No eyes with complicated RRD such as those with a giant retinal tear or retinoschisis were included. All eyes underwent SB with standard explant techniques. Only patients in whom accurate pre- and post operative visual acuity testing was possible were included. Eyes without successful reattachment following the primary procedure (62 patients with re-detachment due to PVR and 35 patients with re-detachment due to other causes) were excluded. All eyes had a minimum follow-up of 3 months (Table 1).

The following pre-operative clinical characteristics of the study patients were collected for statistical analysis: age, gender, eye affected, DMD, preoperative best corrected visual acuity, the number of prior eye operations, including cataract surgery, prior endolaser or cryocoagulation, and follow-up length. The following variables related to the scleral buckling procedure were collected: whether intraocular tamponade with air or cryotherapy was used, intraoperative and postoperative complications and, whether or not a re-detachment occurred. At 1, 3, 6, 12, and 24 months after surgery the visual acuity, retinal status and any possible reoperations were registered. At final follow-up we recorded anatomic result.

\section{Statistical analysis}

For statistical analysis, we consulted a professional statistician at our University Hospital (AGH Kessels, co-author). For statistical analysis Snellen visual acuities were converted to a logarithmic scale (LogMAR, i.e., the logarithm of the minimal angle of resolution), as described earlier. ${ }^{14}$

To compare our results with earlier published studies, eyes were divided into three groups, corresponding to the following time intervals: DMD up to 10 


\section{Chapter II}

days, DMD up to 6 weeks and DMD longer then 6 weeks. ${ }^{11}$ The eyes in the immediate group $(\mathrm{n}=160)$ were also examined at shorter intervals of 2 days: 1 to 2 days of detachment $(\mathrm{n}=23), 3$ to 4 days $(\mathrm{n}=60), 5$ to 6 days $(\mathrm{n}=37)$ 7 to 8 days $(\mathrm{n}=27)$ and 9 to 10 days $(\mathrm{n}=13)$. Statistical analysis comparing the means of pre-operative visual acuity and post-operative visual acuity between the three categories of DMD was performed using one-way ANOVA. The post operative visual acuity was divided into three groups: $20 / 40$ or better, $20 / 50$ to $20 / 100$, and $20 / 200$ or worse. The percentages of patients in each category were compared using the Chi-square test or the Fisher-exact test if appropriate. To determine the maximum DMD time interval in which a patient should be operated, we constructed a graph showing the cumulative mean of the best corrected postoperative visual acuity (LogMAR) as a function of the DMD.

\section{RESULTS}

A group of 202 patients with a primary RRD was included who fulfilled the inclusion criteria as outlined above (Table 1).

Table 1. Exclusion criteria applied on the total of 671 consecutive patients with macula-off retinal detachment.

\begin{tabular}{lcc}
\hline Reasons for exclusion & Total 671 patients & Patients left \\
\hline Follow up $<3$ months & 63 & 608 \\
No exact time of onset of DMD ${ }^{*}$ & 30 & 578 \\
Macula not involved & 258 & 320 \\
Macula evaluation not possible & 2 & 318 \\
Re-detachment due to PVR & 62 & 255 \\
Re-detachment not due to PVR & & 220 \\
Amblyopia & 35 & 212 \\
Retinoschisis & 6 & 211 \\
Vitreous hemorrhage & 1 & 205 \\
Prior or coexistent ocular disease or surgery & 6 & 202 \\
\hline
\end{tabular}

* DMD = duration of macular detachment; PVR = proliferative vitreoretinopathy

The age of the patients ranged from 24 to 80 years, with a mean age of 60.9 years. There were $79(39.2 \%)$ female and $123(60.8 \%)$ male patients included. A total of $111(54.4 \%)$ patients were operated on the right eye and $93(45.6 \%)$ on their left eye. Before surgery 158 eyes $(77.9 \%)$ were phakic and 44 eyes $(22.1 \%)$ were pseudophakic. All 202 patients could time the onset of significant visual loss to a 1-day period in the acute group and to a 3day period if they were included in the subacute or chronic group. For all eyes the mean duration of DMD was 11.4 days (range 1 day - 6 months). 
Gas was used as temporary internal tamponade in 167 patients $(81.9 \%)$ and 165 patients $(80.9 \%)$ received cryotherapy during the scleral buckling procedure to achieve retinopexy. No significant intraoperative complications, such as subretinal hemorrhage or incarceration, occurred in any of the 202 eyes. The follow up time ranged from 3 to 86 months, with a mean of 22.5 months. The mean preoperative visual acuity for all groups was 1.79 $\log$ MAR units $(5 / 200$ Snellen equivalent). The mean preoperative visual acuities in the three comparison groups were not statistically different $(\mathrm{P}=0.530)$.

\section{Visual results}

The mean postoperative visual acuity (in $\log$ MAR) of eyes with DMD up to 10 days was $0.35 \pm 0.31$ (20/40 - 20/50 Snellen Equivalent), in the delayed group (11 days -6 weeks) the mean visual acuity was $0.48 \pm 0.26(20 / 60$ Snellen Equivalent), and in the eyes with DMD longer than 6 weeks it was $0.86 \pm 0.30$ ( $8 / 60$ Snellen Equivalent) (Table 2 on next page). The mean best corrected postoperative visual acuity of eyes in the immediate group was significantly better than in the delayed or late group $(\mathrm{P}<.001)$. This was also the case when comparing the visual acuity results obtained at 3 months $(\mathrm{P}<.001)$, at 6 months $(\mathrm{P}<.001)$, and at 12 months $(\mathrm{P}=0.035)$ after surgery (Table 2).

After the scleral buckling procedure, $58.5 \%$ of eyes repaired within 10 days or less had a best corrected postoperative visual acuity of 20/40 or better. This was significantly better $(\mathrm{P}=0.01)$ than the $32.1 \%$ of patients in the delayed group, which in addition was significantly better $(\mathrm{P}=0.04)$ than the percentage of $0.0 \%$ of patients who had a best corrected postoperative visual acuity of $20 / 40$ or better in the late group. In the immediate group, only $5.6 \%$ of the patients had a mean visual acuity of $20 / 200$ or worse after a scleral buckling procedure. In the subacute and late group, respectively $10.7 \%$ and $30.8 \%$ of the patients had a postoperative visual acuity of $20 / 200$ or worse (Table 3). These differences were not statistically significant.

Table 3. Effect of duration of Macular Detachment on Visual Acuity at after a Scleral Buckling procedure.

\begin{tabular}{lccc}
\hline $\begin{array}{l}\text { Duration of macular } \\
\text { detachment }\end{array}$ & $\begin{array}{c}\text { Visual acuity } \\
\geq 20 / 40 \\
\%(n)^{*}\end{array}$ & $\begin{array}{c}\text { Visual acuity } \\
20 / 50-20 / 200 \\
\%(n)^{*}\end{array}$ & $\begin{array}{c}\text { Visual acuity } \\
<20 / 200 \\
\%(n)^{*}\end{array}$ \\
\hline$\leq 7$ days & $54.2(77)$ & $44.4(63)$ & $1.4(2)$ \\
$\leq 10$ days & $58.8(94)$ & $35.6(57)$ & $5.6(9)$ \\
11 days -6 wks & $32.1(9)$ & $57.1(16)$ & $10.7(3)$ \\
$>6$ wks & $0(0)$ & $69.2(9)$ & $30.8(4)$ \\
\hline
\end{tabular}

$n=$ number of patients. 
Table 2. Effect of duration of Macular Detachment on Visual Acuity at 3, 6 and 12 months after a Scleral Buckling procedure.

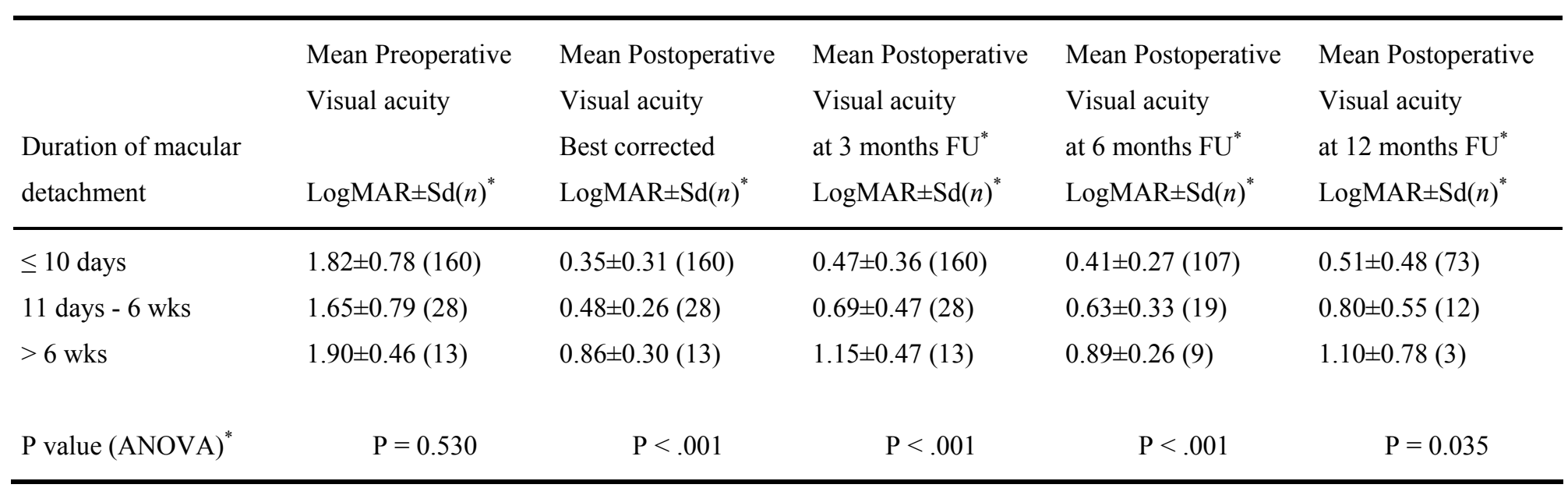

* $\quad \mathrm{FU}=$ follow up; $\operatorname{LogMAR} \pm \mathrm{Sd}=$ visual acuity in $\operatorname{LogMAR}$ units \pm standard deviation; $n=$ number of patients; ANOVA $=$ Statistical analysis was performed using one-way ANOVA. 
Considering all eyes, the cumulative mean of the best corrected postoperative visual auity (LogMAR) as a function of the DMD shows a rapid worsening when DMD exceeds 7 days (Figure 1). As can be seen from this graph, the curve starts to flatten at day 10 ; where after postoperative visual acuity does not significantly alter. The mean best corrected postoperative visual acuity (LogMAR) of patients operated on the first day of macular detachment was $0.49 \pm 0.048$. Because this group only exists of 2 patients these patients were not included in the calculation of the cumulative means of the best corrected post operative visual acuity. They were however included in the other data analyses.

Figure 1. Showing the cumulative mean of the best corrected postoperative visual acuity (VA) (LogMAR) as a function of the duration of macular detachment in days $(D M D)$.

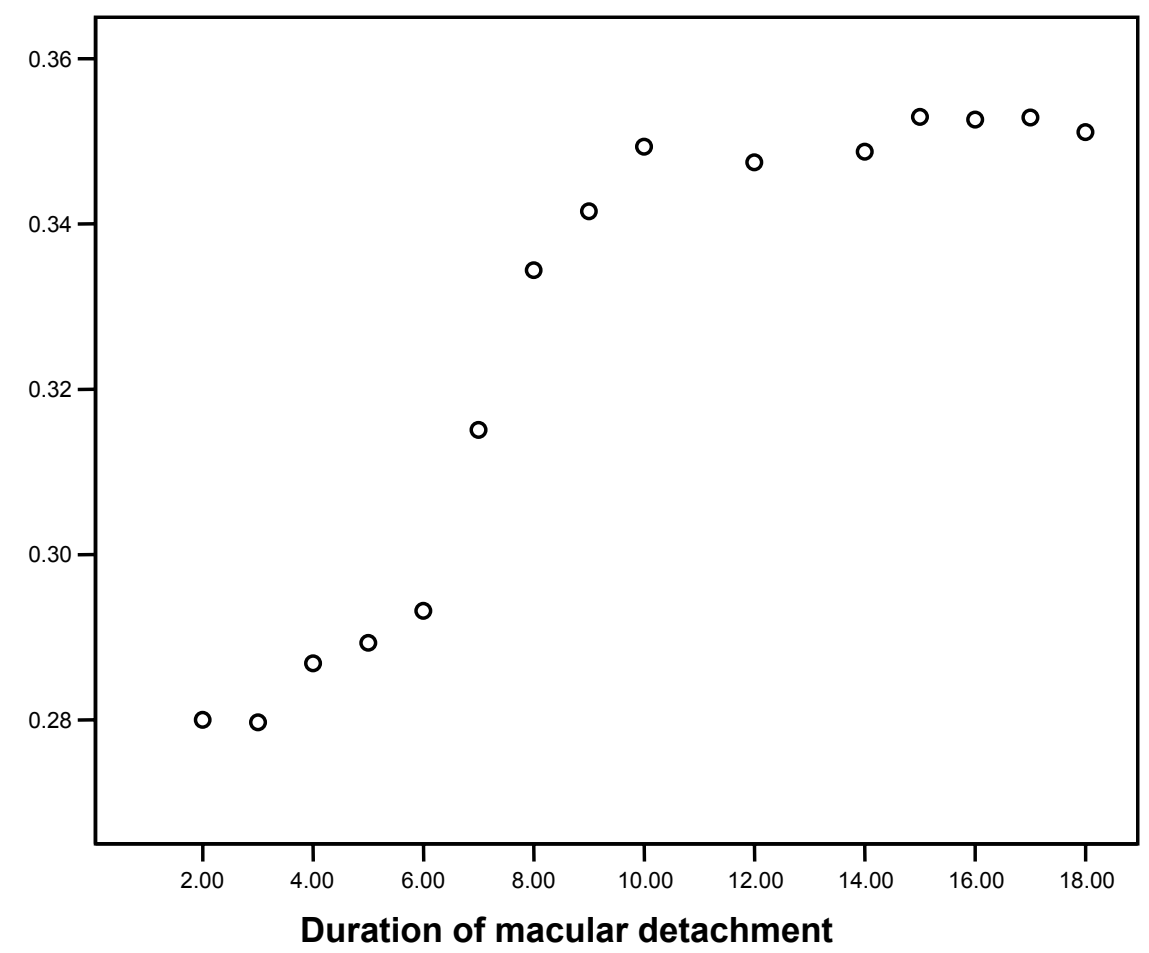

$(\mathrm{N}=$ number of patients, day $2: \mathrm{N}=23$; day $3: \mathrm{N}=57$; day $4: \mathrm{N}=83$; day 5 : $\mathrm{N}=107$ day; $6: \mathrm{N}=120$; day $7: \mathrm{N}=142$; day $8: \mathrm{N}=147$; day $9: \mathrm{N}=153$; day $10: \mathrm{N}=160$ )

In the immediate category the DMD was divided into 2-day intervals to compare our results with earlier published studies. ${ }^{11}$ Table 4 shows the effect of the subdivision in DMD on preoperative and best corrected postoperative visual acuity. Patients operated on the first or second day of DMD had a worse mean preoperative visual acuity $(2.09 \pm 0.72)$ compared to the other 


\section{Chapter II}

patients in this immediate category (mean visual acuity in the entire immediate group: $1.82 \pm 0.78$ ) (Table 4).

Table 4. Effect of duration of Macular Detachment on Visual Acuity at after a Scleral Buckling procedure.

\begin{tabular}{lccc}
\hline & & $\begin{array}{l}\text { Mean Preoperative } \\
\text { Visual acuity }\end{array}$ & $\begin{array}{l}\text { Mean Postoperative } \\
\text { Visual acuity } \\
\text { Best corrected } \\
\text { Duration of macular } \\
\text { detachment }\end{array}$ \\
\hline 1-2 days & 23 & $2.09 \pm 0.72$ & $0.29 \pm 0.22$ \\
3-4 days & 60 & $1.77 \pm 0.78$ & $0.29 \pm 0.27$ \\
5-6 days & 37 & $1.78 \pm 0.76$ & $0.31 \pm 0.19$ \\
7-8 days & 27 & $1.78 \pm 0.88$ & $0.51 \pm 0.48$ \\
9-10 days & 13 & $1.73 \pm 0.79$ & $0.51 \pm 0.38$ \\
Total group & 160 & $1.82 \pm 0.78$ & $0.35 \pm 0.32$ \\
\hline
\end{tabular}

* $\quad \operatorname{LogMAR} \pm \mathrm{Sd}=$ visual acuity in LogMAR units \pm standard deviation; $n=$ number of patients

\section{DISCUSSION}

To determine the critical DMD time interval in which a patient with a macula-off retinal detachment should be operated we constructed a graph showing the cumulative mean of the postoperative visual acuity (LogMAR) as a function of the DMD. The cumulative mean of the best corrected postoperative visual acuity (LogMAR) as a function of the DMD shows a rapid worsening when DMD exceeds 6 days. After a DMD of 10 days the slope of the graph becomes flat, which indicates that after a DMD of 10 days a further delay of scleral buckling surgery does not have a large negative effect on post operative visual acuity. Based on these data, we suggest that the scleral buckling procedure should preferably be done within 7 days of DMD. Given these results it may also be concluded that within 7 days of DMD the surgery is not emergent and delay in surgical repair does not negatively affect the visual outcome. Of course, our sample size does not allow adequate power to detect small day to day differences in outcome within the first 6 to 7 days.

In the current study, the mean postoperative visual acuity of eyes with DMD up to 10 days was significantly better than in the delayed (DMD of 11 days 6 weeks) and late group (DMD longer than 6 weeks). This result is in accordance with results Hassan et al. showed earlier. ${ }^{11}$ The mean postoperative visual acuity of eyes with DMD up to 10 days was somewhat better in the group of Hassan et al. compared to our patients. However, we found a 
slightly better postoperative visual acuity after repair during the delayed and late periods. Hassan et al. used similar exclusion criteria as in the current study; they also included only patients operated on with a standard explant scleral buckle technique. In contrast with the current study however, Hassan et al. were not able to make powerful statistical comparisons within this group of patients with a DMD up to 10 days, due to the small number of patients in the acute or immediate group.

A paper by Ross et al showed visual recovery in macula-off RRD repaired within 1 to 7 days. ${ }^{10}$ The major conclusion from this study was that the length of macular detachment within the first week does not significantly influence visual acuity after scleral buckling surgery. Comparable to Ross et al. we found a minimal visual acuity loss in patients operated within the first 7 days of DMD (table 4). Therefore our findings help support the recommendation of Ross et $\mathrm{al}^{10}$ that delay in surgical repair does not adversely affect visual outcome within the first week after development of macula-off retinal detachment. The study by Ross et al. did however not include patients with a DMD of longer than 7 days. Our results show that postoperative visual acuity declines significantly over time after DMD of 7 days.

Although we conclude that scleral buckling procedure should preferably be done within 7 days of DMD there may be good reasons to delay the surgery, for example, to stabilize patients with certain medical problems.

Delaying surgery until the next scheduled operating day however, enables the hospital staff to schedule the surgery in a more effective and convenient way. Emergency surgery is also more expensive than scheduled surgery due to extra personnel and other costs for evening and weekend surgery. ${ }^{15}$ Many hospitals have three categories of urgency: emergent, urgent, and elective. In most hospitals emergent cases, like endophthalmitis, ruptured globes or malignant glaucoma, are operated on the same day or night. Using this classification a retinal detachment would be urgent and is scheduled for the next day or two. Other departments or hospitals may use only two categories: emergent or not-emergent. The term "surgical emergency" is therefore a complex issue because it can have different meanings in different settings. The term "emergency surgery" as used in this article is reasonably being termed urgent surgery in many settings around the world.

Immediately after macular reattachment a complex process begins, leading to (partial) recovery of visual acuity. ${ }^{16,17} \mathrm{~A}$ rapid increase in the visual acuity was shown previously in the first 6 months after macular reattachment, thereafter further visual improvement was slow and minimal. ${ }^{5}$ This is in accordance with our postoperative visual acuity results. The visual results at $6-$ months postoperative are clearly better than the results after 3 months which may be due to further recovery of the cone photopigments after RRD, as 


\section{Chapter II}

previously shown by Liem et al. ${ }^{5}$ Visual acuity results 12 months after surgery were somewhat worse compared to the results 6 months after surgery. This could be due to development of cataract or macular changes after retinal detachment surgery. ${ }^{2}$

The mean best corrected postoperative visual acuity of patients operated on the first day of macular detachment was the lowest of all patients in the immediate group. In the study of Hartz et al. the most important reason for performing immediate emergency surgery was the inability to schedule an operating room the next day. But also patient characteristics influenced how surgery was scheduled. ${ }^{10}$ In our series, the 2 patients operated on the first day of macular detachment had low pre operative visual acuity which can be one of the explanations for their worse visual outcome.

There are several shortcomings of this study. It is retrospective and nonrandomized. Determination of DMD was uncontrolled and dependent on the reliability and precision of the patient's memory. Recently it was shown that lower height of macular detachment correlates with better visual recovery after treatment of macula-off retinal detachment. ${ }^{18}$ We were not able to include this important pre-clinical finding in our analysis, because the height of macular detachment was not documented carefully for all patients. Furthermore we only included patients who had a successful reattachment. But because surgeons will not know ahead of time which patients are going to need reoperation it is possible that they will use our data to guide patients who will fail as well.

In summary, our results show that the best mean post operative visual acuity was seen in patients with a macula off retinal detachment repaired within the first 10 days (acute or immediate group). The cumulative mean of the best corrected postoperative visual acuity (LogMAR) as a function of the DMD illustrates a rapid worsening when DMD exceeds 6 days. According to our findings, the visual acuity outcomes can be expected to worsen when DMD exceeds 6 days. After DMD of 10 days, visual acuity outcomes can be expected to stabilize. The implication of this study therefore is that the scleral buckling procedure after macula-off retinal detachment should preferably be done within 7 days. 


\section{REFERENCES}

1 Burton TC. Recovery of visual acuity after retinal detachment involving the macula. Trans Am Ophthalmol Soc 1982; 80:475-497.

2 Sabates NR, Sabates FN, Sabates R, Ledd KY, Ziemianski MC. Macular changes after retinal detachment surgery. American Journal of Ophthalmology 1989; 108:22-29.

3 Mervin K Valter K, Maslim J, Lewis G, Fisher S, Stone J. Limiting photoreceptor death and deconstruction during experimental retinal detachment: the value of oxygen supplementation. American Journal of Ophthalmology 1999; 128:155-164.

4 Michels R, Wilkinson C, Rice T. Results of retinal reattachment surgery. In: Retinal detachment. St Louis: CV Mosby 1990; 917-938.

5 Liem AT, Keunen JE, Meel van GJ, Norren van D. Serial foveal densitometry and visual function after retinal detachment surgery with macular involvement. Ophthalmology 1994; 101:1945-52

6 Burton TC. A predictive model for visual recovery following retinal detachment surgery. Ophthalmology 1978; 85:619-625.

7 Marc RE, Murry RF, Fisher SK, Linberg KA, Lewis GP, Kalloniatis M. Amino acid signatures in the normal cat retina. Invest Ophthalmol Vis Sci. 1998; 39:1685-1693.

8 Marc RE, Murry RF, Fisher SK, Linberg KA, Lewis GP. Amino acid signatures in the detached cat retina. Invest Ophthalmol Vis Sci 1998; 39:1694-1702.

9 Sherry DM, Townes-Anderson E. Rapid glutamatergic alterations in the neural retina induced by retinal detachment. IOVS 2000; 41:2779-2790.

10 Ross WH, Kozy DW. Visual recovery in macula-off rhegmatogenous retinal detachments. Ophthalmology 1998; 105:2149-2153.

11 Hassan TS, Sarrafizadeh R, Ruby AJ, Garretson BR, Kuczynski B, Williams GA. The effect of duration of macular detachment on results after the scleral buckle repair of primary, macula-off retinal detachment. Ophthalmology 2000; 109:146-152.

12 The classification of retinal detachment with proliferative vitreoretinopathy. Ophthalmology 1983; 90:121-125.

13 La Heij EC, Hendrikse F, Kessels AGH. Results and complications of temporary silicone oil tamponade in patients with complicated retinal detachments. Retina 2001; 21:107-114.

14 Ferris FL, Kassoff A, Bresnick GH, Bailey I. New visual acuity charts for clinical research. Am J Ophthalmol 1982; 94:91-96.

15 Hartz AJ, Burton TC, Gottlieb MS, McCarty DJ, Williams DF, Prescott A, Klein P. Outcome and cost analysis of scheduled versus emergency scleral buckling surgery. Ophthalmology 1992; 99:1358-1363.

16 Kreissing I, Lincoff H, Witassek B, Kolling G. Color vision and other parameters of macular function after retinal reattachment. Dev Ophthalmol 1981; 2:77-85.

17 Mc Pherson AR, O'Malley RE, Butner RW, Beltangady SS. Visual acuity after surgery for retinal detachment with macular involvement. Ann Ophthalmol 1982; 14:639-45.

18 Ross W, Lavina A, Russell M, Maberley D. The correlation between height of macular detachment and visual outcome in macula-off retinal detachments of $\leq 7$ days. Ophthalmology 2005; 112:1213-1217. 



\title{
CHAPTER III
}

\section{Pre-operative factors influencing visual outcome and anatomic success after retinal detachment without macular in- volvement}

\author{
Submitted
}

\author{
Roselie M.H. Diederen ${ }^{1}$, Ellen C. La Heij ${ }^{1}$, \\ Alfons G.H. Kessels', Fleur Goezinne ${ }^{1}$, \\ Albert T. A. Liem ${ }^{1}$, Aize Kijlstra ${ }^{1}$ and Fred Hendrikse ${ }^{1}$
}

1 Eye Research Institute Maastricht, Department of Ophthalmology, University Hospital Maastricht, The Netherlands

2 Department of Clinical Epidemiology and Medical Technology Assessment, University Hospital Maastricht, The Netherlands 



\section{ABSTRACT}

The objective of this study was to evaluate risk factors associated with redetachment and/or a worse visual outcome in patients with rhegmatogenous retinal detachment without macular involvement following scleral buckling surgery. In a retrospective observational case series, we analyzed 107 consecutive eyes with primary, macula-on retinal detachment, a precise history of when visual field loss had occurred and a minimal follow up of 6 months. The main outcome measures were visual acuity 6 months postoperatively and anatomic re-attachment rate. Of all preoperative clinical variables, which were evaluated to assess their association with a worse postoperative visual outcome, the occurrence of a re-detachment and the presence of preoperative proliferative vitreoretinopathy was found to be statistically significant was found to be statistically significant $(\mathrm{P}<0.001$ and $\mathrm{P}=.033$; respectively), using a stepwise forward multiple logistic regression analysis. A longer reported duration of visual field loss before surgery $(\mathrm{P}=0.014)$ was found to be a statistically significant risk factor associated with a recurrent retinal detachment. Our results furthermore showed that $29 \%$ of the patients had more than 2 Snellen lines visual loss 6 months after a successfully repaired macula-on retinal detachment compared to preoperatively. Five eyes $(4.7 \%)$ had a visual acuity $\leq 20 / 200$ at 6 months after surgery. In rhegmatogenous retinal detachment without macular involvement, the presence of proliferative vitreoretinopathy is an indicator for a low visual outcome after retinal detachment surgery. A longer duration of visual field loss before the scleral buckling procedure increases the chance of a retinal re-detachment after surgery.

\section{INTRODUCTION}

Patients with rhegmatogenous retinal detachment (RRD) without macular involvement represent a distinct category because they generally have good preoperative central visual acuity. Although final visual outcome of successfully reattached macula-on retinal detachments is usually expected to be good, postoperative visual acuity may occasionally be disappointing. In $10 \%$ $-15 \%$ of the patients with a successfully repaired macula-on retinal detachment, visual acuity does not return to the preoperative level. ${ }^{1}$

Because most patients with a macula-on retinal detachment have good visual acuities before surgery, keeping up this visual acuity postoperatively is important to meet the patients' expectations. Knowing the risk factors associated with re-detachment and/or a worse visual outcome after macula-on scleral buckling surgery may therefore be valuable information that can be used for pre-operative counseling. Therefore the aim of this retrospective study was to identify preoperative clinical variables associated with 


\section{Chapter III}

re-detachment and/or a worse visual outcome in patients with RRD without macular involvement after scleral buckling surgery.

\section{MATERIALS AND METHODS}

\section{Patients}

We retrospectively reviewed the records of 671 consecutive eyes with RRD which were operated on with a scleral buckling procedure by one of three experienced vitreoretinal surgeons during a 7-year period (1997 - 2003) in our clinic. The study was performed with the agreement of the University Hospital ethics committee; all patients gave their informed consent prior to inclusion in the study and after the nature of the study had been explained. The study adhered to the tenets of the Declaration of Helsinki.

We used extensive inclusion criteria to achieve the patient database for this series (Table 1). All eyes of patients that were included suffered from a primary RRD without macular involvement, confirmed by slitlamp biomicroscopy and had a best corrected Snellen visual acuity $\geq 80 / 100$. Eyes with vitreous hemorrhage or any other coexistent ocular disease were excluded because poor preoperative visual acuity could not be attributed solely to retinal detachment. When present, proliferative vitreoretinopathy (PVR) was graded according to the classification of RRD. ${ }^{2}$ In our clinic, eyes with RRD with up to PVR grade $\mathrm{C} 1$ are operated with a conventional scleral buckling technique. Eyes with PVR grade $\mathrm{C} 2$ and higher are operated on with a primary vitrectomy (as previously described), ${ }^{3}$ and were excluded from this study. In addition, patients who had any prior ocular surgery other than uncomplicated cataract extraction were excluded. Eyes with complicated RRD such as those with a giant retinal tear, retinoschisis or RRD due to trauma were included. Eyes with preoperative visual acuity $<80 / 100$ (best corrected Snellen visual acuity) were excluded to rule out patients with shallow macular detachment, severe cataract, macular problems, dense vitreous floaters or any other coexistent ocular disease that may compromise visual outcome. All eyes underwent scleral buckling surgery with standard explant techniques. Only patients in whom accurate pre- and postoperative visual acuity testing was possible were included. All eyes had a minimum follow-up of 6 months. After applying these inclusion and exclusion criteria 107 eyes (107 patients) were included in the current study.

The following preoperative clinical characteristics of the study patients were collected for statistical analysis: age, gender, refractive error, eye affected, the number of detached quadrants of the retina, number of retinal breaks, cumulative size of breaks, duration of visual field loss (days), preoperative best corrected visual acuity, whether the patient had diabetes mellitus, the number of prior eye operations, lens status (phakic, pseudophakic or 
aphakic), prior endolaser or cryocoagulation, and follow-up length. High myopia was defined as preoperative refractive error of $-5 \mathrm{D}$ or more. The following variables related to the scleral buckling procedure were collected: whether intraocular tamponade with air or cryotherapy was used, intraoperative and postoperative complications and, whether or not a re-detachment occurred. At 6 months after surgery the best corrected Snellen visual acuity, retinal status and any possible reoperations were registered. Anatomic success was defined as a complete attachment of the retina.

\section{Statistical analysis}

For statistical analysis, we consulted a professional statistician at our University Hospital (AGH Kessels, co-author). For statistical analysis Snellen visual acuities were converted to a logarithmic scale (LogMAR, i.e., the logarithm of the minimal angle of resolution), as described earlier. ${ }^{4}$ A stepwise forward multiple logistic regression analysis was used for to determine the association between visual outcome or re-detachment after initial scleral buckling surgery for the following variables: age, gender, diabetes, preoperative PVR, preoperative visual acuity, number of quadrants detached, number of retinal breaks, lens status, high myopia, and duration of retinal detachment (based on duration of visual field loss before surgery in days). Duration of visual field loss was compared between groups (patients with and without a re-detachment within 6 months after surgery) using Student's t-test.

\section{RESULTS}

A group of 355 patients (53.1\%) was excluded as they had a macular detachment. In total 107 eyes with a primary RRD without macular involvement were included who fulfilled the inclusion criteria as outlined above (Table 1). The age of the patients ranged from 21 to 85 years, with a mean age of 55.0 years. We included $36(33.6 \%)$ female and 71 (66.4\%) male patients. A total of $58(54.2 \%)$ patients were operated on the right eye and 49 (45.8\%) on their left eye. Before surgery 77 eyes $(72.0 \%)$ were phakic and 30 eyes $(28.0 \%)$ were pseudophakic. Gas was used as a temporary internal tamponade in 75 patients $(70.1 \%) .78$ patients $(72.9 \%)$ received cryotherapy during the scleral buckling procedure, the other $27.2 \%$ received postoperative laser therapy to achieve retinopexy. Intraoperative complications, such as subretinal hemorrhage or incarceration, did not occur in any of the eyes. The follow up time ranged from 6 to 89 months, with a mean of 31 months. For all eyes the mean duration of visual field loss was 16.5 days (range 1 day - 12 months). The mean duration of visual field loss for patients who had experienced an earlier RRD of the fellow eye (5 patients) was 2.8 days (range 2 day - 4 days). 
Table 1. Exclusion criteria applied on the total of 671 consecutive eyes with macula-off retinal detachment.

\begin{tabular}{lcc}
\hline Reasons for exclusion & Total 671 eyes & Eyes left \\
\hline Follow up $<6$ months & 11 & 660 \\
No exact time of onset of visual field loss & 27 & 633 \\
Macula detached & 355 & 278 \\
Macula evaluation not possible & 2 & 276 \\
Visual acuity measurement not possible & 1 & 275 \\
Vitreous hemorrhage & 11 & 264 \\
Amblyopia & 3 & 261 \\
Retinoschisis & 7 & 254 \\
Prior or coexistent ocular disease or surgery & 26 & 228 \\
Trauma & 4 & 224 \\
Pre operative VA $<80 / 100^{*}$ & 117 & 107 \\
\hline
\end{tabular}

* Eyes with preoperative visual acuity of less than $80 / 100$ were excluded to rule out patients with shallow macular detachment, severe cataract, macular problems, dense vitreous floaters or any other coexistent unknown ocular disease that may compromise visual outcome.

\section{Anatomic result}

All eyes had a complete reattachment of the retina at 6 months after the initial scleral buckling technique. In total 96 of 107 eyes (89.7\%) were repaired with the initial scleral buckling surgery. Re-operation was required in 11 eyes $(10.3 \%)$. Eight patients $(72.7 \%)$ were treated with a vitrectomy, membrane peeling, and oil-gas exchange after developing a re-detachment due to PVR. The remaining 3 of these 11 patients $(27.3 \%)$ were treated with a vitrectomy due to persistent subretinal fluid or re-detachment not due to PVR (Table 2).

Table 2. Re-detachment after initial scleral buckling procedure versus follow-up period (3 and 6 months postoperatively).

\begin{tabular}{lcc}
\hline & $\begin{array}{c}\text { At } 3 \text { months } \\
n=107^{*}\end{array}$ & $\begin{array}{c}\text { At } 6 \text { months } \\
n=107^{*}\end{array}$ \\
\hline repaired with initial SB & $94.4 \%$ & $89.7 \%$ \\
re-detachment due to PVR & $4.7 \%$ & $7.5 \%$ \\
re-detachment not due to PVR & $0.9 \%$ & $2.8 \%$ \\
\hline
\end{tabular}

$n=$ number of eyes; PVR = proliferative vitreoretinopathy;

$\mathrm{SB}=$ scleral buckling procedure 
A stepwise forward multiple logistic regression analysis was used to analyze the possible predictive value of various preoperative and intraoperative clinical variables on the occurrence of a re-detachment within 6 months after initial scleral buckling surgery. Of all preoperative and intraoperative clinical variables, which were evaluated to assess their association with a recurrent $\mathrm{RRD}$ only reported duration of visual field loss before surgery was found to be statistically significant $(\mathrm{P}=.014)$ (Table 3$)$. None of the other variables tested (age, gender, diabetes, pre-operative visual acuity, number of quadrants detached, number of retinal breaks, extent of detachment, lens status (pseudophakic vs phakic), preoperative PVR, high myopia or cryotherapy during surgery) were found to be statistically significant risk factors for a redetachment (Table 3).

Table 3. Predictive value of various preoperative clinical variables on the occurrence of a re-detachment within 6 months after initial scleral buckling surgery and worse visual acuity at 6 months post operatively (using multiple logistic regression analysis).

\begin{tabular}{lll}
\hline Clinical variables & $\begin{array}{l}\text { Occurance of } \\
\text { re-detachment } \\
P \text { value }\end{array}$ & $\begin{array}{l}\text { Worse visual } \\
\text { acuity } \\
P \text { value }\end{array}$ \\
\hline Age & n.s. & n.s \\
Gender & n.s. & n.s \\
Diabetes & n.s. & n.s \\
Pseudophakic eye & n.s. & n.s \\
Myopia $>5$ dpt & n.s. & n.s \\
Visual acuity preoperative & n.s. & n.s \\
Reported days of visual field loss & 0.014 & n.s \\
Number of breaks & n.s. & n.s \\
Cumulative size of the breaks & n.s. & n.s \\
Extent of detachment & n.s. & n.s \\
PVR ${ }^{*}$ A (preoperative) & n.s. & n.s \\
PVR ${ }^{*}$ B/C (preoperative) & n.s. & 0.033 \\
Re-detachment within 6 months & & $<.001$ \\
\hline
\end{tabular}

* $\quad$ PVR = proliferative vitreoretinopathy; n.s. = not significant

The mean duration of visual field loss before the initial scleral buckling surgery for patients with a re-detachment within 6 months (30.3 days) was significantly longer compared to patients without a re-detachment (7.7 days) $(\mathrm{P}<.05)$. 


\section{Chapter III}

\section{Visual results}

Considering all eyes, preoperative visual acuity ranged from 20/20 tot $80 / 100$, with a mean of $85 / 100(0.067 \pm 0.043 \log$ MAR unit). Postoperative visual acuity at 6 months ranged form 20/20 to light perception, with a mean visual acuity between 20/40 - 30/50 (0.26 $\pm 0.38 \log$ MAR unit) for all eyes. Looking only at eyes with primary success $(\mathrm{N}=96)$, the mean visual acuity at 6 months postoperative for was between 20/30 - 80/100 $(0.18 \pm 0.20$ $\log$ MAR unit).

Of all clinical variables, which were evaluated to assess their association with a worse postoperative visual outcome using stepwise forward multiple logistic regression analysis a re-detachment $(\mathrm{P}<.001)$ and the presence of PVR ( $\mathrm{P}=.033)$ was found to be statistically significant when analyzing all eyes $(\mathrm{N}=107)$. None of the other variables tested (age, gender, diabetes, pre-operative visual acuity, number of quadrants detached, extent of detachment, number of retinal breaks, lens status (pseudophakic vs phakic), high myopia, duration of retinal detachment or cryotherapy during surgery) were significantly correlated with a worse visual outcome (Table 3 ).

When only analyzing eyes with primary success $(\mathrm{N}=96), 29.1 \%(28$ patients) ended up with a loss of Snellen visual acuity of more than 2 lines at 6 months postoperatively compared to their preoperative visual acuity. Considering all eyes $(\mathrm{N}=107), 32.7 \%$ (35 patients) had a more than 2 lines loss of Snellen acuity 6 months after surgery compared to their preoperative visual acuity. Five eyes of the total patient group $(\mathrm{N}=107)(4.7 \%)$ had a visual acuity of $\leq 20 / 200$ at 6 months after surgery (Table 4).

Table 4. Causes of postoperative visual acuity of $\leq 20 / 200,6$ months after scleral buckling surgery

\begin{tabular}{lc}
\hline Cause & Number of patients \\
\hline Re-detachment due to PVR & 4 \\
Re-detachment without PVR & 1 \\
\hline
\end{tabular}

$n=$ number of eyes; PVR = proliferative vitreoretinopathy

\section{DISCUSSION}

Our results show that in patients with a retinal detachment without macular involvement a longer reported duration of visual field loss before surgery is a statistically significant risk factor associated with a recurrent RRD. We found that the presence of preoperative PVR had a significantly negative influence on postoperative visual outcome. Although both the preoperative visual acuity and the postoperative visual acuity of macula-on retinal de- 
tachments are usually good, postoperative visual acuity may occasionally be disappointing. Ho et al. showed that most macula-on retinal detachments do not show rapid progression and thus do not necessarily require immediate surgical treatment. ${ }^{5}$ Knowing the risk factors associated with re-detachment and/or a worse visual outcome after macula-on scleral buckling surgery can be useful to identify those patients that would benefit from earlier scleral buckling surgery.

Our results showed that reported duration of visual field loss is a significant risk factor associated with re-detachment after macula-on RRD surgery. In macula-off RRD, Hassan et al. were not able to show a similar significant effect of duration of macular detachment on final anatomic reattachment. ${ }^{6}$ Grizzard et al. found preoperatively early $(<\mathrm{C} 1)$ or advanced $(\geq \mathrm{C} 1)$ PVR and duration of macular detachment to be significant variables to predict failure of successful retinal reattachment. ${ }^{7}$ However, also this study is not comparable to ours as in this study, patients with and without macular involvement were included. ${ }^{7}$

Our results show that when using a stepwise forward multiple logistic regression analysis the reported duration of visual field loss is a significant risk factor associated with re-detachment after macula-on RRD surgery while preoperative PVR is not. However, using an univariate analysis preoperative PVR is significantly correlated with the occurrence of a re-detachment which is in accordance with previous findings. ${ }^{8}$ The reason for this difference may be the correlation between the duration of visual field loss and the presence of preoperative PVR that make the effect of preoperative PVR on getting a retinal re-detachment fade away when doing a stepwise forward multiple logistic regression analysis using duration of visual field loss as a co-factor.

Our results show that $29 \%$ of the patients, had visual acuity loss of more than 2 lines on the Snellen chart 6 months after a successfully repaired macula-on retinal detachment. This number is higher than the $10-15 \%$ reported earlier, but this may be partly due to the strict inclusion criteria of permitting only eyes with a pre-operative visual acuity of $\geq 80 / 100$ into the study. There might also be a difference in the postoperative follow up period and definition of decreased visual acuity. ${ }^{1}$ Our results are in agreement with the results of Wolfensberger et al., who found that even in the absence of clinically detectable complications like cystoid macular edema or epiretinal membranes, an unexplained decreased final postoperative visual acuity can occur after retinal detachment surgery. ${ }^{9}$ Recent studies have demonstrated that, even in macula-on RRD, photoreceptor atrophy and loss may be responsible for the reduced visual acuity seen in patients after anatomically successful repaired RRD. Schocket et al. showed that patients with retinal detachments not involving the macula had similar abnormalities on ultra-high resolution (UHR) 


\section{Chapter III}

OCT as patients with macular detachment, like distortion of the photoreceptor inner/outer segments junction. ${ }^{9}$ This indicates that an attached macula does not necessarily mean that macular photoreceptors are uninvolved, ${ }^{10}$ and these OCT findings may explain the occasionally disappointing postoperative visual acuity after macula-on RRD. Also postoperative sub-foveal fluid, undetectable by both biomicroscopy and fluorescein angiography, was demonstrated in macula-on RRDs after a successful scleral buckling procedure. ${ }^{11}$ The presence of subfoveal fluid found in these patients coincided with a decrease in visual acuity. ${ }^{9,11}$

We found that the group with final visual acuity of $\leq 20 / 200$ consisted of 5 $(4.7 \%)$ patients. This number is lower compared to the number found by Salicone et al. (17\%). However, we measured final visual acuity at 6 months after surgery where they measured final visual acuity 2 months postoperatively. ${ }^{12}$ This may explain the high number of patients with final visual acuity of $\leq 20 / 200$ after surgery, because at 2 months after surgery the visual acuity is still improving.

Although the status of the macula is proven to be important in visual outcome after RRD surgery, many authors did not distinguish between cases in which the macula was detached and those in which the macula was not involved. $^{7}$ Not much literature has been published solely on macula-on RRD, as most papers who do differentiate between cases in which the macula was detached and those in which the macula was spared, are dealing with macula-off RRD. ${ }^{6,12,13}$

This study is retrospective and nonrandomized. We did not use OCT to confirm biomicroscopy and to make sure that the macula was indeed uninvolved. We did however only include patients with visual acuity of $\geq 80 / 100$ to be sure no patients with shallow macular detachment were included. Determination of duration of retinal detachment was uncontrolled and dependent on the reliability and precision of the patient's memory. Detection of peripheral visual field loss is even more dependent on patients attentiveness compared to detection of macular detachment which is accompanied by an acute drop in visual acuity. This may be illustrated by our finding that in patients who suffered earlier from a RRD in the fellow eye the mean duration of visual field loss is 3 days, compared to over 16 days for the whole patient group.

In conclusion, in RRD without macular involvement the presence of preoperative PVR is an indicators for a low visual outcome after retinal detachment surgery. A longer reported duration of visual field loss before the scleral buckling procedure increases the chance of a retinal re-detachment after surgery. 


\section{REFERENCES}

1 Basic and clinical science course: Retina and Vitreous. American academy of Ophthalmology: San Francisco; 2005.

2 The classification of retinal detachment with proliferative vitreoretinopathy. Ophthalmology 1983; 90:121-125.

3 La Heij EC, Hendrikse F, Kessels AGH. Results and complications of temporary silicone oil tamponade in patients with complicated retinal detachments. Retina 2001; 21:107-114.

4 Ferris FL, Kassoff A, Bresnick GH, Bailey I. New visual acuity charts for clinical research. Am J Ophthalmol. 1982; 94:91-96.

5 Ho SF, Fitt A, Friimpong-Ansah K, Benson MT. The management of primary rhegmatogenous retinal detachment not involving the fovea. Eye 2006; 20:1049-53.

6 Hassan TS, Sarrafizadeh R, Ruby AJ, Garretson BR, Kuczynski B, Williams GA. The effect of duration of macular detachment on results after the scleral buckle repair of primary, macula-off retinal detachment. Ophthalmology 2002; 109:146-152.

7 Grizzard WS, Hilton GF, Hammer ME, Taren D. A multivariate analysis of anatomic success of retinal detachments treated with scleral buckling. Greafe's Arch Clin Exp Ophthalmol. 1994; 232:1-7.

8 Afrashi F, Akkin C, Egrilmez S, Erakgun T, Mentes J. Anatomic outcome of scleral buckling surgery in primary rhegmatogenous retinal detachment. Int. Ophthalmol Int Ophthalmol. 2005; 26(3):77-81.

9 Wolfensberger TJ, Gonvers M. Optical coherence tomography in the evaluation of incomplete visual acuity revovery after macula-off retinal detachments. Graefe's Arch Clin Exp Ophthalmol. 2002; 240:85-89.

10 Socket LS, Within AJ, Fujimoto JG, Ko TH, Schuman JS, Rogers AH, Baumal C, Reichel E, Duker JS. Ultraigh-resolution optical coherence tomography in patients with decreased visual acuity after retinal detachment repair. Ophthalmology 2005; 113:666-672.

11 Theodossiadis PG, Georgalas IG, Emfietzoglou J, Kyriaki TE, Pantelia E, Gogas PS, Moschos MN, Theodossiadis GP. Optical coherence tomography findings in the macula after treatment of rhegmatogenous retinal detachments with spared macula preoperatively. Retina 2003; 23:69-75.

12 Salicone A, Smiddy WE, Venkatraman A, Feuer W. Visual recovery after scleral buckling procedure for retinal detachment. Ophthalmology 2006; 113(10):1734-42.

13 Lui F, Meyer CH, Mennel S, Hoerle S, Kroll P. Visual recovery after scleral buckling surgery in macula-off rhegmatogenous retinal detachment. Ophthalmologica 2006; 220:174-180. 



\title{
CHAPTER IV
}

\section{Increased glutamate levels in the vitreous of patients with retinal detachment}

\author{
Exp Eye Res. 2006; 83(1):45-50
}

\author{
Roselie M.H. Diederen ${ }^{1}$, Ellen C. La Heij ${ }^{l}$, \\ Nicolaas E.P. Deutz, ${ }^{2}$ Aize Kijlstra ${ }^{l}$, \\ Alfons G.H. Kessels ${ }^{3}$ Hans M. H. van Eijk, \\ Albert T.A. Liem ${ }^{l}$, Suzanne Dieudonnéa \\ and Fred Hendrikse ${ }^{l}$
}

1 Department of Ophthalmology, University Hospital Maastricht, The Netherlands.

2 Department of Surgery, University of Maastricht, The Netherlands.

3 Department of Clinical Epidemiology and Medical Technology Assessment, University Hospital Maastricht, The Netherlands. 



\section{ABSTRACT}

Experimental models have implicated glutamate in the irreversible damage to retinal cells following retinal detachment. In this retrospective study we investigated a possible role for glutamate and other amino acid neurotransmitters during clinical rhegmatogenous retinal detachment. Undiluted vitreous samples were obtained from 176 patients undergoing pars plana vitrectomy. The study group consisted of 114 patients (114 eyes) with a rhegmatogenous retinal detachment. Controls included 52 eyes with an idiopathic macular hole or idiopathic epiretinal membrane and 10 eyes with a traction retinal detachment due to proliferative diabetic retinopathy. Vitreous concentrations of glutamate, gamma-aminobutyric acid (GABA), taurine, glycine, and aspartate were determined by high-pressure liquid chromatography (HPLC). Multivariate analysis was used to examine a possible association between amino acid neurotransmitter levels and several clinical variables including visual acuity. The mean vitreous concentration of glutamate in eyes with a rhegmatogenous retinal detachment $(16.6 \pm 5.6 \mu \mathrm{M})$ was significantly higher as compared to the controls $(13.1 \pm 5.2 \mu \mathrm{M})(\mathrm{P}=0.001)$. Taurine levels were also increased in rhegmatogenous retinal detachment, whereas no significant difference could be observed in glycine, aspartate and gammaaminobutyric acid levels when comparing rhegmatogenous retinal detachment with controls. A correlation was found between increased vitreous glutamate and a lower pre-operative visual acuity. No association was, however, observed between post-operative visual acuity and the level of any of the five amino acid neurotranmitters. Using visual acuity as a functional parameter in this study, we could not demonstrate a correlation between vitreous glutamate, or any of the other tested amino acid neurotransmitters and visual outcome.

\section{INTRODUCTION}

Glutamate is an excitatory neurotransmitter in the retina, which after its release from neurons is cleared from the extracellular environment via uptake by Müller cells. Müller cells subsequently transform glutamate into glutamine by the enzyme glutamine synthetase (GS). Ischemia of the retina leads to changes in the localization of the retinal amino acid neurotransmitters glutamate and gamma-aminobutyric acid (GABA) as well as to accumulation of glutamate and GABA in Müller cells. ${ }^{1,2}$ Glutamate toxicity is considered to be caused by an excessive activation of $N$-methyl-D-aspartatic acid (NMDA) glutamate receptors, leading to an increased calcium influx, finally resulting in cell death. ${ }^{3}$

In cat eyes with experimental retinal detachment, a marked decrease in the expression of glutamine synthetase (GS) activity has been found, suggesting 


\section{Chapter IV}

that the clearance capacity of glutamate by Müller cells may be lost after retinal detachment. ${ }^{4}$ Also, there is evidence for large shifts in intracellular glutamate concentrations in the retina following experimental retinal detachment. ${ }^{5}$ Furthermore, in experimental intervention studies, it has been shown that glutamate receptor antagonists were able to decrease retinal damage after experimentally induced retinal ischemia. ${ }^{6-8}$

Experiments detecting changes in neurotransmitter levels after retinal detachment have mostly been performed in animal models. The role of neurotransmitters in human retinal detachment is not yet known and determining their role was therefore the purpose of our study. Since it is not possible to collect retinal samples from patients we decided to study the level of glutamate in vitreous. To address this issue, vitreous fluid was obtained from retinal detachment patients undergoing a vitrectomy. Using high-performance liquid chromatography (HPLC), we determined vitreous fluid levels of all five amino acid neurotransmitters that are known in the central nervous system (glutamate, GABA, aspartate, glycine, and taurine). Glutamate, GABA, and glycine also act as neurotransmitters in the mammalian retina, but there is scant evidence for a retinal transmitter function for aspartate and taurine. ${ }^{9}$

Previous research has shown higher glutamate levels in vitreous fluid of patients with proliferative diabetic retinopathy (PDR) without detachment. ${ }^{10}$ Therefore, we included eyes with proliferative diabetic retinopathy as a positive control.

We found increased levels of glutamate and taurine in eyes with rhegmatogenous retinal detachment (RRD). To examine a role for these amino acids in retinal cell damage, visual acuity was used as a functional parameter. We could however not demonstrate a correlation between vitreous glutamate, nor any of the other tested amino acid neurotransmitters and visual outcome.

\section{METHODS}

\section{Patients}

In a prospective study, vitreous fluid samples were collected from patients with RRD. All patients were operated in our department between May 1999 and January 2003 with a vitrectomy. Eyes with uveitis, trauma or vitreous hemorrhage were excluded. Only patients with a minimum follow-up of three months were included in the analysis. We operate eyes with a RRD with up to proliferative vitreoretinopathy (PVR) grade $\mathrm{C} 1$ with a conventional scleral buckling technique. Eyes with PVR grade $\mathrm{C} 2$ and higher are operated on with a primary vitrectomy, as described earlier. ${ }^{11}$ Vitreous samples from patients with idiopathic macular hole or idiopathic epiretinal membranes were used as controls. We also collected vitreous fluid from eyes 
with a traction retinal detachment due to PDR. The study was performed with the agreement of the institutional ethics committee; all patients gave their informed consent prior to inclusion in the study and after the nature of the study was explained. The study was conducted in accordance with the ethical standards laid down in the 1964 Declaration of Helsinki.

The following pre-operative clinical characteristics of the study patients were collected for statistical analysis: age, sex, eye affected, the number of detached quadrants of the retina, whether or not the central area of the macula (foveal region) was involved in the detachment, pre-operative corrected visual acuity, intraocular pressure (IOP), whether the patients used antiglaucoma medication and the number of anti-glaucoma medications, whether the patient had diabetes mellitus, the number of prior eye operations, including cataract surgery, scleral buckling, prior endolaser or cryocoagulation, and follow-up time. By carefully questioning the patient, the approximate length of time between the occurrence of the retinal detachment and time of sampling was established. The following variables related to the vitrectomy were collected: whether intraocular endotamponade was necessary with oil or gas and whether or not a re-detachment occurred. At final follow-up we recorded visual acuity and the anatomic result.

\section{Sample collection}

Undiluted vitrectomy samples (approximately $0.5 \mathrm{ml}$ ) were obtained by a conventional three- port closed vitrectomy technique by manual suction at the beginning of the vitrectomy, before opening the infusion line of Balanced Salt Solution (BSS, Alcon Laboratories, Texas, USA), as described earlier. $^{12}$ The samples were transferred to Eppendorf tubes and stored at $-80^{\circ} \mathrm{C}$ until the time of amino acid analysis.

\section{Amino acid analysis}

Amino acid analysis of vitreous fluid was performed using high-performance liquid chromatography (HPLC), as described earlier. ${ }^{13}$ Vitreous analysis was performed in a masked fashion, using only the sample number without the technician knowing the clinical history of the patient.

The following five amino acid neurotransmitters were analyzed: aspartate, GABA, glutamate, glycine, and taurine. Amino acid analysis was performed following precolumn derivatization with o-phthaldehyde (OPA). Samples $(50 \mu \mathrm{l})$ were first centrifuged at $50.000 \mathrm{x}$ g. Next, $4 \mu 1$ supernatant was pipetted into a glass $300 \mu \mathrm{l}$ insert, containing $194 \mu \mathrm{l}$ water and $2 \mu \mathrm{l}$ norvaline solution $(500 \mu \mathrm{mol} / 1$; used as an internal standard). From this mixture, $5 \mu \mathrm{l}$ was mixed automatically with $5 \mu \mathrm{l}$ of OPA reagent, incubated for 2 min and injected onto a $150 \times 4.6 \mathrm{~mm}$ (i.d.) column filled with Allsphere $3 \mu \mathrm{m}$ (Alltech, Breda, Netherlands) using a WISP 715 sample processor (Waters, Etten-Leur, Netherlands). Amino acid derivatives were eluted using 25 


\section{Chapter IV}

mmol/l citric acid buffer $\mathrm{pH} 6.8$ containing 3\% tetrahydrofuran as starting solvent, followed by gradient elution using a linear addition to $100 \%$ of solvent B (same buffer, now containing $40 \%$ acetonitril and 5\% tetrahydrofuran) within $30 \mathrm{~min}$. Fluorescence was monitored with a Jasco Model 820FP fluorescence detector (B\&L systems, Zoetermeer, Netherlands). Besides an external standard, norvaline was used as an internal standard. Measurements were made at an excitation wavelength of $335 \mathrm{~nm}$ and an emission wavelength of $440 \mathrm{~nm}$. Data were collected on-line and processed using Turbochrom software (Perkin-Elmer, Oosterhout, Netherlands).

\section{Statistical analysis}

For statistical analysis, we consulted a professional statistician at our University Hospital (AGH Kessels, co-author).

Levels of all amino acid neurotransmitters were compared between groups using Student's t-test. Because the GABA concentration was skewed, the statistics for GABA were performed after a log transformation. Comparisons for sex, glaucoma and prior eye surgery between patients with RRD and controls were performed using the Chi-Square test. The Pearson correlation test was used to test the association between the vitreous concentration of the five amino acid neurotransmitters and age, intraocular pressure, the number of quadrants the retina was detached, whether the patient had diabetes mellitus, the number of prior eye operations, including cataract surgery, scleral buckling, prior endolaser or cryocoagulation, the approximate length of time between occurrence of retinal detachment and time of sampling, whether a re-detachment occurred, and the anatomic result. The Bonferroni-Hochberg correction for multiple comparisons was applied in all tests. ${ }^{14}$

For statistical analysis, Snellen visual acuities were converted to a logarithmic scale (LogMAR, i.e. the logarithm of the minimal angle of resolution), as described earlier. ${ }^{15}$ The association between the levels of the various amino acid neurotransmitters, and pre-operative visual acuity was investigated with a multiple linear regression analysis using the status of the macula as co-variable. The association between the levels of the various amino acid neurotransmitters, and final postoperative visual acuity was investigated with a multiple linear regression analysis using the pre-operative visual acuity as co-variable. Secondly, these associations were investigated with a multivariate linear regression model adjusting for nine variables: pre-operative visual acuity, diabetes, glaucoma, prior scleral buckling, prior endolaser, prior cryocoagulation, duration of detachment, status of the macula and number of quadrants of retinal detachment. 


\section{RESULTS}

Vitreous fluid samples were collected from 114 eyes (114 patients) with RRD. The mean age was 58 years ( $\mathrm{SD} \pm 15$ years). Mean follow-up time was 23 months ( $\mathrm{SD} \pm 13$ months). The mean duration of retinal detachment was 44 days (ranged from 1 to 365 days; Table 1). The control group consisted of 52 patients with an epiretinal membrane or macular hole. The mean age in this group was 68 years ( $\mathrm{SD} \pm 8$ years). In addition, vitreous samples were obtained from a third patient group of 10 patients with traction retinal detachment due to PDR. The mean age in this third group was 52 years (SD \pm 14 years). No significant differences were found between the age of patients and controls.

Table 1. Basic Clinical and Ocular Characteristics

\begin{tabular}{lccc}
\hline & RRD $(n=114)$ & Controls $(n=52)$ & PDR $(n=10)$ \\
\hline Age (years) $^{\mathrm{a}}$ & $58.2 \pm 15.1$ & $66.2 \pm 8.1$ & $51.3 \pm 14.0$ \\
Male $^{\mathrm{b}}$ & $69(61 \%)$ & $26(50 \%)$ & $5(50 \%)$ \\
Female $^{\mathrm{b}}$ & $45(39 \%)$ & $26(50 \%)$ & $5(50 \%)$ \\
Right eye $^{\mathrm{b}}$ & $61(54 \%)$ & $29(56 \%)$ & $5(50 \%)$ \\
Left eye $^{\mathrm{b}}$ & $51(46 \%)$ & $23(44 \%)$ & $5(50 \%)$ \\
IOP $(\mathrm{mmHg})^{\mathrm{a}}$ & $14.5 \pm 5.7$ & $16.9 \pm 5.9$ & $12.7 \pm 5.1$ \\
Diabetes $^{\mathrm{b}}$ & $3(3 \%)$ & $3(6 \%)$ & $10(100 \%)$ \\
Glaucoma $^{\mathrm{b}}$ & $7(6 \%)$ & $4(8 \%)$ & 0 \\
Aphakic $^{\mathrm{b}}$ & $6(5 \%)$ & $1(2 \%)$ & 0 \\
Pseudophakic $^{\mathrm{b}}$ & $31(27 \%)$ & $12(23 \%)$ & 0 \\
Prior scleral buckling $^{\mathrm{b}}$ & $62(54 \%)$ & $3(6 \%)$ & 0 \\
Prior endolaser $^{\mathrm{b}}$ & $32(28 \%)$ & $11(21 \%)$ & $7(70 \%)$ \\
Prior cryocoagulation $^{\mathrm{b}}$ & $41(36 \%)$ & $3(6 \%)$ & 0 \\
Duration of detachment (days) $^{\mathrm{a}}$ & $43.6 \pm 72.1$ & & \\
Macular detachment $^{\mathrm{b}}$ & $70(61 \%)$ & & \\
Number of quadrants of retinal $^{\text {detachment }}{ }^{\mathrm{a}}$ & $2.6 \pm 1.1$ & & \\
Re-detachment $^{\mathrm{b}}$ & $37(33 \%)$ & & \\
Pre-operative visual acuity $^{\text {ad }}$ & $1.7 \pm 0.9$ & & \\
Post-operative visual acuity $^{\text {ad }}$ & $1.4 \pm 1.0$ & & \\
Duration of follow-up (months) $^{\mathrm{a}}$ & $22.9 \pm 13.0$ & $16.6 \pm 14.1$ & $18.0 \pm 9.6$ \\
\hline
\end{tabular}

a Numbers are noted in mean $\pm \mathrm{SD}$ (standard deviation).

b Number (percentage).

c RRD Rhegmatogenous Retinal Detachment. PDR Proliferative Diabetic Retinopathy.

d Snellen visual acuities were converted to a logarithmic scale (LogMAR, i.e. the logarithm of the minimal angle of resolution). 
Table 2. Vitreous Amino Acid Concentration $(\mu M)$.

\begin{tabular}{|c|c|c|c|c|c|c|c|}
\hline & $\begin{array}{l}\text { Controls } \\
(n=52)\end{array}$ & $\begin{array}{l}\text { Eyes with RRD }{ }^{\mathrm{b}} \\
\quad(n=114)\end{array}$ & P Value & PValue $^{\mathrm{a}}$ & $\begin{array}{c}\text { Eyes with PDR }{ }^{\mathrm{b}} \\
(n=10)\end{array}$ & P Value & P Value \\
\hline Glutamate & $13.1 \pm 5.2$ & $16.6 \pm 5.6$ & .001 & .001 & $19.5 \pm 6.5$ & .001 & .001 \\
\hline Glycine & $49.4 \pm 36.3$ & $42.5 \pm 32.0$ & .223 & $>.99$ & $67.5 \pm 23.1$ & .135 & $>.99$ \\
\hline Taurine & $22.6 \pm 6.6$ & $26.0 \pm 7.8$ & .008 & .040 & $28.1 \pm 11.0$ & .154 & $>.99$ \\
\hline
\end{tabular}

After Bonferroni-Hochberg correction for multiple comparions.

RRD Rhegmatogenous Retinal Detachment. PDR Proliferative Diabetic Retinopathy. 
Baseline clinical characteristics of all three groups are summarized in table 1. The mean level of glutamate in vitreous of eyes with RRD was 16.6 \pm 5.6 $\mu \mathrm{M}$, which was significantly higher than in the control group $(13.1 \pm 5.2 \mu \mathrm{M}$; $\mathrm{P}=0.001$; Table 2). The mean vitreous concentration of taurine in eyes with RRD was $26.0 \pm 7.8 \mu \mathrm{M}$ and was also significantly higher than in the control group $(22.6 \pm 6.6 \mu \mathrm{M}: \mathrm{P}=0.04)$. The mean $\mathrm{GABA}$ concentration in the vitreous fluid samples of RRD patients $(1.9 \pm 0.5 \mu \mathrm{M})$ was not significantly different compared to controls $(2.0 \pm 0.5 \mu \mathrm{M} ; \mathrm{P}=0.82$; Table 2$)$. The mean concentration of the other two neurotransmitters, glycine and aspartate also did not differ significantly between patients with RRD and controls.

The mean level of glutamate in the vitreous fluid of eyes with traction retinal detachment due to PDR was $19.5 \pm 6.5 \mu \mathrm{M}$, which was significantly higher than in the control group $(13.1 \pm 5.2 \mu \mathrm{M} ; \mathrm{P}=0.001$; Table 2$)$. No significant difference for glutamate was found between eyes with RRD and PDR. The mean concentration of the other neurotransmitters, GABA, glycine, taurine and aspartate did not differ significantly between the PDR group and controls (Table 2).

In the control group, we found no statistically significant difference in the vitreous concentrations of all five amino acid neurotransmitters between patients with a macular hole and patients with an epiretinal membrane. Of all clinical variables, such as prior scleral buckling, prior endolaser, prior cryocoagulation, duration of detachment, status of the macula and number of quadrants and retinal detachment, analyzed in the present study, none did significantly correlate with the concentration of any of the amino acid neurotransmitters, except for glutamate. There we found a significant correlation between a higher vitreous glutamate concentration and a lower pre-operative visual acuity $(\mathrm{P}=0.039)$ in patients with $R R D$, using the status of the macula as co-variable. No significant correlation was found between any of the five amino acid neurotransmitter levels, taken at the time of retinal detachment and post-operative visual acuity recorded at final follow up in patients with RRD after using multivariate analysis. Finally, of the clinical variables, only pre-operative visual acuity was associated with final visual outcome.

\section{DISCUSSION}

In this study we report a significantly elevated concentration of glutamate in the vitreous of eyes with RRD compared to controls. Similar to RRD, glutamate levels in eyes with a traction retinal detachment due to PDR were also significantly higher than controls. This latter observation confirms an earlier study, in which also raised glutamate levels were detected in the vitreous of eyes with PDR as compared to controls. ${ }^{10}$ 


\section{Chapter IV}

Glutamate is the primary excitatory amino acid neurotransmitter within the retina, and excessive levels of glutamate can cause excitotoxicity. This may, at least in part, be due to excessive activation of NMDA-type glutamate receptors and hence excessive $\mathrm{Ca}^{2+}$ influx through the receptor's associated ion channel. ${ }^{3}$ After its release from neurons glutamate is cleared from the extra cellular environment via uptake by Müller cells. In these Müller cells, highaffinity glutamate transporters, like GLAST are believed to be essential for terminating synaptic transmission and for keeping the extracellular glutamate concentration below neurotoxic levels. ${ }^{16,17}$ Excessive glutamate levels can cause neurotoxicity via overproduction of nitric oxide (NO) which leads to toxic free radical formation. This produces cell death by causing DNA damage and decreased energy production by inhibition of mitochondrial function. ${ }^{18}$

The increased level of glutamate in the vitreous of eyes with clinical retinal detachment as shown in the current study is consistent with earlier experimental findings in cat eyes. ${ }^{19}$ In this cat study, the glutamate content of Müller cells was found to be increased and even remained elevated for many weeks after experimental retinal detachment. Other animal studies have provided evidence that extracellular glutamate can cause retinal ganglion cell death. ${ }^{20}$ In a clinical setting, retinal ganglion cell damage may be demonstrated by decreased visual acuity, or preferably by visual field loss. Because the current study was performed retrospectively and visual field testing is not a routine procedure in patients with RRD, we used visual acuity as a functional parameter. We also analyzed various other clinical variables to detect a possible association with neurotransmitter level. Although we found a correlation between higher vitreous glutamate levels and a lower pre-operative visual acuity, we were not able to demonstrate an association between any of the tested amino acid neurotransmitters and postoperative visual acuity.

Similar to glutamate, we found a significantly higher concentration of taurine in eyes with a RRD compared to control eyes. These findings partly reflect results of the cat study by Marc et al. in which the authors found a supernormal restoration of taurine levels in Müller cells after an initial decline, in eyes with a retinal detachment. ${ }^{19}$

Ischemia has been shown to induce a glutamate-mediated release of GABA from amacrine cells in the rabbit retina. ${ }^{17,21}$ In the current study, RRD was not found to be associated with a significant difference in vitreous GABA concentrations compared to controls. This finding suggests that the glutamate-mediated release of GABA from amacrine cells is not altered after RRD. Glutamate acts as a precursor for GABA. After the glutamate transporter has taken up glutamate in the glial cells the enzyme glutamic acid decarboxylase (GAD) catalyzes the decarboxylation of glutamic acid to form GABA. The glutamate transporter needs ATP and therefore oxygen or glu- 
cose availability. A possible explanation as to why vitreous GABA levels not to increase in patients with retinal detachment could be the lack of ATP in the Müller cells, due to the hypoxia in the detached retina. This may lead to an extracellular glutamate accumulation and less conversion of glutamate to GABA.

Eyes with a traction retinal detachment due to PDR also did not have a significantly higher level of GABA in their vitreous compared to controls. This latter finding however is in contrast with a previous study in which the authors reported a significantly elevated level of GABA in the vitreous of patients compared to controls. ${ }^{10}$ In this study 22 eyes were included with PDR, but these eyes did not have traction retinal detachment which was the main difference with the current study. ${ }^{10}$

In contrast with the current study, the study by Asensio Sanchez et al., reported no significant differences in the glutamate or taurine levels between patient groups with RRD or macular hole. These authors however, included only a small number of patients with a macular hole $(n=5)$, as compared to the current study, in which 25 eyes with macular hole were investigated. ${ }^{22}$ Furthermore, the vitreous amino acid levels of our patient and control group were two to three times higher than vitreous amino acid levels reported earlier by Honkanen et al. and Sanchez et al., but were comparable to the levels found by Dreyer et al. ${ }^{22-24}$ It should be noted that, in the study reported by Dreyer et al. patients with cataract were used as controls, whereas we used patients with idiopathic macular holes or idiopathic epiretinal membranes as controls. Variation in the vitreous glutamate concentration between this study and the current study may be explained by differences in sample collection or in HPLC technique. In the study of Honkanen et al. samples were centrifuged before they were stored, while the samples in the current study and in the study by Dreyer et al. were centrifuged after thawing just before HPLC analysis. Cells that may be present in the vitreous fluid samples may release intracellular glutamate during freezing and thawing prior to centrifugation.

Our patient group included eleven patients with glaucoma, seven patients with RRD and four eyes with a macular hole. Since it was shown that glaucoma might be associated with higher levels of vitreous glutamate, ${ }^{24}$ we also investigated whether these patients had a significantly higher level of glutamate in their vitreous fluid. We could not detect any differences, which was consistent with previous findings (Honkanen et al., 2003). ${ }^{23}$ Moreover, excluding these eyes did not significantly alter the difference in glutamate concentration between patient eyes and control eyes $(16.5 \pm 5.6$ vs $13.2 \pm 5.3 \mu \mathrm{M}$, patients with RRD vs controls). 


\section{Chapter IV}

In conclusion, in this clinical study we found a significantly elevated concentration of glutamate and taurine in the vitreous of eyes with retinal detachment, which confirms earlier experimental retinal detachment studies in the cat. ${ }^{19}$ Although we found a correlation between higher vitreous glutamate levels and a lower pre-operative visual acuity, we were not able to demonstrate an association between any of the tested amino acid neurotransmitters and postoperative visual acuity. 


\section{REFERENCES}

1 Napper GA, Pianta MJ, Kalloniatis M. Localization of amino acid neurotransmitters following in vitro ischemia and anoxia in the rat retina. Visual Neuroscience. 2001; 18:413-427.

2 Napper GA, Kalloniatis M. Neurochemical changes following postmortem ischemia in the rat retina. Visual Neuroscience. 1999; 16:1169-1180.

3 Lipton SA. Failures and Successes of NMDA Receptor Antagonists: Molecular Basis for the Use of Open-Channel Blockers like Memantine in the Treatment of Acute and Chronic Neurologic Insults. Neurorx. 2004 Jan; 1(1):101-110.

4 Lewis GP, Erickson PA, Guèrin CJ, Anderson DH, Fisher SK. Changes in the expression of specific Müller cell proteins during long-term retinal detachment. Exp Eye Res. 1989; 49:93-111.

5 Sherry DM, Townes -Anderson E. Rapid glutaminergic alterations in the neural retina induced by retinal detachment. Invest Ophthalmol Vis Sci. 2000; 41:2779-2790.

6 Vorwerk CK, Lipton SA, Zurakowski D, Hyman BT, Sabel BA, Dreyer EB. Chronic lowdose glutamate is toxic to retinal ganglion cells: toxicity blocked by memantine. Invest Ophthalmol Vis Sci. 1996; 37:1618-1624.

7 Mosinger JL, Price MT, Bai HY, Xiao H, Wozniak DF, Olney JW. Blockage of both NMDA and non-NMDA receptors is required for optimal protection against ischemic neuronal degeneration in the in vivo adult mammalian retina. Exp Neurol. 1991; 113:10-17.

8 YoonYH, Marmor MF. Dextromethorphan protects retina against ischemic injury in vivo. Arch Opthalmol. 1989; 107:409-411.

9 Marc RE, Murry RF, Basinger SF. Pattern recognition of Amino Acid Signatures in retinal neurons. Journal of Neuroscience 1995; 15:5106-5129.

10 Ambati J, Chalam KV, Chawla DK, D'Angio CT, Guillet EG, Rose JS et al. Elevated $\gamma$ Aminobutyric acid, glutamate and vascular endothelial growth factor levels in the vitreous of patients with proliferative diabetic retinopathy. Arch Ophthalmology 1997; 115:1161-1166.

11 La Heij EC, Hendrikse F, Kessels AGH. Results and complications of temporary silicone oil tamponade in patients with complicated retinal detachments. Retina 2001; 21:107-114.

12 La Heij EC, Van den Waarenburg MPH, Blaauwgeers HGT, Theunissen C, Kessels A, Liem ATA, Steinbusch H, Hendrikse F. Levels of basic fibroblast growth factor (b-FGF), glutamine synthetase (GS), and interleukin-6 (IL-6) in vitreous fluid from patients with proliferative vitreoretinopathy (PVR). Am J Ophthalmol. 2002; 134:367-375.

13 Van Eijk HMH, Rooyakkers DR, Deutz NEP. Rapid routine determination of amino acids in plasma by high-performance liquid chromatography with a 2-3 $\mu \mathrm{m}$ Spherisorb ODS II column. Journal of Chromatography. 1993; 620:143-148.

14 Hochberg Y. A Sharper Bonferonni procedure for multiple tests of significance. Biometrika 1988; 75:800-802.

15 Ferris FL, Kassoff A, Bresnick GH, Bailey I. New visual acuity charts for clinical research. Am J Ophthalmol 1982; 94: 91-96.

16 Barnstable CJ. Glutamate and GABA in retinal circuitry. Curr. Opin. Neurobiol. 1993; 3:520-525

17 Harada T, Harada C, Watanabe M, Inoue Y, Sakagawa T, Nakayama N. et al. Functions of the two glutamate transporters GLAST and GLT-1 in the retina. Proc Natl Acad Sci U S A. 1998; 14; 95(8):4663-6.

18 Dawson VL, Dawson TM. Nitric oxide neurotoxicity. J Chem Neuroanat 1996; 10(3-4):179-90.

19 Marc RE, Murry RF, Fisher SK, Linberg KA, Lewis PG. Amino Acid signature In the detached cat retina. Invest Ophthalmol Vis Sci 1998; 39:1694-1702. 


\section{Chapter IV}

20 Luo X, Heidinger V, Picaud S, Lambrou G, Drefus H, Sehel J, Hicks D. Selective excitotoxic degereation of adult pig retinal ganglion cells in vitro. IOVS 2001; 42(5):1096-106.

21 Osborne NN, Herrera AJ. The effect of experimental ischaemia and excitatory amino acid agonists on the GABA and serotonin immunoreactivities in the rabbit retina. Neurocience. 1994; 59: 1071-1081.

22 Asensio Sanchez VM, Corral Azor A, Aguirre Aragon B, De Paz Garcia M. Amino Acid concentrations in the vitreous body in control subjects. Archivos de la Sociedad Espanola. 2002; 77:611-616.

23 Honkanen RA, Baruah S, Zimmerman MB, Khanna CL, Weaver YK, Narkiewicz J et al. Vitreous amino acid concentrations in patients with glaucoma undergoing vitrectomy. Arch Ophthalmology 2003; 121:183-188.

24 Dreyer EB, Zurakowski D, Schumer RA, Podos SM, Lipton SA. Elevated glutamate levels in the vitreous body of humans and monkeys with glaucoma. Arch Ophthalomogy 1996; 114: 299-305. 




\section{CHAPTER V}

\section{Increased nitric oxide (NO) pathway me- tabolites in the vitreous fluid of patients with rhegmatogenous retinal detachment or diabetic traction retinal detachment.}

Graefes Arch Clin Exp Ophthalmol. 2006; 224:683-688

Roselie M.H. Diederen ${ }^{l}$, Ellen C. La Heij ${ }^{\text {, }}$ Nicolaas E.P. Deutz ${ }^{2}$, Alfons G.H. Kessels, Hans M. H. van Eijk ${ }^{2}$ and Fred Hendrikse ${ }^{l}$

Department of Ophthalmology, University Hospital Maastricht, The Netherlands.

2 Department of Surgery, University of Maastricht, The Netherlands.

3 Department of Clinical Epidemiology and Medical Technology Assessment, University Hospital Maastricht, The Netherlands. 



\section{ABSTRACT}

Nitric oxide (NO) plays a significant role in physiological and pathological processes in the retina. In the L-arginine-NO pathway, NO synthase (NOS) converts L-arginine to NO and L-citrulline. Increased NO production, mediated by inducible NOS has been implicated in the pathogenesis of various vitreoretinal diseases. In the present study it is hypothesized that in rhegmatogenous retinal detachment, the production of NO pathway metabolites might be upregulated. Using high-pressure liquid chromatography citrulline, arginine and nitrite were measured in vitreous fluid of 93 eyes with rhegmatogenous retinal detachment, 9 eyes with a traction retinal detachment due to proliferative diabetic retinopathy, and in 49 control samples of vitreous fluid from eyes without retinal detachment. The mean vitreous concentrations of citrulline and arginine were significantly increased in eyes with rhegmatogenous retinal detachment (9.6 \pm 4.3 and $97.3 \pm 29.2$; respectively) or in eyes with a traction retinal detachment $(25.8 \pm 10.3$ and $130.7 \pm 23.7$; respectively) as compared to control eyes $(7.1 \pm 3.2$ and $75.9 \pm 18.1$; respectively). The mean level of nitrite was also higher in vitreous fluid of patients with RRD $(2.24 \pm 1.4)$ or patients with a traction retinal detachment $(2.21 \pm 0.72)$ than in the controls $(2.01 \pm 0.72)$, although not significantly so. We found increased levels of NO pathway metabolites in the vitreous fluid of eyes with retinal detachment, which may reflect a possible role of NO in the pathogenesis of this disease.

\section{INTRODUCTION}

Nitric oxide (NO) is an important mediator of homeostatic processes in the eye, such as regulation of aqueous humour dynamics, retinal neurotransmission and phototransduction. ${ }^{1} \mathrm{NO}$ is produced when the semi-essential amino acid L-arginine is converted to L-citrulline and NO by the family of nitric oxide synthase (NOS) enzymes. ${ }^{2} \mathrm{NO}$ then diffuses into nearby target cells to elevate cyclic GMP levels and thereby triggers different cell functions.

NOS exists in three major isoforms: neuronal, endothelial and inducible NOS. In the retina, neuronal NOS is thought to be responsible for producing NO in photoreceptors and bipolar cells, whereas inducible NOS, is found in Müller cells and in the retinal pigment epithelial (RPE) cell layer.,

Excess NO may lead to toxic free radical formation, which produces cell death by causing DNA damage. It may also cause decreased energy production by inhibition of mitochondrial function. ${ }^{5}$ Inducible NOS is activated by endotoxin and cytokines, while neuronal and endothelial NOS can be activated by glutamate and vasodilatators. ${ }^{1}$ Overproduction of NO may occur when glutamate is generated in excess or when the glutamate re-uptake is 


\section{Chapter $V$}

ineffective, as may happen in ischemia. Once glutamate is released, it binds to NMDA receptors, increasing the intracellular calcium concentration and stimulating NOS to produce NO. ${ }^{6}$

Thus, excessive glutamate release can cause neurotoxicity via overproduction of NO. ${ }^{5}$ High levels of NO have been implicated in the pathogenesis of a variety of disorders, including glaucoma, proliferative diabetic retinopathy, cataract and uveitis. ${ }^{7-10}$ However no clinical study has been done previously to investigate whether NO is also involved during retinal detachment.

In a previous study we found retinal detachment to be associated with increased levels of vitreous glutamate. In the current study our objective was to find out, whether retinal detachment also leads to a local increased NO production and changes in the concentrations of arginine and citrulline. Vitreous levels of citrulline, arginine and nitrite, the stable product of NO, were measured using the highly selective high-pressure liquid chromatography (HPLC) fluorescence method. Elevated concentrations of arginine, citrulline and nitrite were observed in the vitreous fluid of eyes following retinal detachment.

\section{MATERIALS AND METHODS}

\section{Patients}

In a prospective study, vitreous fluid samples were collected from patients with a rhegmatogenous retinal detachment (RRD) and from eyes with a traction retinal detachment due to proliferative diabetic retinopathy (PDR).

All patients were operated on in our department between May 1999 and January 2003 with a vitrectomy. Eyes with uveitis, trauma or vitreous haemorrhage were excluded. Only patients with a minimum follow-up of three months were included in the analysis. We operate on eyes with RRD with up to proliferative vitreoretinopathy (PVR) grade $\mathrm{C} 1$ with a conventional scleral buckling technique. Eyes with PVR grade $\mathrm{C} 2$ and higher are operated on with a primary vitrectomy, as described earlier. ${ }^{11}$ Vitreous samples from patients with macular hole or idiopathic epiretinal membranes were used as controls. The study was performed with the agreement of the University Hospital ethics committee; all patients gave their informed consent prior to inclusion in the study and after the nature of the study had been explained. The study adhered to the tenets of the Declaration of Helsinki.

The following pre-operative clinical characteristics of the study patients were collected for statistical analysis: age, sex, eye affected, the number of detached quadrants of the retina, whether or not the central area of the macula (foveal region) was involved in the detachment, pre-operative corrected 
visual acuity, intraocular pressure (IOP), whether the patients used antiglaucoma medication and whether the patient had diabetes mellitus. The number of prior eye operations, including cataract surgery, scleral buckling, prior endolaser or cryocoagulation, and follow-up time were also registered. By carefully questioning the patient, the approximate length of time between the occurrence of the RRD and the time of sampling was established. The following variables related to the vitrectomy were collected: whether intraocular endotamponade with oil or gas was necessary and, whether or not a re-detachment occurred. At final follow-up we recorded visual acuity and anatomic result.

\section{Sample collection}

Undiluted vitrectomy samples were obtained by a conventional three- port closed vitrectomy technique by manual suction at the beginning of the vitrectomy, before opening the infusion line of Balanced Salt Solution (BSS, Alcon Laboratories, Texas, USA), as described earlier. ${ }^{12}$ The samples were stored at $-80^{\circ} \mathrm{C}$ until the HPLC analysis. Samples contaminated with blood were excluded from the study. The measurements were performed in a masked fashion, without the technician knowing the clinical history of the patient.

\section{Amino acid analysis}

Two amino acids, arginine and citrulline, were analysed as described earlier. ${ }^{13}$ Analysis was performed following precolumn derivatization with ophthaldehyde (OPA) [21]. ${ }^{13}$ Samples $(50 \mu \mathrm{l})$ were centrifuged in a Hereaus Biofuge at $50,000 \mathrm{~g}$. Next, $4 \mu \mathrm{l}$ supernatant was pipetted into a glass $300 \mu \mathrm{l}$ insert, already containing $194 \mu \mathrm{l}$ water and $2 \mu \mathrm{l}$ norvaline solution (500 $\mu \mathrm{mol} / 1)$. From this mixture, $5 \mu 1$ was mixed automatically with $5 \mu 1$ of OPA reagent, incubated for $2 \mathrm{~min}$ and injected in a $150 \times 4.6 \mathrm{~mm}$ (i.d.) column filled with Allsphere $3 \mu \mathrm{m}$ (Alltech, Breda, Netherlands) using a WISP 715 sample processor (Waters, Etten-Leur, Netherlands). Amino acid derivatives were eluted using $25 \mathrm{mmol} / 1$ citric acid buffer $\mathrm{pH} 6.8$ containing 3\% tetrahydrofuran as the starting solvent, followed by gradient elution using a linear addition to $100 \%$ of solvent B (same buffer, now containing $40 \%$ acetonitril and $5 \%$ tetrahydrofuran) within 30 min. Fluorescence was monitored with a Jasco Model 820FP fluorescence detector (B\&L systems, Zoetermeer, Netherlands). Measurements were made at an excitation wavelength of $335 \mathrm{~nm}$ and an emission wavelength of $440 \mathrm{~nm}$. Data were collected on-line and processed using Turbochrom software (Perkin-Elmer, Oosterhout, Netherlands).

\section{Nitrite analysis}

The method is based on the automated reaction of $\mathrm{NO}^{2-}$ with 2,3-diaminonaphtalene (DAN) to 1-(H)-naphthatriazole derivative, followed by a reversed phase separation with a cycle time (injection to injection) of $20 \mathrm{~min}$. 


\section{Chapter V}

Only a $10 \mu 1$ sample is required, resulting in a linear fluorescence response in the range from $0.01-10 \mu \mathrm{mol} / 1(\mathrm{R} 2=0.9989)$. Samples were first centrifuged at $11.000 \mathrm{~g}$ in a Heraeus Biofuge Stratos (Dijkstra, Amsterdam, Netherlands) for $5 \mathrm{~min}$ at $4^{\circ} \mathrm{C}$. Aliquots were frozen immediately in liquid nitrogen and stored at $-80^{\circ} \mathrm{C}$ until analysis. Before analysis, samples were deproteinized through the addition of acetonitril ( $100 \mu \mathrm{l}$ acetonitril for each $50 \mu 1$ sample) in a $1.5 \mathrm{ml}$ vial sealed with a screw cap equipped with a rubber o-ring (Sarstedt, Etten-Leur, Netherlands). The resulting samples were centrifuged for $10 \mathrm{~min}$ at $50.000 \mathrm{~g}$ at $4{ }^{\circ} \mathrm{C}$ using the Biofuge Stratos. Next, $30 \mu 1$ sample supernatant aliquots were filled out into $300 \mu 1$ spring mounted plastic inserts into a Waters model WISP 715 auto sampler. The analysis was initiated by the addition of $10 \mu \mathrm{l}$ of a $0.05 \mathrm{mg}$ diaminonaphtalene (DAN) solution in $1 \mathrm{ml} \mathrm{HCl} 0.6 \mathrm{~N}$ to the sample vials. After one minute, $10 \mu \mathrm{l}$ of the reaction mix was injected onto a 100 x $4.6 \mathrm{~mm}$ (i.d.) column filled with Allsphere C18 $3 \mu \mathrm{m}$ (Alltech, Breda, Netherlands. The DAN-NO2 peak was chromatographed using a $20 \mathrm{~min}$ injection cycle (run to run). At the start of the gradient a $80 / 20(\mathrm{v} / \mathrm{v})$ mixture of solvent A $(15 \mathrm{mmol} / 1$ ammonium acetate (pH 8.0), containing 20\% (v/v) acetonitrile) and solvent B (40-60 (v/v) mixture of the ammonium acetate buffer-acetonitrile) was pumped at a flow rate of $1.0 \mathrm{ml} / \mathrm{min}$ at room temperature resulting in a system back pressure of $20.0 \mathrm{MPa}$. Within $8 \mathrm{~min}$ a linear gradient is applied to $100 \%$ solvent $\mathrm{B}$ in which the DAN-NO ${ }^{2}$ peak elutes after $7.5 \mathrm{~min}$. Hereafter, the column is kept at $100 \%$ solvent B for 1 minute after which initial conditions are restored in the following minute. Fluorescence was monitored with a Jasco Model 820FP fluorescence detector (B\&L systems, Zoetermeer, Netherlands). Measurements were made at an excitation wavelength of $365 \mathrm{~nm}$ and an emission wavelength of $405 \mathrm{~nm}$. Data were collected on-line and processed using Totalchrom software (Perkin-Elmer, Oosterhout, Netherlands).

\section{Statistical analysis}

For statistical analysis, we consulted a professional statistician at our University Hospital (AGH Kessels, co-author).

Levels of all neurotransmitters were compared between groups using Student's t-test. Comparisons for sex, glaucoma and prior eye surgery between patients with RRD and controls were performed using the Chi Square test. The Pearson correlation test was used to test the association between the vitreous concentration of the five neurotransmitters and age, intraocular pressure, the number of quadrants the retina was detached, whether the patient had diabetes mellitus, the number of prior eye operations, including cataract surgery, scleral buckling, prior endolaser or cryocoagulation, the approximate length of time between occurrence of retinal detachment and time of sampling, whether a re-detachment occurred, and the anatomic result. 
For statistical analysis, Snellen visual acuities were converted to a logarithmic scale (LogMAR, i.e. the logarithm of the minimal angle of resolution), as described earlier. ${ }^{14}$ The association between the levels of the various neurotransmitters, and pre-operative visual acuity was investigated with a multiple linear regression analysis using the status of the macula as co-variable. The association between the levels of the various neurotransmitters, and final post-operative visual acuity was investigated with a multiple linear regression analysis using the preoperative visual acuity as co-variable. Finally these associations were investigated with a multivariate linear regression model adjusting for nine variables: pre-operative visual acuity, diabetes, glaucoma, prior scleral buckling, prior endolaser, prior cryocoagulation, duration of detachment, status of the macula and number of quadrants of retinal detachment.

\section{RESULTS}

Vitreous fluid samples were collected from 93 eyes (93 patients, 35 women and 58 men) with RRD. The mean age was 58 years ( $\mathrm{SD} \pm 16$ years). Mean follow-up time was 23 months ( $\mathrm{SD} \pm 13$ months). The mean duration of retinal detachment was 44 days (ranging from 1 to 365 days; Table 1). Furthermore, vitreous samples were obtained from patients with traction retinal detachment due to PDR (5 women and 4 men, Table 1). The mean age in this patient group was 50 years ( $\mathrm{SD} \pm 5$ years). The control group consisted of 49 patients (25 women and 24 men) with an epiretinal membrane or macular hole. The mean age in this group was 69 years ( $\mathrm{SD} \pm 8$ years). No significant differences were found when comparing patients' characteristics between patients and controls. Baseline clinical characteristics of all three groups are summarised in table 1.

The mean level of citrulline, arginine and nitrite in the vitreous fluid of eyes with traction retinal detachment due to PDR $(25.8 \pm 10.3 ; 130.7 \pm 23.7$; $2.21 \pm 1.53$; respectively) was significantly higher than in the control patients $(\mathrm{P}=<0.001 ; \mathrm{P}=0<001 ; \mathrm{P}=0.004$, respectively; Table 2$)$.

The mean level of citrulline in vitreous fluid of eyes with RRD was $9.6 \pm 4.3 \mu \mathrm{M}$, which was significantly higher than in the control group (7.1 $\pm 3.2 \mu \mathrm{M} ; \mathrm{P}=0.034$; Table 2 ). The mean vitreous concentration of arginine in eyes with RRD was $97.3 \pm 29.2 \mu \mathrm{M}$ and was also significantly increased as compared to the control group $(75.9 \pm 18.1 \mu \mathrm{M} ; \mathrm{P}=0.002$; Table $2)$. The mean concentration of nitrite was elevated in vitreous fluid of RRD patients $(2.24 \pm 1.4)$ as compared to controls $(2.01 \pm 0.72)$ although this was not statistically significant $(\mathrm{P}=0.058)$. In the control group, we found no statistically significant difference in the vitreous concentrations of arginine, 


\section{Chapter V}

citrulline and nitrite between patients with a macular hole and patients with an epiretinal membrane.

Table 1. Basic Clinical and Ocular Characteristics

\begin{tabular}{lccc}
\hline & $\begin{array}{c}\text { RRDc } \\
(n=93)\end{array}$ & $\begin{array}{c}\text { Controls } \\
(n=49)\end{array}$ & $\begin{array}{c}\text { PDRc } \\
(n=9)\end{array}$ \\
\hline Age (years) $^{\mathrm{a}}$ & $58.0 \pm 15.7$ & $68.8 \pm 7.7$ & $50.0 \pm 5.0$ \\
Male $^{\mathrm{b}}$ & $58(62 \%)$ & $24(49 \%)$ & $4(43 \%)$ \\
Femaleb & $35(38 \%)$ & $25(51 \%)$ & $5(57 \%)$ \\
Right eye $^{\mathrm{b}}$ & $47(51 \%)$ & $22(45 \%)$ & $4(43 \%)$ \\
Left eye $^{\mathrm{b}}$ & $46(49 \%)$ & $27(55 \%)$ & $5(57 \%)$ \\
IOP (mmHg) & $14.7 \pm 5.9$ & $17.1 \pm 6.1$ & $13.0 \pm 5.2$ \\
Diabetes $^{\mathrm{b}}$ & $3(3 \%)$ & $3(6 \%)$ & $9(100 \%)$ \\
Glaucoma $^{\mathrm{b}}$ & $7(8 \%)$ & $4(8 \%)$ & 0 \\
Aphakic $^{\mathrm{b}}$ & $6(6 \%)$ & $1(2 \%)$ & 0 \\
Pseudophakic $^{\mathrm{b}}$ & $27(29 \%)$ & $11(22 \%)$ & 0 \\
Prior scleral buckling $^{\mathrm{b}}$ & $62(54 \%)$ & $3(6 \%)$ & 0 \\
Prior endolaser $^{\mathrm{b}}$ & $26(28 \%)$ & $11(22 \%)$ & $3(43 \%)$ \\
Prior cryocoagulation $^{\mathrm{b}}$ & $36(39 \%)$ & $3(6 \%)$ & 0 \\
Duration of detachment (days) $^{\mathrm{a}}$ & $43.6 \pm 72.1$ & & \\
Macular detachment $^{\mathrm{b}}$ & $61(66 \%)$ & & \\
Number of quadrants of retinal $^{\text {detachement }}{ }^{\mathrm{a}}$ & $2.6 \pm 1.2$ & & \\
Pre-operative visual acuity $^{\mathrm{a}, \mathrm{d}}$ & $1.49 \pm 0.84$ & & \\
Post-operative visual acuity $^{\mathrm{a}, \mathrm{d}}$ & $1.28 \pm 0.99$ & & \\
Re-detachment $^{\mathrm{b}}$ & $32(34 \%)$ & & \\
Duration of follow-up (months) $^{\mathrm{a}}$ & $24.3 \pm 12.5$ & $16.6 \pm 14.1$ & $18.7 \pm 10.1$ \\
\hline
\end{tabular}

a Numbers are noted in mean $\pm \mathrm{SD}$ (standard deviation).

b Number (percentage).

c RRD Rhegmatogenous Retinal Detachment; PDR traction retinal detachment due to Proliferative Diabetic Retinopathy.

d Snellen visual acuities were converted to a logarithmic scale (LogMAR, i.e. the logarithm of the minimal angle of resolution).

Of all other clinical variables, such as prior scleral buckling, prior endolaser, prior cryocoagulation, duration of detachment, status of the macula and number of quadrants and retinal detachment, analyzed in the present study, none correlated significantly with the concentration of nitrite or arginine. We did observe a statistically significant correlation between a high level of vitreous citrulline and a lower pre-operative visual acuity in patients with RRD $(\mathrm{P}=0.027)$, using the status of the macula as co-variable. Finally, no signifi- 
cant correlation could be found between citrulline, arginine or nitrite and post-operative visual acuity, after using multivariate analysis.

Table 2. Vitreous Amino Acid Concentration $(\mu M)$.

\begin{tabular}{lccccc}
\hline & Controls & $\begin{array}{c}\text { Eyes with } \\
\text { RRD }^{\mathrm{b}} \\
(n=93)\end{array}$ & P value $^{\mathrm{c}}$ & $\begin{array}{c}\text { Eyes with } \\
\text { PDR }^{\mathrm{b}} \\
(n=9)\end{array}$ & P value $^{\mathrm{d}}$ \\
\hline Citrulline & $7.1 \pm 3.2$ & $9.6 \pm 4.3$ & $.034^{\mathrm{a}}$ & $25.8 \pm 10.3$ & $.001^{\mathrm{a}}$ \\
Arginine & $75.9 \pm 18.1$ & $97.3 \pm 29.2$ & $.002^{\mathrm{a}}$ & $130.7 \pm 23.7$ & $.001^{\mathrm{a}}$ \\
Nitrite & $2.01 \pm 0.72$ & $2.24 \pm 1.45$ & .058 & $2.21 \pm 0.72$ & $.004^{\mathrm{a}}$ \\
\hline
\end{tabular}

a Statistically significant, $\mathrm{P}<0.05$.

b RRD Rhegmatogenous Retinal Detachment; PDR traction retinal detachment due to Proliferative Diabetic Retinopathy.

c Eyes with RRD compared to controls.

d Eyes with PDR compared to controls.

\section{DISCUSSION}

We found significantly increased levels of the NO pathway metabolites arginine, citrulline and nitrite in the vitreous fluid of eyes with traction retinal detachment due to PDR. Elevated NO metabolites were also observed in eyes with RRD, but not as striking as in the PDR group. These findings suggest that NO may play a role in the pathogenesis of retinal detachment.

Only one earlier study reported elevated nitrite levels in the vitreous of eyes with traction retinal detachment due to $\mathrm{PDR}^{3}{ }^{3}$ but levels of nitrite in that study were not comparable to our data. This may be due to the fact that these authors used a spectrophotometric method based on the Griess reaction while we used the more sensitive HPLC technique.

NO is produced by various cell types in the picomolar to nanomolar range, and has a very short half-life $(\mathrm{t} 1 / 2<5 \mathrm{~s})$ in biological fluids. Therefore, it is difficult to measure its presence directly. $\mathrm{NO}^{2-}$ and $\mathrm{NO}^{3-}$, the stable products of NO oxidation, are often analysed instead to estimate the NO level in biological fluid. ${ }^{2}$ The fluorometric HPLC method described in the present study offers high reproducibility and specificity for measuring picomolar levels of $\mathrm{NO}^{2-}$. Also, the sensitivity of this HPLC method for $\mathrm{NO}^{2-}$ analysis is greater than that of the batch fluorometric method (detection limit, 10-20 mM), the Griess colorimetric assay (detection limit 0.1-1 mM), and the HPLC methods with UV-VIS or conductimetric detection (detection limit, 0.1-0.5 $\mathrm{mM}){ }^{15}$ 


\section{Chapter $V$}

The majority of NO is synthesised by the inducible isoform of NOS (iNOS). ${ }^{1}$ It has been shown previously that iNOS is expressed in Müller cells and RPE cells after cytokine stimulation. ${ }^{16,17}$ Since increased levels of cytokines have been found in eyes with RRD, it may be postulated that iNOS is upregulated by these cytokines, in the detached retina or vitreous fluid of patients with a retinal detachment. ${ }^{12,18}$ This may be an explanation for the increased levels of NO pathway metabolites found in the current study.

NO has many sites of production and actions in the retina, which are both physiological and pathophysiological in nature. Earlier studies have shown that excess amounts of NO may become damaging to the retina. ${ }^{19,20} \mathrm{NO}$ was found to be functionally as well as histologically toxic to the rabbit retina. ${ }^{20}$ In addition, it has been demonstrated that $\mathrm{NO}$ is able to mediate excitotoxic and anoxic damage in retinal ganglion cells. ${ }^{18}$ The pathological role of NO in retinal cell death was supported by the finding that non-specific inhibition of NOS might protect the retina from ischemic damage. ${ }^{21}$ Another pathologic mechanism may be that overproduction of NO can cause damage to the retina by perturbing rod outer segment (ROS) membrane phagocytosis by RPE cells. ${ }^{22}$ This could lead to the accumulation of ROS debris between the photoreceptors and RPE cells, and could ultimately result in photoreceptor degeneration. $^{22}$

Binding of glutamate to the NMDA receptor increases the influx of $\mathrm{Ca}^{2+}$, which stimulates NOS to produce NO. The glutamate content of Müller cells has been found to be increased and remained elevated for many weeks after experimental retinal detachment. ${ }^{23}$ In an earlier study, we found increased levels of glutamate in the vitreous of patients with retinal detachment. Thus, increased levels of glutamate might also be responsible for the increased level of NO in the vitreous fluid of patients with retinal detachment.

In conclusion, we found increased levels of the NO pathway metabolites in the vitreous fluid of eyes with retinal detachment, which may reflect a possible role for $\mathrm{NO}$ in the pathogenesis of this disease.

\section{ACKNOWLEDGEMENTS}

The authors thank Aize Kijlstra, Albert T.A. Liem and Suzanne C. Dieudonné of the Eye Research Institute Maastricht, for their help in the preparation of the manuscript.

This study was supported by the Algemene Nederlandse Vereniging ter Verkoming van Blindheid. 


\section{REFERENCES}

1 Becquet F, Courtois Y, Goureau O. Nitric oxide in the eye: multifaceted roles and diverse outcomes. Surv Ophthalmol 1997; 42(1):71-82.

2 Moncada S, Palmer RM, Higgs EA. Nitric oxide: physiology, pathophysiology, and pharmacology. Pharmacol Rev 1991; 43(2):109-42.

3 Yilmaz G, Esser P, Kociok N, Aydin P, Heimann K, Kociek N. Elevated vitreous nitric oxide levels in patients with proliferative diabetic retinopathy. Am J Ophthalmol 2000; 130(1):87-90.

4 Yoshida A, Pozdnyakov N, Dang L, Orselli SM, Reddy VN, Sitaramayya A. Nitric oxide synthesis in retinal photoreceptor cells. Vis Neurosci 1995; 12(3):493-500.

5 Dawson VL, Dawson TM. Nitric oxide neurotoxicity. J Chem Neuroanat 1996; 10(3-4):179-90.

6 Choi DW, Rothman SM. The role of glutamate neurotoxicity in hypoxic-ischemic neuronal death. Annu Rev Neurosci 1990; 13:171-82.

7 Goldstein IM, Ostwald P, Roth S. Nitric oxide: a review of its role in retinal function and disease. Vision Res 1996; 36(18):2979-94.

8 Inomata M, Hayashi M, Shumiya S, Kawashima S, Ito Y. Aminoguanidine-treatment results in the inhibition of lens opacification and calpain-mediated proteolysis in Shumiya cataract rats (SCR). J Biochem (Tokyo) 2000; 128(5):771-6.

9 Neufeld AH, Sawada A, Becker B. Inhibition of nitric-oxide synthase 2 by aminoguanidine provides neuroprotection of retinal ganglion cells in a rat model of chronic glaucoma. Proc Natl Acad Sci U S A 1999; 96(17):9944-8.

10 Tilton RG, Chang K, Corbett JA, Misko TP, Currie MG, Bora NS, Kaplan HJ, Williamson JR. Endotoxin-induced uveitis in the rat is attenuated by inhibition of nitric oxide production. Invest Ophthalmol Vis Sci 1994; 35(8):3278-88.

11 La Heij EC, Hendrikse F, Kessels AG. Results and complications of temporary silicone oil tamponade in patients with complicated retinal detachments. Retina 2001; 21(2):107-14.

12 La Heij EC, Van De Waarenburg MP, Blaauwgeers HG, Kessels AG, De Vente J, Liem AT, Steinbusch H, Hendrikse F. Levels of basic fibroblast growth factor, glutamine synthetase, and interleukin-6 in subretinal fluid from patients with retinal detachment. Am J Ophthalmol 2001;132(4):544-50.

13 Van Eijk HMH, Rooyakkers DR, Deutz NEP. Rapid routine determination of amino acids in plasma by high-performance liquid chromatography with a 2-3 $\mu \mathrm{m}$ Spherisorb ODS II column. Journal of Chromatography 1993; 620:143-148.

14 Ferris FL 3rd, Kassoff A, Bresnick GH, Bailey I. New visual acuity charts for clinical research. Am J Ophthalmol 1982; 94(1):91-6.

15 Gharavi N, El-Kadi AO. Measurement of nitric oxide in murine Hepatoma Hepa1c1c7 cells by reversed phase HPLC with fluorescence detection. J Pharm Pharm Sci 2003;6(2):302-7.

16 Kelly MEM, Barnes S. Physilogy and Pathophysiology of Nitric Oxide in the Retina. The Neuroscientist 1997; 3(6):357-360.

17 Koga T, Zhang WY, Gotoh T, Oyadomari S, Tanihara H, Mori M. Induction of citrullinenitric oxide (NO) cycle enzymes and NO production in immunostimulated rat RPE-J cells. Exp Eye Res 2003; 76(1):15-21.

18 Kenarova B, Voinov L, Apostolov C, Vladimirova R, Misheva A. Levels of some cytokines in subretinal fluid in proliferative vitreoretinopathy and rhegmatogenous retinal detachment. Eur J Ophthalmol 1997; 7(1):64-7.

19 Morgan J, Caprioli J, Koseki Y. Nitric oxide mediates excitotoxic and anoxic damage in rat retinal ganglion cells cocultured with astroglia. Arch Ophthalmol 1999; 117(11):1524-9. 


\section{Chapter $V$}

20 Oku H, Yamaguchi H, Sugiyama T, Kojima S, Ota M, Azuma I. Retinal toxicity of nitric oxide released by administration of a nitric oxide donor in the albino rabbit. Invest Ophthalmol Vis Sci 1997; 38(12):2540-4.

21 Roth S (1997) Role of nitric oxide in retinal cell death. Clin Neurosci 4(5):216-23.

22 Becquet F, Courtois Y, Goureau O. Nitric oxide decreases in vitro phagocytosis of photoreceptor outer segments by bovine retinal pigmented epithelial cells. J Cell Physiol 1994; 159(2):256-62.

23 Marc RE, Murry RF, Fisher SK, Linberg KA, Lewis GP. Amino acid signatures in the detached cat retina. Invest Ophthalmol Vis Sci 1998; 39(9):1694-702. 




\title{
CHAPTER VI
}

\section{Cyclic GMP synthesis by human retinal pigment epithelial cells is mainly mediated via the particulate guanylyl cyclase pathway}

Ophthalmic Res. 2007; 39:55-59

\author{
Roselie M.H. Diederen ${ }^{1,2}$, Ellen C. La Heij, \\ Marianne Markerink-van Ittersum ${ }^{2}$, Aize Kijlstra ${ }^{l}$, \\ Fred Hendrikse ${ }^{l}$ and Jan de Vente ${ }^{2}$
}

1 Eye Research Institute Maastricht, Department of Ophthalmology, University Hospital Maastricht, The Netherlands

2 European Graduate School of Neuroscience (EURON), Psychiatry and Neuropsychology, University of Maastricht, The Netherlands 



\section{ABSTRACT}

Cyclic 3', 5'-guanosine monophosphate (cGMP), a central molecule in the phototransduction cascade, is also involved in a number of other physiological processes in the retina, like stimulating the absorption of subretinal fluid by activating the retinal pigment epithelium (RPE) cell pump. The aim of this study was to quantify cGMP synthesis by RPE cells and to investigate the role of two separate enzymatic pathways (soluble versus particulate guanylyl cyclase) in its production. Cyclic GMP expression was evaluated by immunochemistry and radioimmunoassay following culture of the D407 RPE cell line in the presence of a non-selective phosphodiesterase inhibitor (IBMX), in combination with the particulate guanylyl cyclase stimulator atrial natriuretic peptide (ANP) or the soluble guanylyl cyclase stimulator sodium nitroprusside (SNP).

Stimulation of the particulate guanylyl cyclase in RPE cells with ANP resulted in high intra- and extracellular cGMP levels. Stimulation of the soluble guanylyl cyclase by SNP resulted in a slight elevation of cGMP levels compared to controls. These results show that cultured human RPE cells are capable of producing cGMP and that most cGMP is generated following stimulation of the particulate guanylyl cyclase pathway.

\section{INTRODUCTION}

In addition to its role in phototransduction, cyclic 3', 5'-guanosine monophosphate (cGMP) is involved in many other physiological mechanisms, in the retina. ${ }^{1}$ One important aspect of cGMP in the retina is its stimulating role in the absorption of subretinal fluid by activating the RPE pump. ${ }^{2}$ In the retina, cGMP gated channels were found in photoreceptors, ganglion cells, bipolar cells and Müller cells. ${ }^{3-5}$

Two separate classes of enzymes can each catalyze the conversion of GTP into cGMP. These enzymes can be classified into either particulate (membrane-bound) or soluble (cytosolic) cyclases based on their general structure and cellular distribution. There are several isoforms known of each class. Soluble guanylyl cyclase is activated by nitric oxide (NO), and is expressed in neurons of the inner retina. ${ }^{6}$ Increasing tissue levels of NO, by incubation with sodium nitroprusside (SNP), results in an increased cGMP immunoreactivity in amacrine, ganglion and bipolar cells. ${ }^{7-10}$ Particulate guanylyl cyclase activity is primarily localized in neurons of the outer retina and is not activated by enhanced tissue NO levels. ${ }^{6}$ Particulate guanylyl cyclases are either ligand-activated receptors (e.g. natriuretic factors) or calcium-regulated, integral membrane proteins. ${ }^{11}$ In turtle retina, stimulation with exogenous natriuretic peptides increased total retinal cGMP levels. ${ }^{7}$ 


\section{Chapter VI}

The cellular concentration of cGMP represents the net balance between synthesis by guanylyl cyclases and breakdown into 5'-cGMP by cyclic nucleotide phosphodiesterases (PDEs). ${ }^{12}$ PDE isoforms have been classified into eleven different subfamilies, based on their affinities for cGMP and cAMP, and a number of proteomic and genomic characteristics. Cyclic GMP phosphodiesterase activities were detected earlier in homogenates of cultured rat RPE cells. ${ }^{13}$ In the retina, PDE6 is present in rods and cones in a high concentration and plays an important role in phototransduction. ${ }^{14}$ Production of cGMP can readily be measured in vitro by blocking PDE enzymes with inhibitors such as 3-isobutyl-1-methylxanthine (IBMX).

Retinal pigment epithelial (RPE) cells form a monolayer situated between the photoreceptor cell layer and the choroid. RPE cells play an essential role in the control of outer retinal homeostasis and in maintaining blood-retinal barrier integrity. ${ }^{15}$ In addition, RPE cells are involved in absorption of subretinal fluid, ${ }^{2}$ which is part of the mechanism keeping the photoreceptor layer in close contact with the RPE cells, thus facilitating the exchange of nutrients and oxygen. RPE cells play a key role in the pathogenesis of various diseases of the retina like proliferative vitreoretinopathy following retinal detachment.

Newsome et al. showed that the cGMP concentration in RPE cells is two- to fourfold higher in the macular region than in more peripheral regions. ${ }^{16} \mathrm{Sev}-$ eral studies have focused on the role of NO and localization of cGMP in the various layers of the retina. ${ }^{7,8,10}$ However less is known about cGMP synthesis and metabolism in RPE cells and the activation of both the soluble and the particulate guanylyl cyclases. Recently we found that retinal detachment was associated with a decrease in the cGMP concentration in the subretinal fluid as compared to controls. ${ }^{17}$ The source of cGMP in subretinal fluid is unknown, as is the reason for the decrease in cGMP concentration after retinal detachment. We therefore decided to investigate cGMP synthesis in cultured human RPE cells (D407 cell line) following stimulation of either the soluble or particulate guanylyl cyclase pathways. ${ }^{18}$ Our results show that cGMP production by RPE cells is most efficiently stimulated via the particulate guanylyl cyclase pathway.

\section{MATERIALS AND METHODS}

\section{Cell Culture}

Human retinal pigment epithelial cells (D407 cell line) ${ }^{19}$ were suspended in Dulbecco's modified Eagle's medium (DMEM) containing 5\% fetal calf serum, $2 \mathrm{mM}$ glutamine and $100 \mu \mathrm{g} / \mathrm{ml}$ penicillin streptomycin, at a concentration of $0.5-1.0 \times 106$ viable cells $/ \mathrm{ml}$. One $\mathrm{ml}$ portions of the suspension 
were seeded onto $40 \mathrm{~mm}$ diameter plastic Petri-dishes and incubated at $37^{\circ} \mathrm{C}$ in a humidified atmosphere of $95 \%$ air and $5 \% \mathrm{CO}^{2}$ for 48 hours.

\section{Cyclic GMP Radioimmunoassay (RIA)}

After seeding $(0.5-1.0 \times 106$ viable cells $/ \mathrm{ml})$ and 48 hour culturing (confluence), the RPE cells were washed and further incubated in Krebs buffer $\mathrm{pH} 7.4$ at $37^{\circ} \mathrm{C}$ with or without $1.0 \mathrm{mM}$ IBMX for 40 minutes. IBMX was added to non-selectively inhibit phosphodiesterases which cause cGMP breakdown into 5'-cGMP. The cells were stimulated with $100 \mu \mathrm{M}$ SNP (soluble guanylyl cyclase stimulation) or $0.1 \mu \mathrm{M}$ atrial natriuretic peptide (ANP; particulate guanylyl cyclase stimulation) for the final 10 minutes. Thereafter $180 \mu \mathrm{l}$ of incubation medium was collected and analyzed for cGMP content without further purification. Cells were denatured in 5\% $(\mathrm{w} / \mathrm{v})$ ice cold TCA to stop cGMP metabolism in the cells. Cells were detached and homogenized by sonification. After centrifugation for 10 minutes (at $17.000 \mathrm{~g}$ ) at $4^{\circ} \mathrm{C}$ the supernatant was collected to measure the intracellular cGMP content and stored at $-80^{\circ} \mathrm{C}$. The pellet was used for analysis of total protein content according to Lowry et al. ${ }^{20}$ The acidified supernatants were extracted with diethylether as described. ${ }^{21}$ Cyclic GMP content was measured in triplicate using a RIA as described earlier and expressed as $\mathrm{pmol} / \mathrm{mg}$ of protein. ${ }^{22}$ The detection limit for this cGMP assay was $0.12 \mathrm{nM}$.

\section{Statistics}

The cGMP radioimmunoassay was repeated 4 times. Within every experiment different incubation conditions were tested twice and all samples were measured in triplicate. Cyclic GMP concentrations were compared between different incubation groups using one-way ANOVA. The BonferroniHochberg correction for multiple comparisons was applied in all tests. ${ }^{23}$

\section{Immunohistochemistry}

After fixation with $4 \%$ freshly depolymerized paraformaldehyde in the cold $\left(4^{\circ} \mathrm{C}\right)$ the cells were washed $3 \times 5$ min, twice with Tris-buffered saline (TBS) and once with TBS containing 0.3\% Triton X-100 (TBS-T). Cells were incubated overnight at $4^{\circ} \mathrm{C}$ with the primary antibodies. Cyclic GMP was visualized using sheep anti-formaldehyde-fixed cGMP antiserum diluted 1:4000 in TBS-T. ${ }^{18}$ Cells were washed for $15 \mathrm{~min}$ with respectively TBS, TBS-T and TBS. Then the cells were incubated with Alexa 488 conjugated donkey anti-sheep IgG (Molecular Probes) diluted 1:100 in TBS-T for 1.5 hours at room temperature. Negative controls were processed in exactly the same way with the omission of the primary antibody. After three further washings with TBS the cells were cover slipped with TBS/glycerol $(1: 2 \mathrm{v} / \mathrm{v})$. 


\section{Chapter VI}

\section{RESULTS}

We studied cGMP production in human RPE cells, following stimulation of soluble guanylyl cyclase (by SNP) or particulate guanylyl cyclase (by ANP) and simultaneous inhibition of cGMP breakdown by PDE's using IBMX (Table 1). RPE cells were cultured until they formed a confluent monolayer. Without stimulation cGMP levels were very low, being just above detection levels (Table 1). Blocking phosphodiesterase activity in unstimulated cell cultures did not result in a detectable increase in cGMP levels. Addition of $0.1 \mu \mathrm{M}$ ANP as a stimulator of particulate guanylyl cyclase in the presence of IBMX resulted in a readily detectable level of cGMP in the RPE cultures. When calculated in relation to total protein, the relative amount of intracellular cGMP was much higher than the extracellular level. Culturing RPE cells with $100 \mu \mathrm{M}$ SNP as a stimulator of soluble guanylyl cyclase in the presence of IBMX resulted in the appearance of very low levels of cGMP, which were not markedly different from the levels seen with IBMX alone. As compared to stimulation of the particulate guanylyl cyclase, intracellular levels of cGMP were approximately 200 fold lower in confluent RPE cells after stimulation of the soluble guanylyl cyclase pathway $(\mathrm{P}=<.000)$.

Table 1. The effect of SNP $(100 \mu M)$ or ANP $(0.1 \mu M)$ on extracellular and intracellular cGMP content in confluent RPE cells. Cyclic GMP was assayed following a 40 minute culture of cells in the presence of various stimuli.

\begin{tabular}{lccc}
\hline Treatment & $n$ & Intracellular & Extracellular \\
\hline Krebs & 4 & $0.01 \pm 0.02$ & $0.16 \pm 0.21$ \\
IBMX & 4 & $0.01 \pm 0.02$ & $0.10 \pm 0.18$ \\
IBMX + SNP & 4 & $0.16 \pm 0.42$ & $0.29 \pm 0.30$ \\
IBMX + ANP & 4 & $12.60 \pm 4.33^{*}$ & $81.59 \pm 20.05^{*}$ \\
\hline
\end{tabular}

* $\mathrm{P}<0.001$ when compared to Krebs, IBMX or IBMX+SNP.

$n$ is number of experiments; data are expressed as $\mathrm{pmol} / \mathrm{mg}$ protein.

The findings mentioned above could be confirmed using immunohistochemistry (Figure 1). Stronger intracellular cGMP staining was observed when stimulating the particulate guanylyl cyclase as compared to the soluble guanylyl cyclase pathway. Using immunohistochemistry we did observe a stronger intracellular expression of cGMP when cells were stimulated with SNP as compared to controls with IBMX alone. 
Figure 1. Cyclic GMP immunoreactivity in cultured human RPE cell. Cells were incubated: $\boldsymbol{A}$ Without PDE inhibition; $\boldsymbol{B}$ In the presence of $1 \mathrm{mM} I B M X ; \boldsymbol{C}$ With a combination of $1 \mathrm{mM} I B M X$ and $0.1 \mathrm{mM} S N P$; $\boldsymbol{D}$ With a combination of $1 \mathrm{mM} I B M X$ and 100 nM ANP.
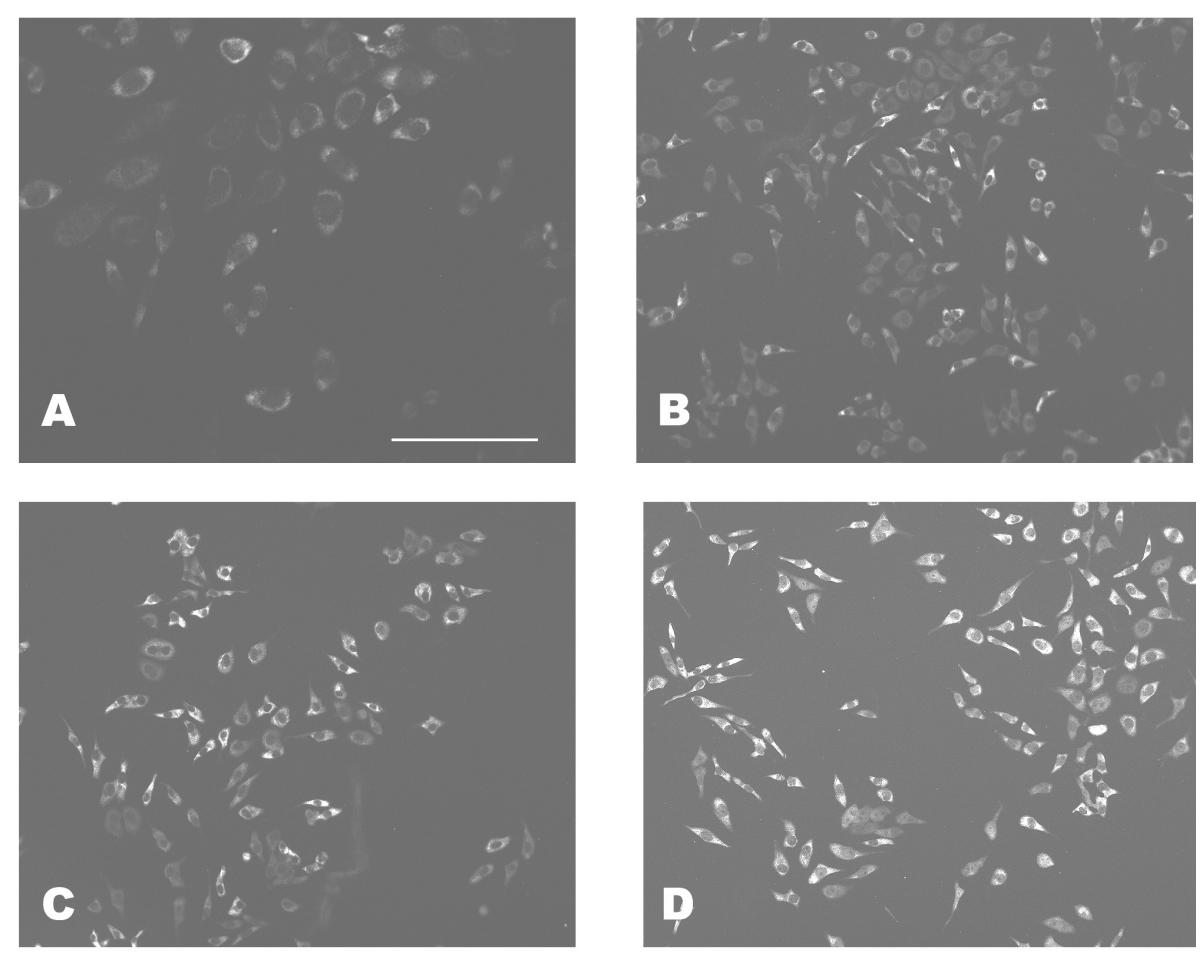

Bar in A represents $100 \mu \mathrm{m}$

\section{DISCUSSION}

In the current study we demonstrate that RPE cells are capable of producing significant amounts of cGMP following appropriate stimulation. Of the two currently known pathways involved in cGMP production it is evident that production via the particulate guanylyl cyclase pathway results in much higher levels than via the soluble guanylyl cyclase pathway. Previous reports comparing both enzymatic pathways involved in the cGMP production in the rat retina show that the NO-cGMP pathway (via soluble guanylyl cyclase) exists dominantly in the inner nuclear layer and the ANP-cGMP pathway (via particulate guanylyl cyclase) exists dominantly in the rod photoreceptor. $6,11,24,25$

The strong stimulation of cGMP production in RPE cells by ANP has not been reported earlier. ANP belongs to the natriuretic peptide (NP) family to- 


\section{Chapter VI}

gether with BNP and CNP and is mainly produced in the heart. ANP is a circulating peptide and has been detected in different cell layers of the rat and rabbit retina. Also in the RPE cell layer of the human retina strong ANP immunolabeling has been previously shown. ${ }^{26}$ In addition, mRNA of NPR-A and NPR-B, both ANP receptors, has been demonstrated in cultured rabbit RPE cells. ${ }^{9}$ Histochemical and molecular cloning studies have also revealed the presence of the NPR-A and NPR-B in the human and turtle retina. ${ }^{7,10,24}$ ANP is furthermore involved in controlling the extracellular fluid homeostasis. Also in RPE cells it has been shown that ANP stimulates Cl- transport. ${ }^{27}$

Besides detection of ANP in the eyes of experimental animals, studies in humans have also provided evidence for the presence of ANP in the eye. The ANP concentration in vitreous fluid of diabetic and non-diabetic patients was $60.5 \mathrm{pg} / \mathrm{ml}$ and $15.6 \mathrm{pg} / \mathrm{ml}$, respectively. ${ }^{28}$ These values found in vivo are much lower than the ANP concentration we used to stimulate the cGMP production in RPE cells $(0.1 \mu \mathrm{M} ; 300 \mathrm{ng} / \mathrm{ml})$. We did not test whether a lower ANP concentration would also lead to a stimulation of cGMP expression. On the other hand, the level found in vitreous fluid may not actually represent local levels found at the tissue or cell level. When expressed in $\mathrm{pmol} / \mathrm{mg}$ protein, our intracellular cGMP levels are comparable with cGMP levels found earlier in the rat retina. ${ }^{25}$ In our previous study, the mean cGMP level in subretinal fluid from eyes with a retinal detachment was $2.4 \mathrm{nM} \cdot{ }^{17} \mathrm{In}$ the current study, the extracellular cGMP concentration measured in the culturing media after 40 minutes of culturing, with or without IBMX, was maximally $0.16 \mathrm{nM}$. After stimulation of the particulate guanylyl cyclase with ANP the cGMP concentration in the culture medium ranged between 2.2 and $4.10 \mathrm{nM}$. These findings suggest that in case of a retinal detachment RPE cells could be responsible for the total production of cGMP present in the subretinal fluid.

Intracellular cGMP levels found in the current study are comparable to the levels found by Newsome et al. in human and monkey RPE cells and correspond most to the levels Newsome et al. found in RPE cells situated in the macular region. ${ }^{16}$

It is difficult to say how well the cell line (D407) represents normal RPE cells in vivo. It has, however been shown that the D407 cell line retains many of the metabolic and morphologic characteristics of RPE cells in vivo, although there are some minor differences. ${ }^{19}$ In order to mimic the in vivo situation we used confluent single RPE cell layers.

Most studies concerning retinal cGMP have focused on its role in phototransduction. Little is known about the functional significance of cGMP in RPE cells. It has been shown that cGMP stimulates subretinal fluid absorption whereas cAMP inhibits this process. ${ }^{2}$ Moreover, cGMP analogues were 
shown to increase the rate of fluid absorption from the subretinal space by $33 \%$ in rabbits with experimental retinal detachment. ${ }^{2}$ These data indicate a possible role for cGMP in the clearance of subretinal fluid in retinal detachment. The involvement of cGMP in retinal detachment was furthermore suggested by a previous study, in which we observed a decreased level of cGMP in vitreous and subretinal fluid of patients with retinal detachment. ${ }^{17}$ A combination of these results could implicate a possible therapeutic effect from cGMP in retinal detachment. A higher cGMP level could be beneficial in clearing subretinal fluid and could even make a scleral puncture unnecessary during retinal detachment surgery. As can be concluded from our results, the RPE cell layer would be a good therapeutic target in order to increase the cGMP concentration in subretinal fluid after retinal detachment.

In conclusion, cGMP production was analysed using two different methods, i.e. by a radioimmunoassay and by immunocytochemistry using specific cGMP antibodies. The results show that cultured human RPE cells are capable of producing cGMP and that most cGMP is generated following stimulation of the particulate guanylyl cyclase pathway.

\section{ACKNOWLEDGEMENT}

This study was financially supported by the Algemene Nederlandse Vereniging ter Voorkoming van Blindheid. 


\section{Chapter VI}

\section{REFERENCES}

1 Baylor DA. Photoreceptor signals and vision. Invest Ophthalmol Vis Sci. 1987; 28:34-39.

2 Marmor MF, Negi A. Pharmacologic modification of subretinal fluid absorption in the rabbit eye. Arch Ophthalmol 1986; 104, 1674-1677.

3 Ahmad I, Leinders-Zufaal R, Kocsis JD, Shepherd GM, Zufall F, Barnstable CJ. Retinal ganglion cells express a cGMP-gated cation conductance activatable by nitric oxide donors. Neuron 1994:12; 155-165.

4 Nawy S, Jahr E. cGMP-gated conductance in retinal bipolar cells is suppressed by the photoreceptor transmitter. Neuron 1991; 7:677-683.

5 Kusaka S. Dabin I, Barnstable CJ, Puro DG. CGMP mediated effects on the physiology of bovine and human retinal Müller cells. Journal of Physiology 1996; 497:813-824.

6 Ahmad I, Barnstable CJ. Differential laminar expression of particulate and soluble guanylate cyclase genes in rat retina. Exp Eye Res 1993; 56:51-62.

7 Blute TA, Lee HK, Huffmaster T, Haverkamp S, Eldred WD. Localization of natriuretic peptides and their activation of particulate guanylate cyclase and nitric oxide synthase in the retina. J Comp Neurol 2000; 424:689-700.

8 Gotzes S, de Vente J, Muller F. Nitric oxide modulates cGMP levels in neurons of the inner and outer retina in opposite ways. Vis Neurosci 1998; 15:945-55.

9 Fujiseki Y, Omori K, Omori K, Mikami Y, Suzukawa J, Okugawa G, Uyama M, Inagaki C. Natriuretic peptide receptors, NPR-A and NPR-B, in cultured rabbit retinal pigment epithelium cells. Jpn J Pharmacol 1999; 79:359-68.

10 Blute TA, Velasco P, Eldred WD. Functional localization of soluble guanylate cyclase in turtle retina: modulation of cGMP by nitric oxide donors. Vis Neurosci 1998; 15:485-98.

11 Shyjan AW, de Sauvage FJ, Gillett NA, Goeddel DV, Lowe DG. Molecular cloning of a retina-specific membrane guanylyl cyclase. Neuron 1992; 9:727-37.

12 Francis SH, Corbin JD. Cyclic nucleotide-dependent protein kinases: intracellular receptors for cAMP and cGMP action. Crit Rev Clin Lab Sci 1999; 36:275-328.

13 Kurtz MJ, Edwards RB, Schmidt SY. Cyclic nucleotide phosphodiesterases in cultured normal and RCS rat pigment epithelium: kinetics of cyclic AMP and cyclic GMP hydrolysis. Exp Eye Res. 1987; 45(1):67-75.

14 Yamazaki A, Moskvin O, Yamazaki RK. Phosphorylation by cyclin-dependent protein kinase 5 of the regulatory subunit (Pgamma) of retinal cgmp phosphodiesterase (PDE6): its implications in phototransduction. Adv Exp Med Biol 2002; 514:131-53.

15 Zinn K. Anatomy of the human retinal pigment epithelium. Cambridge: Harvard University Press, 1979.

16 Newsome DA, Fletcher RT, Chader GJ. Cyclic nucleotides vary by area in the retina and pigmented epithelium in the human and monkey. Invest Ophthalmol Vis Sci. 1980; 19(8):864-9.

17 La Heij EC, Blaauwgeers HG, de Vente J, Markerink M, Liem AT, Kessels AG, Steinbusch H, Hendrikse F. Decreased levels of cGMP in vitreous and subretinal fluid from eyes with retinal detachment. Br J Ophthalmol 2003; 87:1409-12.

18 De Vente J, Markerink-van Ittersum M, van Abeelen J, Emson PC, Axer H, Steinbusch HW. NO-mediated cGMP synthesis in cholinergic neurons in the rat forebrain: effects of lesioning dopaminergic or serotonergic pathways on nNOS and cGMP synthesis. Eur J Neurosci. 2000; 12:507-19.

19 Davis AA, Bernstein PS, Bok D, Turner J, Nachtigal M, Hunt RC. A human retinal pigment epithelial cell line that retains epithelial characteristics after prolonged culture. Invest Ophthalmol Vis Sci.1995; 36:955-64.

20 Lowry OH, Rosebrough NJ, Farr AL, Randall RJ. Protein measurement with the Folin phenol reagent. J Biol Chem 1951; 193:265-75.

21 Steiner AL, Pagliara AS, Chase LR, Kipnis DM. Radioimmunoassay for cyclic nucleotides. II. Adenosine 3',5'-monophosphate and guanosine 3',5'-monophosphate in mammalian tissues and body fluids. J Biol Chem 1972; 247:1114-20. 
22 Brooker G, Harper JF, Terasaki WL, Moylan RD. Radioimmunoassay of cyclic AMP and cyclic GMP. Adv Cyclic Nucleotide Res. 1979; 10:1-33

23 Hochberg Y. A Sharper Bonferonni procedure for multiple tests of significance. Biometrika 1988; 75:800-802.

24 Garbers DL, Lowe DG. Guanylyl cyclase receptors. J Biol Chem.1994; 269:30741-30744.

25 Moriwaki Y, Kamisaki Y, Itoh T, Nagata M, Tamai A. Cyclic 3',5'-Guanosine monophosphate synthesis induced by atrial natriuretic peptide, C-type natriuretic peptide, and nitric oxide in the rat. Jpn J Ophthalmology 1997;42:269-274 Rollin R, Mediero A, Roldan-Pallares M, Fernandez-Cruz A, Fernandez-Durango R. Natriuretic peptide system in the human retina. Mol Vision 2004;10:15-22.

27 Mikami Y, Hara M, Yasukura T, Uyama M, Minato A, Inagaki C. Atrial natriuretic peptide stimulates $\mathrm{Cl}$ - transport in retinal pigment epithelial cells. Curr Eye Res. 1995;14, 391-397.

28 Rollin R, Mediero A, Martinez-Montero JC, Roldan-Pallares M, Suarez-Leoz M, VidalFernandez P, Cortes-Valdes C, Fernandez-Cruz A, Fernandez-Durango R. Atrial natriuretic system in the vitreous humor and epiretinal membranes of patients with proliferative diabetic retinopathy. Mol Vision 2004;10:450-457. 



\title{
CHAPTER VII
}

\section{Two autocrine pathways to regulate cGMP synthesis in cultured human RPE cells}

\author{
Submitted
}

\author{
Roselie M.H. Diederen ${ }^{l, 2}$, Ellen C. La Heij ${ }^{l}$, \\ Marianne Markerink-van Ittersum ${ }^{2}$, \\ Fred Hendrikse $e^{1}$ and Jan de Vente ${ }^{2}$
}

1 Eye Research Institute Maastricht, Department of Ophthalmology, University Hospital Maastricht, The Netherlands

2 European Graduate School of Neuroscience (EURON), Psychiatry and Neuropsychology, University of Maastricht, The Netherlands 



\section{ABSTRACT}

The aim of this study was to investigate the role of two separate enzymatic pathways (soluble versus particulate guanylyl cyclase) in the synthesis of cyclic 3', 5'-guanosine monophosphate (cGMP) in cultured human retinal pigment epithelium cells. Cyclic GMP accumulation was evaluated by quantitative analysis of cGMP-immunoreactivity. We showed NADPH-diaphorase activity and inducible NOS-immunoreactivity in retinal pigment epithelium cells. Incubation of the cells in the presence of $1 \mathrm{mM}$ IBMX to inhibit phosphodiesterase activity, and the simultaneous inhibition of NOS activity with L-NAME suggested the involvement of soluble guanylyl cyclase in maintaining a low level of cGMP in the retinal pigment epithelium cells. The involvement of soluble guanylyl cyclase was further supported by detection of the $\beta-1$ and $\alpha-2$ subunits of soluble guanylyl cyclase. Incubation of the cells in the presence of atrial natriuretic peptide to stimulate particulate guanylyl cyclase increased cGMP-immunoreactivity strongly. We also demonstrated the presence of atrial natriuretic peptide in all retinal pigment epithelium cells. In conclusion, cultured human retinal pigment epithelium cells are capable of producing cGMP after stimulation of soluble guanylyl cyclase or particulate guanylyl cyclase. The presence of inducible NOS and atrial natriuretic peptide in all cells suggests two different autocrine pathways of stimulating cGMP production in these cells. The possible role of cGMP in regulation inducible NOS gene expression and in the regulation of atrial natriuretic peptide is discussed.

\section{INTRODUCTION}

Retinal pigment epithelium cells (RPE cells) form a monolayer situated between the photoreceptor cell layer and the choroid. RPE cells play an essential role in the control of outer retinal homeostasis and in maintaining bloodretinal barrier integrity. ${ }^{1}$ In addition, RPE cells are involved in absorption of subretinal fluid, which is part of the mechanism keeping the photoreceptor layer in close contact with the RPE cells. ${ }^{2}$ Furthermore, RPE cells facilitate the exchange of nutrients and oxygen to the photoreceptor cells. Together, RPE cells are critical to the functioning of the eye and play a role in the pathogenesis of various eye diseases, such as age-related macular degeneration and proliferative vitreoretinopathy (PVR). Recently we found that retinal detachment was associated with a decrease in the cGMP concentration in the subretinal fluid as compared to controls. ${ }^{3}$ Whether cGMP in subretinal fluid is produced by RPE cells is still unknown, as is the reason for the decrease in cGMP concentration after rhegmatogenous retinal detachment (RRD). 


\section{Chapter VII}

Cyclic GMP is synthesized by the enzyme guanylyl cyclase (GC). Different isoforms of this enzyme are classified into two types, the nitric oxidereceptive (soluble) isoform ( $\mathrm{sGC}$ ), and the receptor-stimulated transmembrane (particulate) isoform (pGC). sGC is a heterodimeric molecule containing an $\alpha$-subunit and a $\beta$-subunit with a ferrous-heme group attached to the $\beta$-subunit. ${ }^{4,5}$ Two $\alpha$ subunits $(\alpha-1, \alpha-2)$, and two $\beta$-subunits $(\beta-1, \beta-2)$ are known. Only the heterodimeric forms of soluble GC, which contain one of the $\alpha$-subunits in combination with the $\beta-1$ subunit can be activated by nitric oxide (NO). The presence of NO-sensitive GC has been demonstrated in cultured rat RPE cells and in cultured immortalized human RPE cells. ${ }^{6,7}$ At least seven isoforms of the particulate GC are known, designated GC-A through G. ${ }^{8}$ In human and rabbit RPE cells the mRNA of the receptors of GC-A and GC-B has been demonstrated. ${ }^{9,10}$ GC-A and GC-B are activated by natriuretic peptides. GC-A is activated by atrial natriuretic peptide (ANP) and brain natriuretic peptide (BNP), whereas GC-B is activated by C-type natriuretic peptide (CNP). All three natriuretic peptides have been observed in human RPE cells. ${ }^{10}$ Recently we showed that human RPE cells are capable of producing cGMP and that most cGMP is generated following stimulation of the particulate GC pathway. ${ }^{11}$

The above data indicate that cGMP in RPE cells can be synthesized by two different mechanisms, either by stimulation of NO-sensitive soluble GC or by activation of particulate GC by natriuretic peptides. Cyclic GMP in RPE cells has been implicated in stimulation of $\mathrm{Cl}^{-}$transport, suppression of hypoxia-associated vascular endothelial growth factor (VEGF) gene expression, and phagocytosis of rod outer segments. ${ }^{6,712} \mathrm{The}^{-}$transport was stimulated by ANP and by NO, suggesting that there is no selective GC stimulating pathway regulating this RPE cell property. ${ }^{12}$ VEGF gene expression was studied only as a sodium nitroprusside mediated effect. ${ }^{7}$ The phagocytic activity of RPE cells was NO dependent but could also be stimulated by the addition of the cell permeable cGMP analog 8-Br-cGMP, which suggest that a NP-mediated increase in cGMP might be effective as well. ${ }^{6}$

The inducible isoform of nitric oxide synthase (iNOS) has been demonstrated in RPE cells and might be the sole source of endogenous NO in RPE cells because expression of the neuronal isoform was not observed. ${ }^{13,14}$ However, the relation between NO-synthesis and cGMP synthesis in the cultured RPE cells has not been investigated. As also NP's stimulate cGMP synthesis in RPE cells, we hypothesized that continuous synthesis of NO by iNOS results in a low level of cGMP synthesis in RPE cells, and that ANP stimulated cGMP synthesis might occur in (a) different compartment(s). Therefore, we studied cGMP synthesis after inhibition of NOS using L-NAME, inhibition of soluble GC using $10 \mu \mathrm{M} 1 \mathrm{H}-(1,2,4)$ oxadiazolo(4,3-a) quinoxalin-1-one (ODQ) or inhibition of particulate GC using isatin. Furthermore, we investigated the immunoreactivity (IR) of $\beta-1$ and $\alpha-2$ subunits 
of soluble GC, iNOS, and ANP in cultured human RPE cells (D407 cell line).

\section{METHODS}

\section{Cell Culture}

Human RPE cells (D407 cell line) ${ }^{15}$ were suspended in Dulbecco's modified Eagle's medium (DMEM) containing 5\% fetal calf serum, $2 \mathrm{mM}$ glutamine and $100 \mu \mathrm{g} / \mathrm{ml}$ penicillin streptomycin, at a concentration of $0.5-1.0 \times 106$ viable cells $/ \mathrm{ml}$. One $\mathrm{ml}$ portions of the suspension were seeded on to $40 \mathrm{~mm}$ diameter plastic Petri-dishes and incubated at $37^{\circ} \mathrm{C}$ in a humidified atmosphere of $95 \%$ air and $5 \% \mathrm{CO}^{2}$ for 24 hours.

\section{Pharmacology}

Twenty-four hours after seeding, the RPE cells were incubated for 40 minutes in aerated Krebs buffer ( $\mathrm{pH}$ 7.4) with or without the following compounds: $1 \mathrm{mM}$ IBMX (a non-specific PDE inhibitor) (Sigma), $0.1 \mathrm{mM}$ NG-nitro-L-arginine methyl ester (L-NAME) (a NOS inhibitor) (Sigma), 10 $\mu \mathrm{M} 1 \mathrm{H}-(1,2,4)$ oxadiazolo(4,3-a)quinoxalin-1-one (ODQ) (inhibitor of the soluble GC) $)^{16}$ (Tocris), or $0.1 \mathrm{mM}$ isatin (inhibitor of the particulate GC) ${ }^{17}$ (Fluka). During the last ten minutes of the incubation the cells were stimulated with $100 \mu \mathrm{M}$ of the NO donor SNP or $0.1 \mu \mathrm{M}$ ANP.

\section{Immunohistochemistry}

After fixation with $4 \%$ freshly depolymerized paraformaldehyde in the cold $\left(4^{\circ} \mathrm{C}\right)$ the cells were washed $3 \times 5 \mathrm{~min}$, twice with Tris-buffered saline (TBS) and once with TBS containing 0.3\% Triton X-100 (TBS-T). Cells were incubated overnight at $4{ }^{\circ} \mathrm{C}$ with the primary antibodies. Cyclic GMP was visualized using sheep anti-formaldehyde-fixed cGMP antiserum diluted $1: 4000$ in TBS-T. ${ }^{18}$ The $\beta-1$ and $\alpha-2$ subunits of soluble GC were detected by using rabbit anti- $\beta-1$ subunit or $\alpha-2$ subunit antibodies both diluted 1:1000 in TBS-T. ${ }^{19,20}$ Inducible NOS was investigated using mouse anti-iNOS diluted 1:50 in PBS (Santa Cruz Biotechnology) and ANP was stained using rabbit anti-ANP diluted 1:400 inTBS-T (RDI division of Fitzgerald Industries Intl). Cells were washed for 15 minutes with respectively TBS, TBS-T and TBS. Then the cells were incubated with Alexa 488 conjugated donkey anti-sheep IgG (Molecular Probes) diluted 1:100 in TBS-T, Alexa 488 conjugated donkey anti-rabbit IgG (Molecular Probes) diluted 1:100 in TBS-T or Biotin conjugated donkey anti-mouse diluted 1:400 in PBS (Sanbio) for 1.5 hours at room temperature. Negative controls were processed in exactly the same way with the omission of the primary antibody. After three further washings with TBS the cells were cover slipped with TBS/glycerol $(1: 2 \mathrm{v} / \mathrm{v})$. 


\section{NADPH-Diaphorase Cytochemistry}

The nicotinamide adenine dinucleotide phosphate (NADPH)-diaphorase histochemical technique was used as a general marker for NOS. ${ }^{21}$ After fixation of the RPE cells as described above, cells were washed 2 times for 15 minutes each in TBS at room temperature and one time for 30 minutes in $0.1 \mathrm{M}$ Tris- $\mathrm{HCl}(\mathrm{pH} \mathrm{8.0)}$ at room temperature. Subsequently, the cells were incubated in Tris- $\mathrm{HCl}$, containing $0.4 \mathrm{mg} / \mathrm{ml}$ nitro blue tetrazolium and 8.4 $\mathrm{mg} / \mathrm{ml} \mathrm{NADPH}$ at $37^{\circ} \mathrm{C}$ for 1 hour. Finally, cells were washed with TBS twice for 15 minutes and mounted with TBS-glycerol.

\section{Quantification of Immunostainings}

Immunostainings were examined using an Olympus AX70 microscope equipped with a cooled CCD Olympus F-view camera. Experiments were repeated three times. From each experiment, six images (16 bits) were made randomly of each condition. Each image showed at least 50 RPE cells. Fluorescence intensities were converted into gray values (AnalySIS ${ }^{\circledR}$, Softimaging system, $\mathrm{GmbH}$ ) ranging from 0 (blank) to 4096 (white). After establishing a threshold setting using a blank preparation incubated with the secondary antibody only, 5 classes with increasing gray values were set from 0 - 300 (blank), 301 - 600, 601 - 1500, 1501 - 2700 and 2701 - 4096. All cells were classified according to the highest gray value they were demonstrating (Figure 2c,d). The distributions of the cells over the different classes were analyzed using the chi-square test.

\section{RESULTS}

After fixation of the cells, NADPH-diaphorase activity, as a marker for NOS, was demonstrated in the cytoplasm of all human RPE cells (Figure 1a). The intensity of the diaphorase staining was rather heterogeneous between cells, but highest intensity was always around the nucleus. This result was also obtained using an antibody against iNOS (Figure 1b).

Figure 1. A: NADPH-diaphorase activity in human RPE cells; B: iNOS-IR in human RPE cells, using a mouse anti-iNOS antibody. Bar represents $100 \mu \mathrm{m}$.
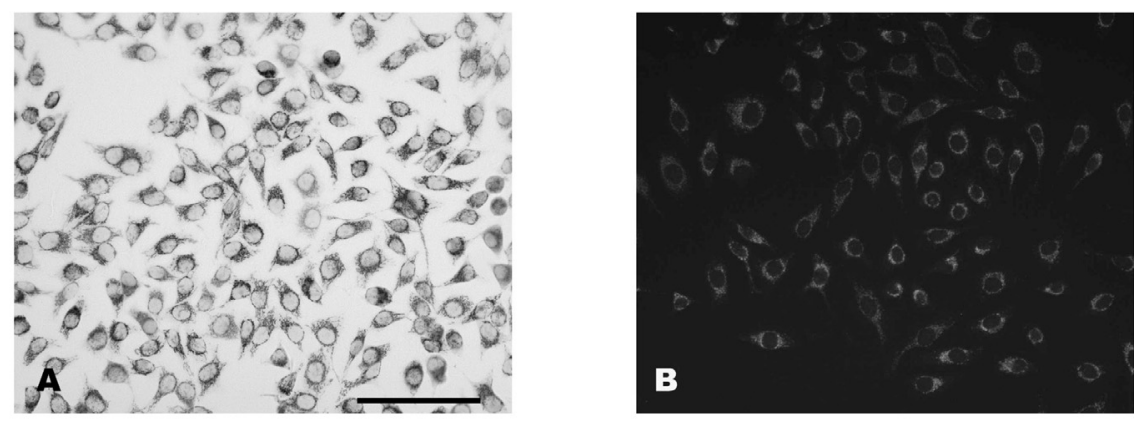
Figure 2. cGMP-IR in cultured human RPE cells. Cells were incubated; A: without addition; B: in the presence of IBMX; $\boldsymbol{C}$ : in the presence of $100 \mathrm{nM} A N P$. D: shows the same picture as in $C$, however, cells are presented in false colors depicting the different classes of fluorescence intensity. Bar represents $100 \mu \mathrm{m}$ in picture $B$, and $50 \mu \mathrm{m}$ in picture $A, C$ and $D$.
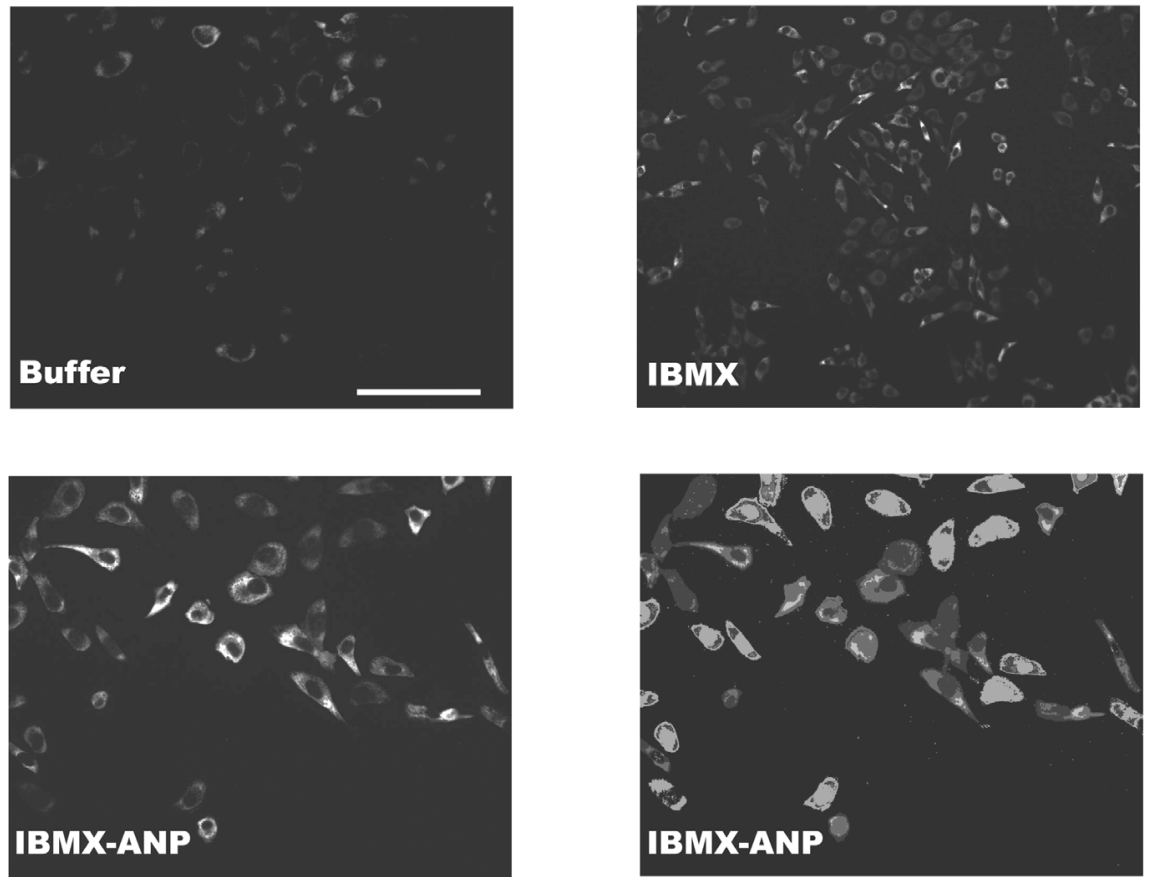

Figure 3. Immunohistochemical demonstration of the $\alpha-2$ (A) and the $\beta-1$ (B) subunit of soluble guanylyl cyclase in the cultured human RPE cells. Bar represents 100 $\mu m$ in picture $A$ and $C$, and $50 \mu m$ in picture $B$ and $D$.
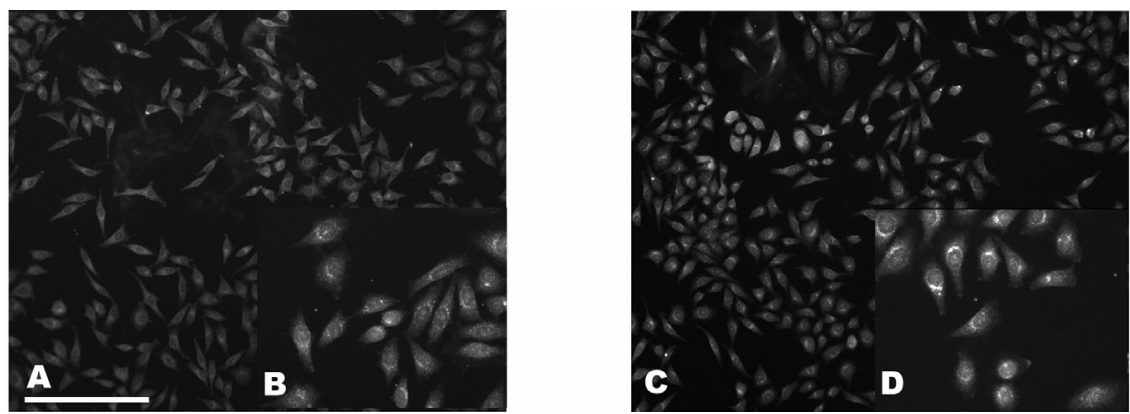

The intensity of the cGMP-immunostaining is very low in cells that have been incubated without any addition. Inhibition of phosphodiesterase (PDE) activity by the nonselective inhibitor IBMX resulted in a significant increase in cGMP-IR in the cells (Table 1; Figure 2a,b). Incubation of the cells in the presence of the NO-donor SNP did not result in a significant further increase 


\section{Chapter VII}

in cGMP-IR. However, when we incubated the cells in the presence of 0.1 mM L-NAME (a NOS inhibitor) in combination with IBMX, cGMP-IR was reduced as compared to incubation with IBMX alone ( $<<0.001$; Table 1). This result suggests the involvement of soluble GC in maintaining a certain (low) level of cGMP in the RPE cells. The involvement of soluble GC in the synthesis of cGMP was further supported by detection of the $\alpha-2$ subunit and the $\beta-1$ subunit of soluble GC by immunohistochemistry in all RPE cells (Figure 3). Immunostaining for both subunits was strongest around the nucleus. We observed a few cells (Figure 3A) with $\alpha-2$ subunit immunostaining in the nucleus. The punctate staining that is observed for both subunits in almost all nuclei is probably a staining in the cytoplasm overlying the nucleus.

Table 1. Analysis of cGMP fluorescence intensity in human RPE cells after incubation of the cells under various conditions (SNP $0.1 \mathrm{mM}$; ANP $0.1 \mathrm{nM}$; L-NAME $0.1 \mathrm{mM}$ ). Individual cells were grouped in defined gray value classes. Numbers are the means of all experiments and express the percentage of cells in each class.

\begin{tabular}{lcccccc}
\hline & & \multicolumn{5}{c}{ Gray Values } \\
\multicolumn{2}{c}{ Treatment } & $n$ & $300-600$ & $600-1500$ & $1500-2700$ & $2700-4095$ \\
\hline Krebs & & 5 & 86 & 13 & 1 & 0 \\
& + SNP $^{\mathrm{a}}$ & 4 & 75 & 23 & 2 & 0 \\
IBMX $^{\mathrm{b}}$ & & 6 & 60 & 27 & 13 & 0 \\
& $+\mathrm{SNP}^{\mathrm{c}}$ & 3 & 55 & 38 & 6 & 1 \\
& + ANP $^{\mathrm{d}}$ & 3 & 15 & 46 & 30 & 9 \\
& + L-NAME $^{\mathrm{e}}$ & 3 & 98 & 2 & 0 & 0 \\
\hline
\end{tabular}

a $\quad$ Krebs vs. Krebs + SNP: P $=0.145$

c IBMX vs. IBMX + SNP: P $=0.129 ; \quad$ d IBMX vs. IBMX + ANP: $\mathrm{P}<0.001$;

e IBMX vs. IBMX + L-NAME: $\mathrm{P}<0.001$.

Incubation of the cells in the presence of ANP increased cGMP-IR in almost all cells, although to different extends (Table 1; Figure 2c). The ANP stimulated cGMP-IR was not homogeneously distributed throughout the cell but clearly had a punctate appearance. Immunostaining of the RPE cells with an antibody against ANP revealed the presence of ANP in all cells, also in a punctate manner (Figure 4a,b).

To further explore the role of soluble GC and particulate GC we did an additional series of experiments with known inhibitors of these enzymes. RPE cells were incubated with IBMX in combination with $10 \mu \mathrm{M}$ ODQ, a soluble GC inhibitor (Table 2). As compared with IBMX alone, ODQ markedly suppressed cGMP synthesis and the intensity of the cGMP-IR did not reach further than the lowest intensity class $(\mathrm{P}<0.001)$. When SNP was added as a 
stimulator of soluble GC, ODQ also blocked cGMP-IR. To obtain further evidence for a role of particulate $\mathrm{GC}$ we performed experiments with isatin, which has been claimed to be an inhibitor of particulate GC. ${ }^{17}$ Isatin $(0.1$ $\mathrm{mM}$ ) inhibited unstimulated cGMP production in cultures incubated with IBMX alone $(\mathrm{P}<0.001)$. Isatin was however not able to suppress ANP induced stimulation of cGMP production (Table 2).

Figure 4. Immunohistochemical demonstration of the presence of ANP in the cultured human RPE cells. Bar in A represents $100 \mu \mathrm{m}$ in picture A and $50 \mu \mathrm{m}$ in picture B. Preabsorbation of the ANP antibody with of $0.1 \mu M$ ANP before staining the cells did not result in any ANP-IR.
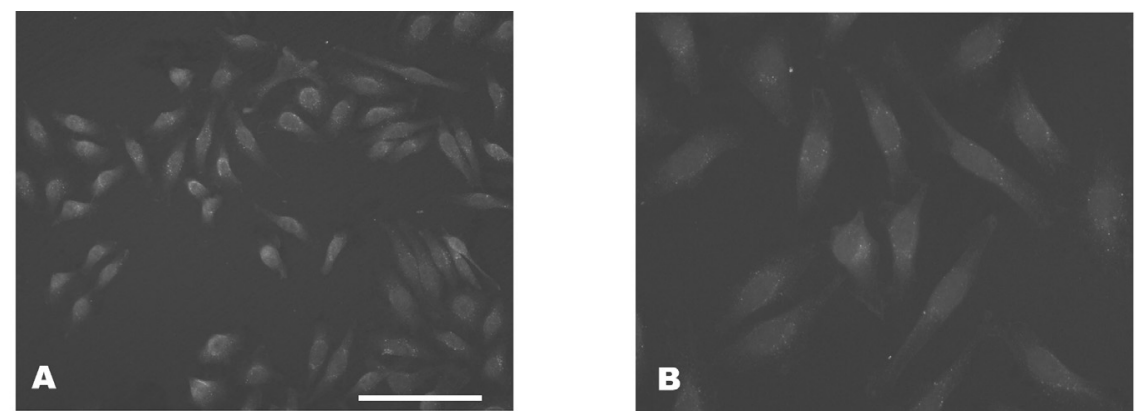

\section{DISCUSSION}

We investigated cGMP synthesis in human RPE cell (D407) cultures using cGMP-immunocytochemistry. Our results show that both soluble- and particulate GC are involved in the synthesis of cGMP by RPE cells. In addition we presented evidence that endogenous NO synthesis is occurring in these cells and, as a consequence a continuous level of cGMP is present in RPE cells.

Stimulation of cGMP synthesis by SNP in the presence of IBMX was not significant. As incubation of the cells in the presence of L-NAME resulted in a decrease in cGMP-immunofluorescence intensity, these two observations lead to the conclusions that soluble GC is present in the cultured RPE cells, however apparently maximal activity of soluble GC is already achieved through the endogenous synthesized NO.

The source of this endogenous NO could very well be iNOS, as we demonstrated the presence of iNOS in the cytoplasm of cultured RPE cells using immunocytochemistry. These findings confirm earlier studies that showed expression of iNOS in rat as well as human RPE cells using RT-PCR. ${ }^{13,14}$ iNOS activity in the RPE cells is the source of NO, which keeps cGMP synthesis at a certain low level. Known functions of the RPE cells are uptake of deteriorated photoreceptor outer segments by means of phagocytosis and 


\section{Chapter VII}

maintenance of the blood-retinal barrier. ${ }^{6}$ Cyclic GMP might play a role in both these processes.

It has been shown that ANP stimulates Cl- transport in RPE cells. ${ }^{12}$ mRNA of NPR-A and NPR-B, both ANP receptors, has been demonstrated in cultured rabbit RPE cells. ${ }^{9}$ Histochemical and molecular cloning studies have also revealed the presence of the NPR-A and NPR-B receptors in the human and turtle retina. ${ }^{22-24} \mathrm{We}$ found that the cGMP response to ANP was not the same in all RPE cells. It is not known whether this differentiation of the ANP response is caused by changes in the activity or availability of the ANP-receptors, or that differences in PDE activity are involved. The difference in response to ANP between the individual cells may also depend on their differentiation stage.

Isatin has previously been described as an inhibitor of particulate GC in a number of different tissues, e.g. brain, kidney and heart. ${ }^{17}$ In our experiments isatin was not able to inhibit cGMP-synthesis after stimulation with ANP. However we did observe inhibition of basal production of cGMP in the presence of IBMX. This points to inhibition of soluble GC by isatin in RPE cells, as has been reported earlier for human platelets. ${ }^{25}$

Most studies concerning retinal cGMP have focused on its role in phototransduction. Little is known about the functional significance of cGMP in RPE cells. It has been shown that cGMP stimulates subretinal fluid absorption whereas cAMP inhibits this process. ${ }^{1}$ Moreover, cGMP analogues were shown to increase the rate of fluid absorption from the subretinal space by $33 \%$ in rabbits with experimental retinal detachment. ${ }^{1}$ These data indicate a possible role for cGMP in the clearance of subretinal fluid in retinal detachment. The involvement of cGMP in retinal detachment was suggested by a previous study, in which we observed a decreased level of cGMP in vitreous and subretinal fluid of patients with retinal detachment. ${ }^{3}$

We were able to show the presence of ANP in the cultured RPE cells, confirming in part the finding of Rollin et al. ${ }^{10}$ The question arises why there are two autocrine mechanisms in the RPE cells both using cGMP as a second messenger. It has been shown that ANP regulates iNOS activity through cGMP in LPS-activated macrophages by different mechanisms, i.e. reduced binding of NF-KB, the transcription factor responsible for the iNOS expression, and second, acceleration of iNOS mRNA decay. ${ }^{26}$ On the other hand, this effect may be tissue specific as blockade of the NPR-A receptor resulted in inhibition of NF-KB activation by ischemia/reperfusion in coronary arteries. ${ }^{27}$ In addition, ANP also controls iNOS activity by regulating the availability of L-arginine, the substrate for iNOS. ${ }^{28}$ As it has been shown that ANP suppresses the expression of the NPR-A receptor also through cGMP it follows that cGMP signaling in the RPE cells must be highly compartmen- 
talized. $^{29,30}$ Our observations of a punctuate cGMP-IR in the cells after stimulation with ANP, and the punctate staining for the $\beta-1$ subunit and $\alpha-2$ subunit are in agreement with this suggestion. It might also be possible that expression of iNOS and the NPR-A receptor are in an equilibrium state which keeps ANP signaling in the RPE layer at a low level, but high enough to reach a level that controls iNOS expression and thus the endogenous NO concentration at such a low level that the toxic properties of NO will not become a hazard. This hypothesis is shown schematized in figure 5.

In conclusion, our studies show that there are interacting signaling pathways using cGMP as a second messenger in cultured human RPE cells. ANP is present in these cells as well as the NPR-A receptor. The presence of iNOS and the ongoing cGMP synthesis by soluble GC in the RPE cells is causally linked and might be part of a regulatory cGMP dependent mechanism integrating the effects ANP and NO.

Figure 5. cGMP controlled pathways in cultured RPE cells. The amount of iNOS in the cytoplasm, and subsequently the amount of NO synthesized, is negatively controlled by cGMP at the level of $N F k B$ availability as a transcription factor for $i N O S$, at the level of $m R N A$ turnover, and at the level of substrate availability. The expression of the NPR-A is also negatively regulated by cGMP. Presently, we cannot differentiate between the role of $c G M P$ synthesized by $s G C$ or cGMP synthesized by $p G C$.

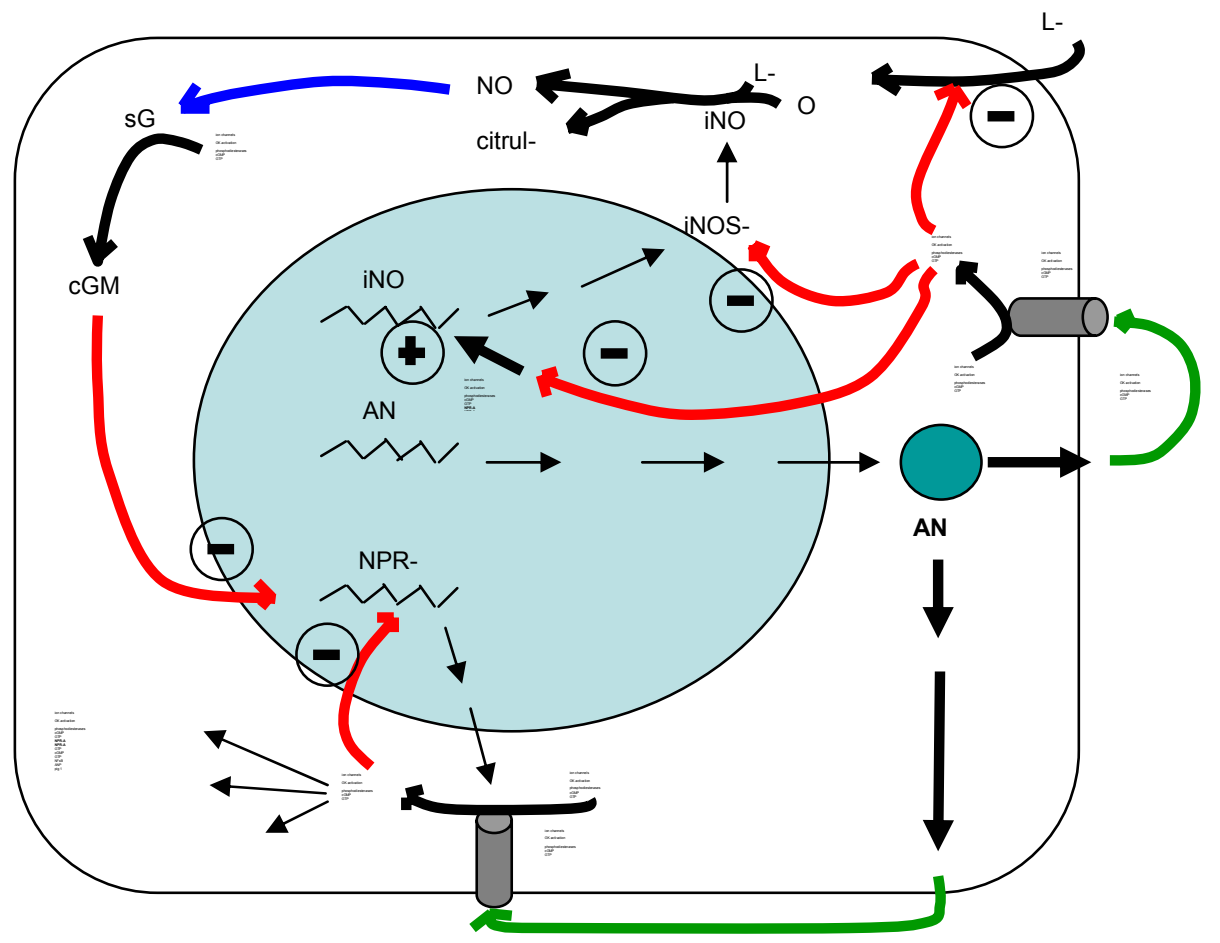




\section{Chapter VII}

\section{LITERATURE}

1 Zinn K. Anatomy of the human retinal pigment epithelium. Harvard University Press, Cambridge, 1979, pp. 3-31.

2 Marmor MF, Negi A. Pharmacologic modification of subretinal fluid absorption in the rabbit eye. Arch Ophthalmol. 1986; 104:1674-1677.

3 La Heij EC, Blaauwgeers HG, de Vente J, Markerink M, Liem AT, Kessels AG, Steinbusch H, Hendrikse F. Decreased levels of cGMP in vitreous and subretinal fluid from eyes with retinal detachment. Br J Ophthalmol. 2003; 87:1409-1412.

4 Denninger JW, Marletta MA. Guanylate cyclase and the .NO/cGMP signaling pathway. Biochim Biophys Acta. 1999; 5:334-50.

5 Friebe A, Koesling D. Regulation of nitric oxide-sensitive guanylyl cyclase. Circ Res 2003;93:96-105.

6 Kogishi JI, Akimoto M, Mandai M, Kuriyama S, Hall MO, Honda Y, Yoshimura N. Nitric oxide as a second messenger in phagocytosis by cultured retinal pigment epithelial cells. Ophthalmic Res. 2000; 32:138-142.

7 Ghiso N, Rohan RM, Amano S, Garland R, Ademis AP. Suppression of hypoxiaassociated vascular endothelial growth factor gene expression by nitric oxide via cGMP. Invest Ophthalmol Vis Sci. 1999;40(6):1033-9.

8 Tamura N, Chrisman TD, Garbers DL. The regulation and physiological roles of the guanylyl cyclase receptors. Endocrine Journal. 2001;48(6):611-634.

9 Fujiseki Y, Omori K, Mikami Y, Suzukawa J, Okugawa G, Uyama M, Inagaki C. Natriuretic peptide receptors, NPR-A and NPR-B, in cultured rabbit retinal pigment epithelium cells. Jpn J Pharmacol. 1999; 79:359-368.

10 Rollin R, Mediero A, Roldan-Pallares M, Fernandez-Cruz A, Fernandez-Durango. Natriuretic peptide system in the human retina. Mol Vis. 2004; 10:15-22.

11 Diederen RM, La Heij EC, Markerink M, Kijlstra A, Hendrikse Fred, De Vente J. Cyclic GMP synthesis by human retinal pigment epithelial cells is mainly mediated via the particulate guanylyl cyclase pathway. Ophthalmic Research 2006; In press.

12 Mikami Y, Hara M, Yasukura T, Uyama M, Minato A, Inagaki C. Atrial natriuretic peptide stimulates Cl- transport in retinal pigment epithelial cells. Curr Eye Res. 1995; 14:391-397.

13 Liversidge J, Grabowski P, Ralston S, Benjamin N, Forrester JV. Rat retinal pigment epithelial cells express an inducible form of nitric oxide synthase and produce nitric oxide in response to inflammatory cytokines and activated T cells. Immunology 1994; 83:404-409.

14 Vasilaki A, Papadaki T, Notas G, Kolios G, Mastrodimou N, Hoyer D, Tsilimbaris M, Kouroumalis E, Pallikaris I, Thermos K. Effect of somatostatin on nitric oxide production in human retinal pigment epithelium cell cultures. Invest Ophthalmol Vis Sci. 2004; 45:1499-1506.

15 Davis AA, Bernstein PS, Bok D, Turner J, Nachtigal M, Hunt RC. A human retinal pigment epithelial cell line that retains epithelial characteristics after prolonged culture. Invest Ophthalmol Vis Sci. 1995; 36:955-964.

16 Garthwaite J, Southam E, Boulton CL, Nielsen EB, Smith K, Mayer B. Potent and selective inhibition of nitric oxide-sensitive guanylyl cyclase by $1 \mathrm{H}-$ (1,2,4)oxadiazolo(4,3-a)quinoxalin-1-one. Mol. Pharmacol. 1995; 48:184-188.

17 Glover V, Medvedev A, Sandler M. Isatin is a potent endogenous antagonist of guanylate cyclase-coupled atrial natriuretic peptide receptors. Life Sci. 1995; 57:2073-2079.

18 De Vente J, Markerink-van Ittersum M, van Abeelen J, Emson PC, Axer H, Steinbusch HW. NO-mediated cGMP synthesis in cholinergic neurons in the rat forebrain: effects of lesioning dopaminergic or serotonergic pathways on nNOS and cGMP synthesis. Eur $\mathbf{J}$ Neurosci. 2000; 12(2):507-19.

19 Bamberger AM, Koglin M, Kempfert J, Loning T, Scholz H, Behrends S. Expression and tissue localization of soluble guanylyl cyclase in the human placenta using novel 
antibodies directed against the alpha(2) subunit. J Clin Endocrinol Metab. 2001; 86:909-912.

20 Behrends S, Kempfert J, Mietens A, Koglin M, Scholz H, Middendorff R. Developmental changes of nitric oxide-sensitive guanylyl cyclase expression in pulmonary arteries. Biochem Biophys Res Commun. 2001; 283:883-887.

21 Hope BT, Michael GJ, Knigge KM, Vincent SR. Neuronal NADPH diaphorase is a nitric oxide synthase. Proc Natl Acad Sci U S A. 1991; 88(7):2811-4.

22 Blute T A, Velasco P, Eldred WD. Functional localization of soluble guanylate cyclase in turtle retina: modulation of cGMP by nitric oxide donors. Vis Neurosci. 1998; 15:485-498.

23 Blute T A, Lee H K, Huffmaster T, Haverkamp S, Eldred WD. Localization of natriuretic peptides and their activation of particulate guanylate cyclase and nitric oxide synthase in the retina. J Comp Neurol. 2000; 424:689-700.

24 Garbers DL, Lowe DG. Guanylyl cyclase receptors. J Biol Chem. 1994; 269:30741-30744.

25 Medvedev A, Bussygyna O, Pyatakova N, Glover V, Severina I. Effect of isatin on nitric oxide-stimulated soluble guanylate cyclase from human platelets. Biochem Pharmacol. 2002;63: 763-766.

26 Kiemer AK, Vollmar AM. Autocrine regulation of inducible nitric-oxide synthase in macrophages by atrial natriuretic peptide. J Biol Chem. 1998; 273(22):13444-13451.

27 Izumi T, Saito Y, Kishimoto I, Harada M, Kuwahara K, Hamanaka I, Takahashi N, Kawakami R, Li Y, Takemura G, Fujiwara H, Garbers DL, Mochizuki S, Nakao K. Blockade of the natriuretic peptide receptor guanylyl cyclase-A inhibits NF-KB activation and alleviates myocardial ischemia/reperfusion injury. J Clin Invest. 2001; 108(2):203-213.

28 Kiemer AK, Vollmar AM. Induction of L-arginine transport is inhibited by atrial natriuretic peptide: a peptide hormone as a novel regulator of inducible nitric-oxide synthase substrate availability. Mol Pharmacol. 2001; 60(3):421-426. Cao L, Wu J, Gardner DG. Atrial natriuretic peptide suppresses the transcription of its guanylyl cyclase-linked receptor. J Biol Chem. 1995; 270:24891-24897.

30 Cao L, Chen SC, Cheng T, Humphreys MH, Gardner DG. Ligand-dependent regulation of NPR-A gene expression in inner medullary collecting duct cells. Am J Physiol. 1998; 275:F119-F125. 



\title{
CHAPTER VIII
}

\section{Selective blockade of Phosphodiesterases Types 2,5 and 9 results in cGMP accumulation in Retinal Pigment Epithelium Cells}

\author{
Br J Ophthalmol. (in press)
}

\author{
Roselie M.H. Diederen ${ }^{1,2}$, Ellen C. La Heij ${ }^{l}$, \\ Marianne Markerink-van Ittersum ${ }^{2}$, Aize Kijlstra ${ }^{l}$, \\ Fred Hendrikse ${ }^{1}$ and Jan de Vente ${ }^{2}$
}

1 Eye Research Institute Maastricht, Department of Ophthalmology, University Hospital Maastricht, The Netherlands

2 European Graduate School of Neuroscience (EURON), Psychiatry and Neuropsychology, University of Maastricht, The Netherlands 



\section{ABSTRACT}

The aim of the current study was to investigate which phosphodiesterases (PDE) are involved in regulating cyclic 3', 5'-guanosine monophosphate (cGMP) breakdown in retinal pigment epithelium (RPE) cells. Cyclic GMP content in the cultured RPE cells (D407 cell line) was evaluated by immunocytochemistry in the presence of non-selective or isoform-selective PDE inhibitors in combination with the particulate guanylyl cyclase stimulator atrial natriuretic peptide (ANP) or the soluble guanylyl cyclase stimulator sodium nitroprusside (SNP). Messenger RNA expression of PDE2, PDE5 and PDE9 was studied in cultured human RPE cells and rat RPE cell layers using nonradioactive in situ hybridisation. In the absence of PDE inhibitors cGMP levels in cultured RPE cells are very low. Cyclic GMP accumulation was readily detected in cultured human RPE cells after incubation with Bay607550 as a selective PDE2 inhibitor, sildenafil as a selective PDE5 inhibitor or Sch51866 as a selective PDE9 inhibitor. In the presence of PDE inhibition, cGMP content strongly increased after stimulation of the particulate guanylyl cyclase. mRNA of PDE2, PDE5 and PDE9 was detected in all cultured human RPE cells and in rat RPE cell layers. In conclusion, our results show that PDE2, PDE5 and PDE9 have a role in cGMP metabolism in RPE cells.

\section{INTRODUCTION}

Cyclic 3', 5'-guanosine monophosphate (cGMP), a central molecule in the phototransduction cascade, ${ }^{1,2}$ is also involved in a number of other physiological processes in the retina. cGMP stimulates the absorption of subretinal fluid by activating the retinal pigment epithelium (RPE) cell pump. ${ }^{3,4} \mathrm{Re}$ cently, we found that retinal detachment was associated with a decrease in the cGMP concentration in the subretinal fluid as compared to controls. ${ }^{5}$ These findings prompted us to investigate the mechanisms involved in retinal cGMP metabolism.

Intracellular concentrations of cGMP represent the net balance between synthesis by guanylyl cyclases and breakdown by 3', 5'- cyclic nucleotide phosphodiesterases (PDEs). ${ }^{6}$ PDEs comprise a large group of enzymes that hydrolyze cyclic adenosine monophosphate (cAMP) and cGMP to their inactive 5 ' -derivates. Eleven different subfamilies of PDE isozymes (PDE1 PDE11) are known. The classification is based on their affinities for cGMP and cAMP, and a number of proteomic and genomic characteristics. ${ }^{7}$ PDE2, PDE5, PDE6, PDE9 and PDE10 are the major cGMP-degrading enzymes. ${ }^{8-12}$ PDE10, which hydrolyzes both cAMP and cGMP, was however not detected in the eye and PDE6 is known to be only present in retinal photoreceptor cells. $^{13,14}$ 


\section{Chapter VIII}

cAMP-hydrolyzing and cGMP-hydrolyzing activities have been detected in homogenates of cultured pigment epithelium from rats. ${ }^{15}$ Although the first papers about PDE activity in RPE cells were already published in the early 1980 's ${ }^{16,17}$ there are no data on the expression of the individual PDE isoforms which have been characterized over the past 10 years. RPE cells are in close contact with the photoreceptor layer and facilitate the supply of necessary substrates, including oxygen, to the photoreceptor cells. We have found that RPE cells are capable of producing cGMP and that most cGMP is generated following stimulation of the particulate guanylyl cyclase pathway and simultaneous non-selective PDE inhibition with 3-isobutyl-1-methylxanthine (IBMX). ${ }^{18}$

The aim of the current study was to identify the PDE isoforms involved in the cGMP breakdown in RPE cells. To investigate PDE activity in RPE cells, we studied cGMP accumulation in the RPE cells after stimulating particulate guanylyl cyclase (pGC) or soluble guanylyl cyclase (sGC) in the presence of PDE inhibitors with different selection properties. We used IBMX as a non-specific PDE inhibitor, Bay 60-7550 as a selective PDE2 inhibitor, ${ }^{19}$ sildenafil as a selective PDE5 inhibitor and, Sch51866 as a selective PDE9 inhibitor. ${ }^{20}$ In addition, mRNA expression of PDE2, PDE5 and PDE9 was studied in cultured human RPE cells using non radioactive in situ hybridisation. As it is impossible to detect the in situ hybridisation signal in pigmented RPE cells we studied the in vivo situation by analysing the mRNA expression of PDE2, PDE5 and PDE9 in the unpigmented RPE cell layer of albino Lewis rats.

Our results indicate that PDE2, PDE5 and PDE9 are present in cultured human RPE cells and rat RPE cell layers, and that these different PDE isoforms have a role in controlling cGMP levels in RPE cells.

\section{METHODS}

\section{Cell Culture}

Human retinal pigment epithelial cells (D407 cell line) ${ }^{21}$ were suspended in Dulbecco's modified Eagle's medium containing 5\% fetal calf serum, $2 \mathrm{mM}$ glutamine and $100 \mu \mathrm{g} / \mathrm{ml}$ penicillin streptomycin, at a concentration of $0.5-$ $1.0 \times 106$ viable cells $/ \mathrm{ml}$. Portions of the suspension $(1 \mathrm{ml})$ were seeded on to $40 \mathrm{~mm}$ diameter plastic Petri-dishes and incubated at $37^{\circ} \mathrm{C}$ in a humidified atmosphere of $95 \%$ air and $5 \% \mathrm{CO}^{2}$.

\section{Pharmacology}

Twenty four hours after seeding, the subconfluent RPE cells were incubated for 40 minutes in aerated Krebs buffer ( $\mathrm{pH} 7.4$ ) with or without the following compounds: $1 \mathrm{mM}$ IBMX (non-specific PDE inhibitor;Sigma), $1.0 \mu \mathrm{M}$ 
Bay 60-7550 (selective PDE2 inhibitor), ${ }^{19} 10 \mu \mathrm{M}$ sildenafil (selective PDE5 inhibitor), and $10 \mu \mathrm{M}$ Sch51866 (selective PDE9 inhibitor). ${ }^{13}$ During the last ten minutes of the incubation the cells were stimulated with $100 \mu \mathrm{M}$ of the NO donor sodium nitroprusside (SNP) or $0.1 \mu \mathrm{M}$ atrial natriuretic peptide (ANP).

\section{Immunohistochemistry}

After fixation with $4 \%$ freshly depolymerized paraformaldehyde in the cold $\left(4{ }^{\circ} \mathrm{C}\right)$, the cells were washed $3 \times 5 \mathrm{~min}$, twice with Tris-buffered saline (TBS) and once with TBS containing $0.3 \%$ Triton X-100 (TBS-T). Cells were incubated overnight at $4{ }^{\circ} \mathrm{C}$ with the primary antibodies. cGMP was visualized using sheep polyclonal anti-formaldehyde-fixed cGMP antiserum diluted 1:4000 in TBS-T. ${ }^{22}$ Cells were washed for 15 minutes with TBS, TBS-T and TBS, respectively. Then the cells were incubated with Alexa 488 conjugated donkey anti-sheep IgG (Molecular Probes) diluted 1:100 in TBS$\mathrm{T}$ for 1.5 hours at room temperature. Negative controls were processed in exactly the same way with the omission of the primary antibody. After three further washings with TBS, the cells were cover-slipped with TBS/glycerol $(1: 2 \mathrm{v} / \mathrm{v})$.

\section{Rats}

Adult male Lewis rats (200-240 g) were reared under standard conditions and were cared for in accordance with the guidelines of the Association for Research in Vision and Ophthalmology Statement for the use of animals in ophthalmic and vision research. The animals were decapitated and their eyes were immediately frozen. Frozen sections of $10 \mu \mathrm{m}$ were cut en kept at $80^{\circ} \mathrm{C}$ until the experiment was completed.

\section{In Situ Hybridisation of PDE2, PDE5 and PDE9}

In situ hybridisation was performed with digoxigenin (DIG) labeled RNA probes as described previously. ${ }^{23}$ Frozen sections were thawed for 10 minutes at $50^{\circ} \mathrm{C}$ and thereafter fixed with $4 \%$ paraformaldehyde in $0.1 \mathrm{M}$ phosphate buffer for 20 minutes at room temperature. The RPE cells were fixed with $4 \%$ paraformaldehyde in $0.1 \mathrm{M}$ phosphate buffer for 30 minutes at $4{ }^{\circ} \mathrm{C}$. Then the samples (sections and cells) were washed shortly with PBS and incubated for 10 minutes with $0.1 \mathrm{M}$ triethanolamine (TEA) containing $0.25 \%$ acetic anhydride. Samples were washed two times with $2 \mathrm{x}$ SSC and thereafter washed at $37^{\circ} \mathrm{C}$ with $2 \mathrm{x}$ SSC containing $50 \%$ formamide. Hybridisation was performed overnight in a humid chamber at $55^{\circ} \mathrm{C}$ under cover slips in 100-200 $\mu$ l hybridisation mix $(50 \%(\mathrm{v} / \mathrm{v})$ deionised formamide, $250 \mu \mathrm{g} / \mathrm{ml}$ salmon sperm DNA, $1 \mathrm{mg} / \mathrm{ml}$ tRNA, $10 \%$ dextran sulfate, $2 x$ SSC, 1x Denhardt's solution and $200 \mathrm{ng} / \mathrm{ml}$ DIG-labeled RNA probe. After hybridisation, the samples were washed in $2 \mathrm{x}$ SSC, $1 \mathrm{x}$ SSC and $0.1 \mathrm{x}$ SSC, all solutions containing $50 \%$ formamide. Each wash step was performed at $55^{\circ} \mathrm{C}$ for 20 


\section{Chapter VIII}

minutes. Next, the samples were treated with RNAse T1 $2 \mathrm{U} / \mathrm{ml}$ (Roche) in $2 \mathrm{x}$ SSC containing $1 \mathrm{mM}$ EDTA for 15 minutes at $37^{\circ} \mathrm{C}$, followed by a 20 min wash with $1 \mathrm{x}$ SSC and a 10 min wash with $2 \mathrm{x}$ SSC. The samples were then incubated for 5 min with buffer $1(0.15 \mathrm{M} \mathrm{NaCl}$ and $0.1 \mathrm{M}$ maleic acid (pH 7.5)) followed by blocking for $2 \mathrm{hr}$ at RT with buffer $2(0.15 \mathrm{M} \mathrm{NaCl}$, $0.1 \mathrm{M}$ maleic acid (pH 7.5) and 1\% blocking reagent (Roche, \#1096176)) containing 5\% sheep serum. Next, samples were incubated overnight with a 1:2000 dilution of anti-DIG-alkaline phosphatase (Roche) in buffer 2 containing $1 \%$ sheep serum. Thereafter, samples were washed 3 times with buffer 1 , followed by washing for $10 \mathrm{~min}$ with TBS containing $0.025 \%$ Tween 20 and thereafter, three times 5 min with TBS. After two washes in buffer $3\left(\left(0.1 \mathrm{M}\right.\right.$ Tris- $\mathrm{HCl}(\mathrm{pH} 9,5), 0.1 \mathrm{M} \mathrm{NaCl}$ and $\left.0.05 \mathrm{M} \mathrm{MgCl}^{2}\right)$, the samples were incubated with freshly prepared nitro-blue tetrazolium and 5-bromo-4-chloro-3-indolyl-phosphate in buffer $4(0.05 \mathrm{M}$ Tris $(\mathrm{pH} 9,5)$ $0.1 \mathrm{M} \mathrm{NaCl}, 6 \%$ polyvinylalcohol, $0.05 \mathrm{M} \mathrm{MgCl}^{2}, 1 \mathrm{mM}$ levamisole) and stained overnight in the dark at $25^{\circ} \mathrm{C}$. The color reaction was stopped with 0.01 M Tris-HCl -1 mM EDTA (pH 8.0).

\section{Quantification of Immunostainings}

Immunostainings were examined using an Olympus AX70 microscope equipped with a cooled charge couple devices Olympus F-view camera. Experiments were repeated three times. From each incubation setting, six images were made randomly chosen. Each image contained at least 50 RPE cells. Fluorescence intensities were converted into gray values (AnalySIS ${ }^{\circledR}$, Softimaging system, $\mathrm{GmbH}$ ) ranging from 0 (blank) to 4096 (white). After establishing a threshold setting using a blank preparation incubated with the secondary antibody only, five classes with increasing gray values were set as 0 - 300 (blank), 301 - 600, 601 - 1500, 1501 - 2700 and 2701 - 4096. All cells were classified according to the highest gray value they were demonstrating (Table 1). The mean percentage of cells in each class was calculated of the 6 images made of each incubation setting. Thereafter the mean percentage was calculated for the three experiments. The distributions of the cells over the different classes were analysed using the chi-square test.

\section{RESULTS}

\section{Effect of PDE inhibition on cGMP levels in cultured human RPE cells}

In unstimulated cells incubated without PDE inhibition, a low level of cGMP immunoreactivity was visualized in the cells (Table 1; Figure 2a). Hardly any differentiation in the intensity of the cGMP-immunofluorescence was present. Addition of $1 \mathrm{mM}$ IBMX to the incubation medium resulted in a general increase in the intensity of the cGMP immunostaining. We also ob- 
served more differentiation in the intensity of the cGMP immunofluorescence compared to incubation without PDE inhibition (Table 1).

Table 1. cGMP fluorescence intensity in human RPE cells after incubation with different PDE inhibitors and guanylyl cyclase stimulation. Individual cells were grouped in defined gray value classes. Numbers are the means of 3 experiments (6 pictures per incubation in each experiment were taken) and express the percentage of cells in each intensity class.

\begin{tabular}{|c|c|c|c|c|c|c|}
\hline \multirow{2}{*}{\multicolumn{2}{|c|}{ Treatment }} & \multicolumn{5}{|c|}{ Gray Values } \\
\hline & & $n$ & $300-600$ & $600-1500$ & $1500-2700$ & $2700-4095$ \\
\hline \multirow[t]{3}{*}{ control } & & 3 & 95 & 5 & 0 & 0 \\
\hline & + SNP & 3 & 87 & 13 & 0 & 0 \\
\hline & + ANP & 3 & 95 & 5 & 0 & 0 \\
\hline \multirow[t]{3}{*}{ IBMX } & & 3 & 65 & 24 & 11 & 0 \\
\hline & $+\mathrm{SNP}$ & 3 & 64 & 34 & 2 & 0 \\
\hline & $+\mathrm{ANP}^{*}$ & 3 & 22 & 39 & 32 & 7 \\
\hline \multirow[t]{3}{*}{ Sildenafil } & & 3 & 91 & 9 & 0 & 0 \\
\hline & + SNP & 3 & 96 & 4 & 0 & 0 \\
\hline & $+\mathrm{ANP}^{*}$ & 3 & 18 & 60 & 10 & 12 \\
\hline \multirow[t]{3}{*}{ BAY 60-7550 } & & 3 & 99 & 1 & 0 & 0 \\
\hline & $+\mathrm{SNP}$ & 3 & 86 & 14 & 0 & 0 \\
\hline & $+\mathrm{ANP}^{*}$ & 3 & 1 & 88 & 5 & 6 \\
\hline \multirow[t]{3}{*}{ Sch51866 } & & 3 & 99 & 1 & 0 & 0 \\
\hline & + SNP & 3 & 93 & 7 & 0 & 0 \\
\hline & $+\mathrm{ANP}^{*}$ & 3 & 40 & 46 & 14 & 0 \\
\hline
\end{tabular}

* $\quad \mathrm{P}<0.001$ when compared to control + ANP.

Incubation of the cells without stimulation of $\mathrm{sGC}$ or pGC, although in the presence of Bay 60-7550 (PDE2 inhibitor), sildenafil (PDE5 inhibitor), and Sch51866 (PDE9 inhibitor), did not increase cGMP immunoreactivity compared to incubation without PDE inhibition (Table 1).

Exposure of RPE cells to $0.1 \mu \mathrm{M}$ ANP in combination with BAY60-7550, sildenafil or Sch51866 did result in a strong increase in cGMP immunoreactivity in a large number of cells (Figures 1 and 2). Figures 1 and 2 show that the effect of sildenafil and IBMX are quite similar, both with a number of cells in the highest grey value intensity class. The effect of Bay-60-7550 is more homogenous in all cells, resulting in $88 \%$ of the cells in the second grey value intensity class. The distribution of GMP throughout the cytoplasm is not homogeneous but seemed to be compartmentalized in many cells (Figure 2). This holds true for all three PDE inhibitors. These results 
show that Bay 60-7550, sildenafil and Sch51866 were able to inhibit PDE activity. We found no major significant stimulating effect of SNP on cGMP synthesis in the presence of all three PDE inhibitors.

Figure 1. cGMP fluorescence intensity in human RPE cells after incubation with different PDE inhibitors and guanylyl cyclase stimulation with $0.1 \mu M$ ANP. Individual cells were grouped in defined gray value classes. Numbers are the means of 3 experiments (6 pictures per incubation in each experiment were taken) and express the percentage of cells in each of 4 intensity classes.

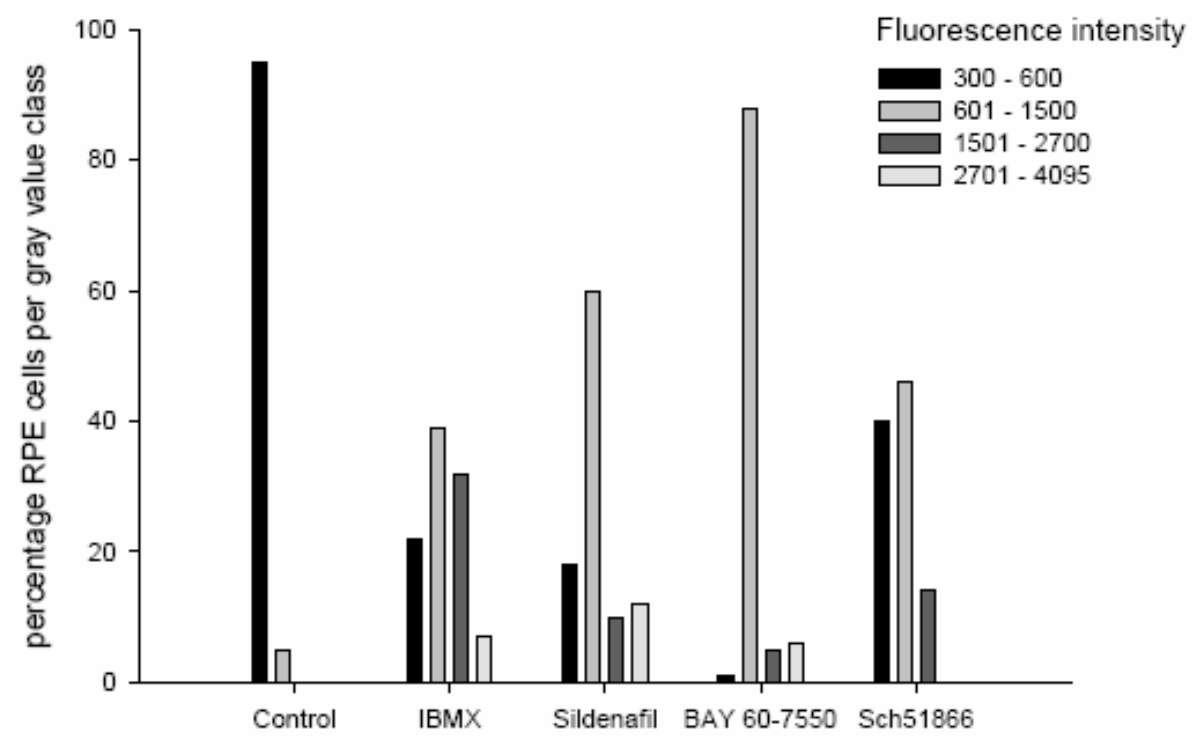

\section{mRNA expression}

Non-radioactive in situ hybridisation was used to study the mRNA expression patterns of PDE2, PDE5 and PDE9. RPE cells were hybridised with antisense and sense probes from these three different PDE families. In human RPE cell cultures PDE2, PDE5 and PDE9 mRNAs were detected in all cells and most of the mRNA is visualized concentrated around the nucleus (Figure $3)$. Control sections hybridized with sense probes did not show any specific staining.

In addition, also rat RPE cell layers were hybridised with antisense and sense probes from PDE2, PDE5 and PDE9, and mRNA of PDE2, PDE5 and PDE9 was shown to be present (Figure 4). The in situ hybridisation signal was present in all RPE cells almost to the same extent. Control sections hybridised with sense probes did not show any specific staining. 
Figure 2. Cyclic GMP immunoreactivity in human RPE cell. $\boldsymbol{A}$ Without PDE inhibition. B,E, Combination of $1.0 \mu M$ BAY 60-7550, and 0.1 $\mu$ M ANP. C,F, Combination of $10 \mu M$ sildenafil and $0.1 \mu M$ ANP. D Combination of $10 \mu M$ Sch51866 and $0.1 \mu M$ ANP. Sections incubated without primary antibody show no cGMPimmunoreactivity (not shown). Pictures are not taken from the same experiment. Scale bar is $100 \mu \mathrm{m}$ in picture $B, C$ and $D, 50 \mu \mathrm{m}$ in picture $A, E$ and $F$.
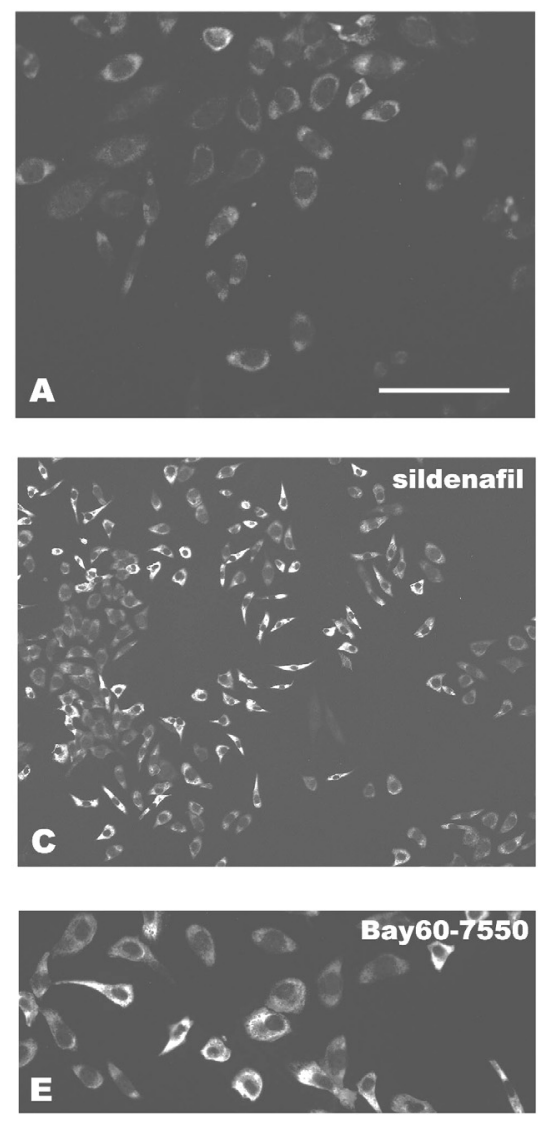
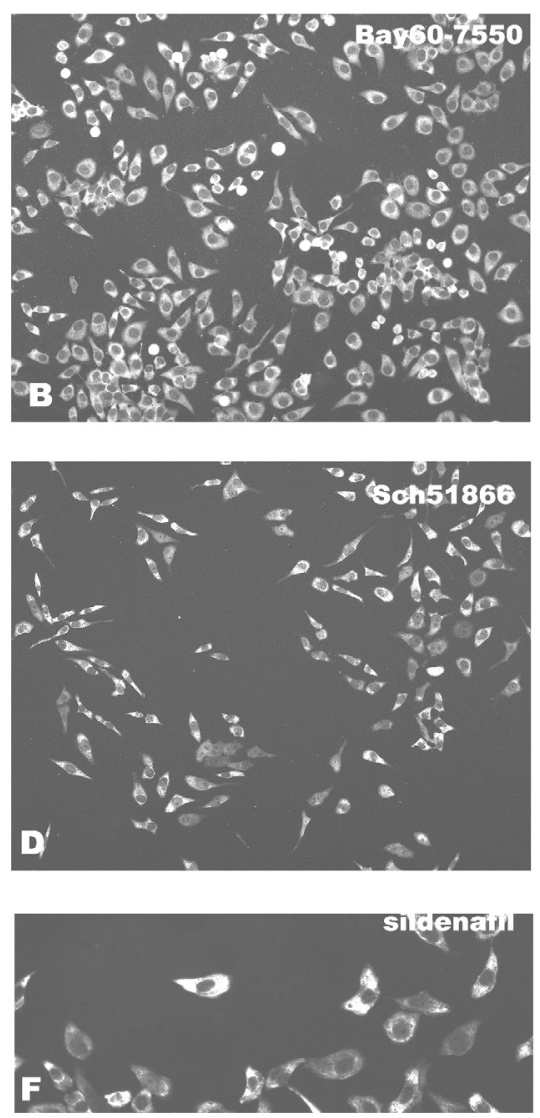

Figure 3. In situ hybridisation of PDEs 2, 5 and 9 in human RPE cells. A Localization of PDE2 mRNA. B Localization of PDE5 $m R N A$. C Localization of PDE9 $m R N A$. D Hybridisation with the sense probe of PDE9. Scale bar is $100 \mu \mathrm{m}$.
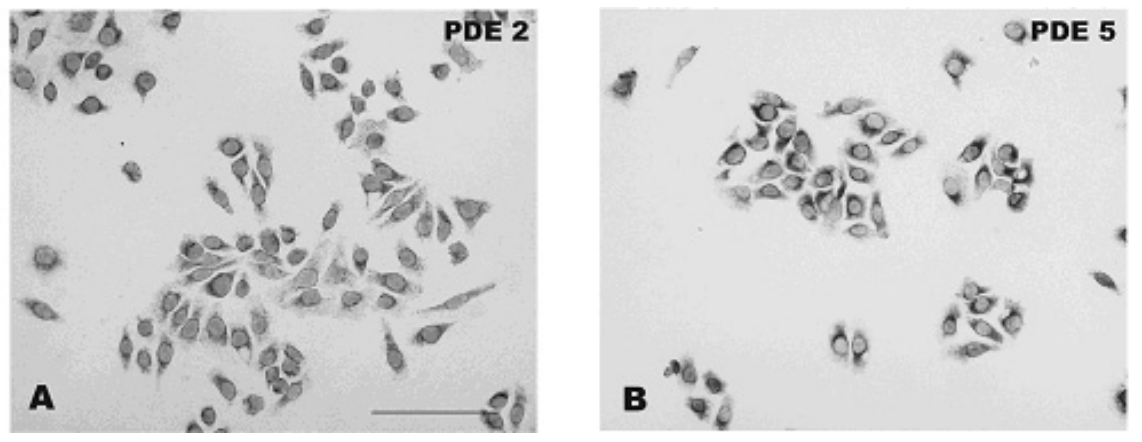
Figure 3 (continued). In situ hybridisation of PDEs 2, 5 and 9 in human RPE cells. C Localization of PDE9 $\mathrm{mRNA}$. D Hybridisation with the sense probe of PDE9.
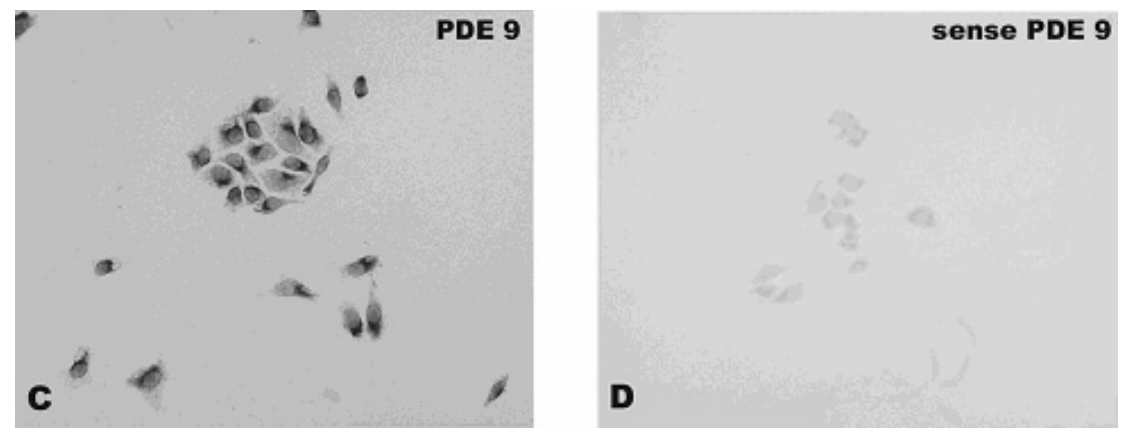

Figure 4. In situ hybridisation of PDEs 2, 5 and 9 rat RPE cell layers. A Localization of PDE2 mRNA. B Localization of PDE5 mRNA. C Localization of PDE9 $m R N A$. D Hybridisation with the sense probe of PDE9. * $=R P E$ cell layer. Scale bar is $100 \mu \mathrm{m}$ in picture $A, B$ and $D, 50 \mu m$ in picture $C$.
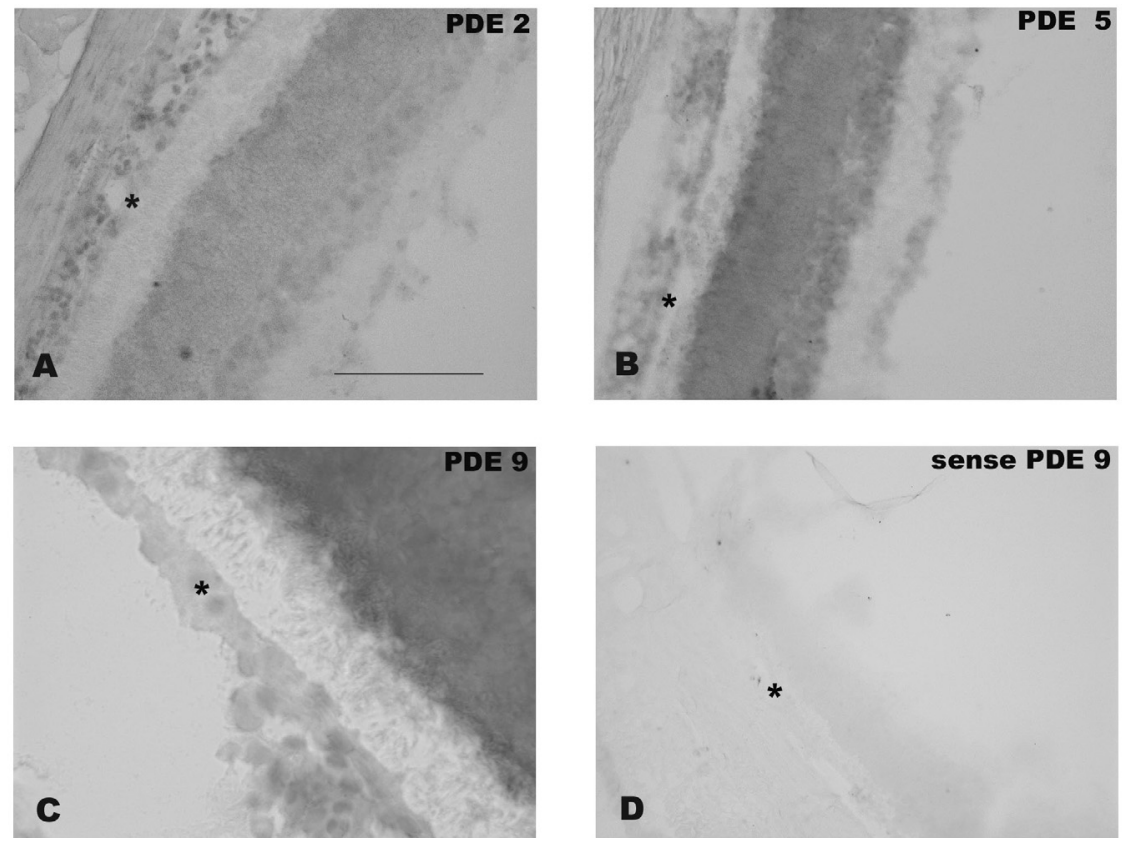

\section{DISCUSSION}

We investigated the contribution of three isoforms of the PDE family of enzymes in controlling cGMP levels in human RPE cell cultures. Data obtained by using selective PDE inhibitors in combination with cGMP immunocytochemistry indicate that at least PDE2, PDE5 and PDE9 are present in cultured human RPE cells. This was confirmed by the presence of mRNA of 
PDE2, PDE5 and PDE9 in the human RPE cells and rat RPE cell layers studied by using in situ hybridisation. These three different PDE isoforms seem to be involved in controlling cGMP levels in RPE cells, as PDE10 was found not to be present in the eye. ${ }^{13}$ Differences in mRNA expression between cells might be caused by cells being in a different cells cycle phase. Therefore, it is not surprising that a similar difference in the localisation of cGMP immunocytochemistry was observed in the cells, irrespective of the PDE inhibitor being present during the incubation.

PDE2 has an almost equal affinity for cGMP and cAMP. However, cAMP hydrolysis is greatly stimulated by low levels of cGMP. ${ }^{14}$ The compound Bay 60-7550 is a highly selective inhibitor of PDE2 and more potent than erythro -9-(2-hydroxy-3-nonyl) adenine (EHNA), which is generally used as a PDE2 inhibitor. ${ }^{19}$ In addition, in contrast to EHNA, Bay 60-7550 is devoid of adenosine deaminase activity. ${ }^{19}$

PDE5 has been implicated in the control of vascular resistance. ${ }^{14}$ Also in the retina PDE5 has been shown to have a possible role in the regulation of retinal blood flow. ${ }^{24}$ Sildenafil, a relatively selective inhibitor for PDE5 also weakly inhibits PDE6, an enzyme involved in the process of phototransduction, with an efficacy of $1 / 10$ of that for PDE5. ${ }^{25}$ A single oral dose of $100 \mathrm{mg}$ sildenafil has been shown to cause impaired photoreceptor function, which is being attributed to weak inhibition of PDE6 by sildenafil. ${ }^{26,27}$ To date, PDE6 is known to be only present in retinal photoreceptor cells. ${ }^{14}$

As PDE9 has the highest affinity for cGMP of all the mammalian PDEs, this enzyme can have a fundamental role in keeping cGMP at a low basal level. ${ }^{9}$ In contrast to the other PDEs, PDE9 is not inhibited by IBMX. ${ }^{11,13}$ Sch51866 is a somewhat selective inhibitor of PDE9 as it also weakly inhibits PDE5, with an efficacy of $1 / 15$ of that for PDE9.$^{20}$ So the effect of Sch51866 on the cGMP immunoreactivity in the current study can not be solely attributed to inhibition of PDE9.

Using in situ hybridisation, we showed the presence of PDE2, PDE5 and PDE9 mRNA in RPE cells, but this is not a quantitative technique. The immunohistochemistry data clearly show that a combination of sildenafil and ANP results in the largest percentage of cells in the highest gray value intensity class compared to other incubation settings. This may indicate a prominent role of PDE5 in cGMP breakdown in RPE cells.

The D407 cell line was shown to retain many of the metabolic and morphologic characteristics of RPE cells in vivo, although there are some minor differences. ${ }^{21}$ Given our results, it may be concluded that the expression of PDE2, PDE5 and PDE9 is similar in the D407 cell line compared to rat RPE cells in vivo. 
The major function for PDEs in the cell is to terminate the amplitude and duration of the cyclic nucleotide second messenger signal. ${ }^{14}$ As shown previously, retinal detachment is associated with a decrease in the cGMP concentration in the subretinal fluid. ${ }^{5}$ Hypoxia due to retinal detachment may cause a reduced activity of guanylyl cyclases which produce cGMP. This could lead to a reduced expression of cGMP by retinal cells after retinal detachment. By knowing the specific PDE families located in retinal cells these enzymes could in the future become therapeutic targets in order to limit cGMP breakdown by using selective PDE inhibitors. Clinically, this could be important as cGMP is known for its stimulating role in the reabsorption of subretinal fluid by activating the RPE pump.,4

In conclusion, our studies show that there is a complex regulation of cGMP synthesis in RPE cells. The three PDE isoforms, PDE2, PDE5 and PDE9, are involved in the breakdown of cGMP in these cells. This process of controlling cGMP levels might have a role in the regulation of fluid absorption from the subretinal space by RPE cells. 


\section{LITERATURE}

1 Baylor DA. Photoreceptor signals and vision. Proctor lecture. Invest Ophthalmol Vis Sci. 1987; 28, 34-49.

2 Yamazaki A, Moskvin O, Yamazaki RK. Phosphorylation by cyclin-dependent protein kinase 5 of the regulatory subunit (Pgamma) of retinal cgmp phosphodiesterase (PDE6): its implications in phototransduction. Adv Exp Med Biol. 2002; 514, 131-153.

3 Marmor MF, Negi A. Pharmacologic modification of subretinal fluid absorption in the rabbit eye. Arch Ophthalmol . 1986; 104, 1674-1677.

4 Marmor MF. Control of subretinal fluid: Experimental and clinical studies. Eye. 1990; 4, 340-344.

5 La Heij EC, Blaauwgeers HG, de Vente J, Markerink M, Liem AT, Kessels AG, SteinbuschH, HendrikseF. Decreased levels of cGMP in vitreous and subretinal fluid from eyes with retinal detachment. Br J Ophthalmol. 2003; 87, 1409-1412.

6 Francis SH, Corbin JD. Cyclic nucleotide-dependent protein kinases: intracellular receptors for cAMP and cGMP action. Crit Rev Clin Lab Sci. 1999; 36, 275-328.

7 Beavo JA, Conti M, Heaslip RJ. Multiple cyclic nucleotide phosphodiesterases. Mol Pharmacol. 1994; 46, 399-405.

8 Gillespie PG, Beavo JA. Characterization of a bovine cone photoreceptor phosphodiesterase purified by cyclic GMP-sepharose chromatography. J Biol Chem. 1988; 263:8133-41.

9 Thomas MK, Francis SH, Corbin JD. Characterization of a purified bovine lung cGMPbinding cGMP phosphodiesterase. J Biol Chem. 1990; 265:14964-70.

10 Sonnenburg WK, Mullaney PJ, Beavo JA. Molecular cloning of a cyclic GMP-stimulated cyclic nucleotide phosphodiesterase cDNA. Identification and distribution of isozyme variants. J Biol Chem. 1991; 266:17655-61.

11 Fisher DA, Smith JF, Pillar JS, St Denis SH, Cheng JB. Isolation and characterization of PDE9A, a novel human cGMP-specific phosphodiesterase. J Biol Chem. 1998; 19:15559-64.

12 Fujishige K, Kotera J, Michibata H, Yuasa K, Takebayashi S, Okamura K, Omori K. Cloning and characterization of a novel human phosphodiesterase that hydrolyzes both cAMP and cGMP (PDE10A). J Biol Chem. 1999; 274:18438-45.

13 Soderling SH, Bayuga SJ, Beavo JA. Isolation and characterisation of a dual-substrate phosphodiesterase gene family: PDE10A.Proc. Natl. Acad. Sci USA.1999; 96:7071-7076.

14 Beavo JA. Cyclic nucleotide phosphodiesterases: functional implications of multiple isoforms. Physiol. Rev. 1995; 75:725-748.

15 Kurtz MJ, Edwards RB, Schmidt SY: Cyclic nucleotide phosphodiesterases in cultured normal and RCS rat pigment epithelium: kinetics of cyclic AMP and cyclic GMP hydrolysis. Exp Eye Res. 1987; 45(1):67-75.

16 Miller S, Farber D. Cyclic AMP modulation of ion transport across frog retinal pigment epithelium. Measurements in the short-circuit state. J Gen Physiol. 1984; 83:853-74.

17 Sanyal A, Fletcher R, Liu YP, Aguirre G, Chader G. Cyclic nucleotide content and phosphodiesterase activity in de rds mouse (020/A) retina.

Exp Eye Res. 1984; 38:247-256.

18 Diederen RMH, La Heij EC, Markerink-van Ittersum M, Kijlstra A, Hendrikse F, De Vente J. Cyclic GMP synthesis by human retinal pigment epithelial cells is mainly mediated via the particulate guanylyl cyclase pathway. Ophthalmic Res. 2007; 39:55-59.

19 Boess FGHM, Hendrix M. van der Staay FJ, Erb C, Schreiber R, van Staveren W, De Vente J, Prickaerts J, Blokland A, Konig G. Inhibition of phosphodiesterase 2 increases cGMP neuronal plasticity and memory performance. Neuropharmacoloy. 2004; 47:1081-92.

20 Soderling SH, Bayuga SJ, Beavo JA. Identification and characterization of a novel family of cyclic nucleotide phosphodiesterases. J Biol Chem. 1998; 273(25):15553-8. 


\section{Chapter VIII}

21 Davis AA, Bernstein PS, Bok D, Turner J, Nachtigal M, Hunt RC. A human retinal pigment epithelial cell line that retains epithelial characteristics after prolonged culture. Invest Ophthalmol Vis Sci.1995; 36:955-64.

22 De Vente J, Steinbusch HW. On the stimulation of soluble and particulate guanylate cyclase in the rat brain and the involvement of nitric oxide as studied by cGMP immunocytochemistry. Acta Histochem. 1992; 92, 13-38.

23 Van Staveren WC, Steinbusch HW, Markerink-Van Ittersum M, Repaske DR, Goy MF, Kotera J, Omori K, Beavo JA, De Vente J. mRNA expression patterns of the cGMPhydrolyzing phosphodiesterases types 2,5 , and 9 during development of the rat brain. $\mathrm{J}$ Comp Neurol. 2003; 467, 566-580.

24 Pache M, Meyer P, Prünte C, Orgül S, Nuttli I, Flammer J. Sildenafil induces retinal vasodilatation in healthy subjects . British Journal of Ophthalmology 2002; 86:156-158.

25 Ballard SA, Gingell CJ, Tang K, Turner LA, Price ME, Naylor AM. Effects of Sildenafil on the relaxation of human corpus cavernosum tissue in vitro and on the activities of cycylic nucleotide phosphodiesterase isozymes. J Urol 1998; 159:2164-71.

26 Vobig MA, Klotz T, Staak M, Bartz-Schmidt KU, Engelman U, Walter P. Retinal sideeffects of Sildenafil. The Lancet. 1999; 353:375.

27 Vobig MA. Retinal side-effects of Sildenafil. The Lancet. 1999; 353:1442. 




\title{
CHAPTER IX
}

\section{Cyclic GMP in the pig vitreous and retina after experimental retinal detachment}

\author{
Submitted
}

\author{
Roselie M.H. Diederen ${ }^{l}, 2$, Ellen C. La Heij ${ }^{l}$, \\ Marijke A.M. Lemmens ${ }^{2}$, Aize Kijlstra', \\ Jan de Vente ${ }^{2}$ and Fred Hendrikse ${ }^{l}$
}

1 Eye Research Institute Maastricht, Department of Ophthalmology, University Hospital Maastricht, The Netherlands

2 European Graduate School of Neuroscience (EURON), Psychiatry and Neuropsychology, University of Maastricht, The Netherlands 



\section{ABSTRACT}

Earlier studies have shown a decreased level of cyclic 3', 5'-guanosine monophosphate (cGMP) in vitreous fluid of patients with retinal detachment. The mechanisms causing this decrease and the biological significance are unknown and were therefore the subject of the current study. Experimental retinal detachments were created in pig eyes and vitreous and retinas were analyzed for cGMP expression. After enucleation, the retinas were incubated in the presence of a non-selective phosphodiesterase inhibitor, and the particulate guanylyl cyclase stimulator atrial natriuretic peptide (ANP) or the soluble guanylyl cyclase stimulator sodium nitroprusside (SNP). Cyclic GMP was visualized in retinal wholemounts by immunochemistry. Cyclic GMP levels in vitreous were determined by ELISA. Cyclic GMP was also measured in vitreous of patients suffering from rhegmatogenous retinal detachment to compare cGMP concentrations between pigs and humans. The mean vitreous cGMP level in pig eyes after retinal detachment (1.45 $\mathrm{pmol} / \mathrm{ml}$ ) was significantly lower compared to the mean level of cGMP in healthy pig eyes $(4.61 \mathrm{pmol} / \mathrm{ml})(\mathrm{P}=0.028)$. No difference in vitreous cGMP level was found between human $(1.10 \mathrm{pmol} / \mathrm{ml})$ and pig eyes with retinal detachment $(P=0.30)$. In the inner retina, both ANP and SNP induced cGMP immunoreactivity in the detached and healthy retina. After incubation with ANP, cGMP could also be detected in the outer nuclear layer of the detached retina, whereas this was not the case in the normal retina. The presence of cGMP in vitreous and its decrease after retinal detachment may indicate a potential regulatory role in the physiologic responses of the retina after detachment.

\section{INTRODUCTION}

A retinal detachment occurs when the photoreceptor layer and the retinal pigment epithelium separate. A retinal detachment often causes blindness if left untreated. But even when reattachment surgery is successful, a reattached retina rarely regains normal sensitivity or acuity. ${ }^{1-3}$ This may be due to irreversible damage to the retina, caused by hypoxia and/or ischemia of retinal cells, like photoreceptor cells and Müller cells.,

Cyclic 3', 5'-guanosine monophosphate (cGMP) can modulate several aspects of retinal physiology, besides its role in phototransduction. Cyclic GMP analogues were shown to increase the rate of fluid absorption from the subretinal space by $33 \%$ in rabbits with experimental retinal detachment. ${ }^{5}$ It has also been shown that cGMP analogues or nitric oxide (NO) donors reduce the gap-junction coupling of amacrine cells with cone bipolar cells. ${ }^{6}$ In retinal pigment epithelium (RPE) cells, cGMP has been implicated in stimulation of $\mathrm{Cl}$ - transport, suppression of hypoxia-associated vascular endothe- 


\section{Chapter IX}

lial growth factor (VEGF) gene expression, and phagocytosis of rod outer segments. ${ }^{7-9}$ In photoreceptor cells, the NO-cGMP signaling pathway is active in the regulation of the structural plasticity of cone and rod cells. ${ }^{10}$

Two different enzymes catalyze the conversion of the substrate guanosine '5-triphosphate (GTP) into cGMP. These enzymes are called the particulate (membrane-bound) and soluble (cytosolic) cyclases based on their general structure and cellular distribution, of which there are several isoforms known of each class. Soluble guanylyl cyclase (sGC) is activated by NO. In the retina, increasing tissue levels of NO by incubation with the NO donor sodium nitroprusside (SNP), result in increased cGMP immunoreactivity in amacrine, ganglion and bipolar cells. ${ }^{11,12}$ Membrane bound or particulate guanylyl cyclases (pGC) are either ligand-activated receptors (e.g. natriuretic peptides), or calcium-regulated (retGC). ${ }^{12}$ In turtle and rat retina, stimulation with exogenous natriuretic peptides increased total retinal cGMP levels. ${ }^{7,12}$ All three natriuretic peptides, atrial natriuretic peptide (ANP), brain natriuretic peptide (BNP), and C-type natriuretic peptide (CNP) have been observed in human ganglion and RPE cells. ${ }^{13}$ In situ hybridisation analysis in monkey eyes showed retGC transcripts to be localized exclusively along the retinal outer nuclear layer, corresponding to the nuclei of the rod and cone photoreceptor cells. ${ }^{14}$ Reports comparing both enzymatic pathways involved in the cGMP production in the rat retina show that the NO-cGMP pathway (via soluble guanylyl cyclase) exists dominantly in the inner nuclear layer and the ANP-cGMP pathway (via particulate guanylyl cyclase) exists dominantly in the rod photoreceptors. ${ }^{6,7,12,15}$

Cyclic GMP is hydrolyzed to inactive 5' -derivates by 3', 5'-cyclic nucleotide phosphodiesterases (PDE's) of which eleven different subfamilies of PDE isozymes (PDE1 - PDE11) have been classified. The major function for PDEs in the cell is to diminish the amplitude and terminate the duration of the cyclic nucleotide second messenger signal. ${ }^{16}$

The increased rate of fluid absorption from the subretinal space indicates a possible role for cGMP in the clearance of subretinal fluid after retinal detachment. ${ }^{5}$ The involvement of cGMP in retinal detachment was furthermore suggested by a previous study, in which we observed a decreased level of cGMP in vitreous and subretinal fluid of patients with retinal detachment. ${ }^{17}$ Moreover, a significant decrease was found in the mean subretinal cGMP levels when the retinal detachment existed longer. The source of cGMP in vitreous fluid is unknown, as is the reason for the decrease in cGMP concentration after retinal detachment. Because of energy and oxygen deprivation due to the separation of the retina, the expression, release and metabolism of cGMP may be reduced. The aim of the current study was to investigate whether the findings observed during clinical retinal detachment could be reproduced in an animal model. Further analysis of cGMP expression in the 
retina might provide an explanation for the mechanisms involved in the changes occurring during detachment.

\section{MATERIALS AND METHODS}

\section{Retinal Detachments}

Dutch domestic female pigs (Dutch landrace; 28 - $33 \mathrm{Kg}$ in weight; 3 months old) were used as experimental animals. Unilateral retinal detachments were created in the right eyes of 6 pigs. Animals were anesthetized, and a solution of $0.25 \%$ sodium hyaluronate was infused between the neural retina and RPE via a 20-gauge subretinal canula attached to a $5 \mathrm{ml}$ syringe. The Healon is necessary to prevent spontaneous reattachment of the retina. All surgery was done via an entry site at the level of the pars plana. Approximately half the retina was detached in each eye. By indirect ophthalmoscopy we made sure that the retinas remained detached for the duration of the experiment. The left eyes were used as the control for all the experiments. Following 14 days of detachment, the animals were euthanized using intravenous pentobarbital (200 mg/ml) (Euthesate; Aesculaap, Boxtel, The Netherlands). All experimental procedures conformed to the ARVO statement for the Use of Animals in Ophthalmic and Vision Research and the guidelines of the Animal Resource Center of the University of California Santa Barbara (Santa Barbara, CA).

\section{Vitreous fluid collection}

Within a few minutes after enucleation, before taking out the retina from the pig eye, the vitreous fluid was extracted, centrifuged and stored at $-80^{\circ} \mathrm{C}$ until tested for cGMP. Vitreous fluid samples of 9 patients with a rhegmatogenous retinal detachment (RRD) were collected to compare the cGMP content in vitreous fluid of pigs after a retinal detachment with the human situation. Patients with uveitis, trauma or vitreous haemorrhage were excluded. Undiluted vitrectomy samples were obtained by a conventional three-port closed vitrectomy technique by manual suction at the beginning of the vitrectomy, before opening the infusion line of Balanced Salt Solution (BSS, Alcon Laboratories, Texas, USA), as described earlier. ${ }^{18}$ The samples were centrifuged and stored at $-80^{\circ} \mathrm{C}$ until the cGMP analysis. Samples contaminated with blood were excluded from the study. The study was performed with the agreement of the University Hospital ethics committee; all patients gave their informed consent prior to inclusion in the study and after the nature of the study had been explained. The study adhered to the tenets of the Declaration of Helsinki. 


\section{Chapter IX}

\section{Cyclic GMP assay}

Extracellular cGMP content was measured in duplicate using a commercially available ELISA kit (Assay designs, Ann Arbor, USA). We used $100 \mu 1$ of undiluted vitreous fluid and performed the measurement according to the manufacturer's instructions. The amount of cGMP was expressed as $\mathrm{pmol} / \mathrm{ml}$ undiluted vitreous. The sensitivity of the cGMP assay was 0.088 $\mathrm{pmol} / \mathrm{ml}$.

\section{Tissue Preparation}

After enucleation, an incision was made at the margin of the ora serrata to remove the lens, vitreous and ciliary body. The retina was then removed. Small pieces of retina were incubated for 40 minutes in aerated Krebs buffer (pH 7.4) with or without $1 \mathrm{mM}$ IBMX (a non-specific PDE inhibitor) (Sigma, Amsterdam, The Netherlands). During the last ten minutes of the incubation the cells were stimulated with $100 \mu \mathrm{M}$ of the NO donor sodium nitroprusside (SNP) or $0.1 \mu \mathrm{M}$ of the particulate guanylyl cyclase stimulator atrial natriuretic peptide (ANP).

\section{Immunohistochemistry}

After incubation the retinal tissue pieces were fixed with $4 \%$ freshly depolymerized paraformaldehyde in the cold $\left(4^{\circ} \mathrm{C}\right)$. Retina wholemounts were washed $3 \times 5 \mathrm{~min}$, twice with Tris-buffered saline (TBS) and once with TBS containing $0.3 \%$ Triton X-100 (TBS-T). Samples were subsequently incubated overnight at $4{ }^{\circ} \mathrm{C}$ with the primary antibodies. Cyclic GMP was visualized using sheep anti-formaldehyde-fixed cGMP antiserum diluted 1:4000 in TBS-T (de Vente et al. 2000). ${ }^{19}$

The following day the samples were washed for $15 \mathrm{~min}$ with respectively TBS, TBS-T and TBS. The tissues were subsequently incubated with Alexa 488 conjugated donkey anti-sheep IgG (Molecular Probes) diluted 1:100 in TBS-T, for 1.5 hours at room temperature. Negative controls were processed in exactly the same way with the omission of the primary antibody. After three further washings in TBS the nuclei of the cells were stained with Hoechst 33342, (Sigma) for 20 minutes at room temperature (diluted 1:1000), washed again in TBS. Wholemounts were cover slipped with TBS:glycerol $(1: 2 \mathrm{v} / \mathrm{v})$.

\section{Microscopy}

Retinal wholemounts were analyzed by fluorescence microscopy using twophoton laser scanning microscopy (TPLSM). TPLSM was performed as previously described using a microscope objective (40x; water dipping; numerical aperture $[\mathrm{NA}]=1.0$ ) connected to an upright Nikon E600FN microscope (Nikon Corporation, Tokyo, Japan). ${ }^{20}$ If needed, further magnification was achieved by optical zoom in the scan head. To remove noise, each image was filtered applying the Kalman filtering procedure on three subsequent 
images during experiments. The fluorescent secondary antibody Alexa 488 was mainly visible in the green channel, whereas Hoechst was only visible in the red channel. The obtained images (coded green and red, respectively) were combined into single images if needed.

Pictures in Figure 3 and 4 were taken with a MBF Bioscience Stereo Investigator Confocal Spinning Disk (SI-SD) system (MBF Bioscience; Williston, VT), consisting of a modified Olympus BX51 fluorescence microscope (Olympus, Tokyo, Japan) with UPlanSApo objectives, customized spinning disk unit (DSU; Olympus), computer-controlled excitation and emission filter wheels (Olympus), three-axis high-accuracy computer-controlled stepping motor specimen stage ( $4 \times 4$ Grid Encoded Stage; Ludl Electronic Products, Hawthorne, NY), linear z-axis position encoder (Ludl), ultra-high sensitivity monochrome electron multiplier CCD camera $(1,000 \times 1,000$ pixels, C9100-02; Hamamatsu Photonics, Hamamatsu City, Japan) and controlling software (MBF Bioscience). Pictures were taken in a single focal plane with a 40x UPlanSApo objective (N.A $=0.9$ ) and processed with Imaris software (Version 4.0; Bitplane, Zurich, Switzerland). Only minor adjustments of contrast and brightness were made, without altering the appearance of the original materials. No deconvolution was performed on the images.

\section{Statistical analysis}

Because the cGMP values were paired and non-parametric we used the Wilcoxon signed ranks test to compare the cGMP content in pig vitreous fluid of eyes with and without retinal detachment. Vitreous cGMP levels between human and pig eyes after retinal detachment were compared using the Mann Whitney test for independent samples. Differences were considered significant when the $\mathrm{P}$ value was less than 0.05 (two-tailed)

\section{RESULTS}

Vitreous fluid was obtained from the left and right eyes of 6 pigs, 2 weeks after creating an experimental retinal detachment to all right eyes. Cyclic GMP could be detected in all samples. In vitreous fluid from eyes with retinal detachment, the mean level of cGMP was $1.45 \mathrm{pmol} / \mathrm{ml}$ (range between 0.09 to $4.32 \mathrm{pmol} / \mathrm{ml}$ ). In the control eyes without retinal detachment, the mean vitreous level of cGMP was $4.61 \mathrm{pmol} / \mathrm{ml}$ (range between 0.40 to $14.10 \mathrm{pmol} / \mathrm{ml}$ ). The difference in vitreous cGMP levels between experimental and detached eyes was statistically significant (Wilcoxon signed ranks test $\mathrm{P}=0.028$ ). A large variation in cGMP levels between pigs was observed, however in every pig the cGMP level in the right eye with retinal detachment was lower (between 1.6 and 5.8 times) than in the healthy left eye (figure 1). Cyclic GMP could be detected in 9 out of 9 vitreous fluid samples from human eyes with retinal detachment. The mean level of cGMP in these 


\section{Chapter IX}

eyes was $1.10 \mathrm{pmol} / \mathrm{ml}$ (ranged from 0.15 to $7.35 \mathrm{pmol} / \mathrm{ml}$ ). Comparing human and pig eyes with retinal detachment showed no difference in vitreous cGMP level $(\mathrm{P}=0.30)$.

Figure 1. Vitreous cGMP level (pmol/ml) in the eye with detached retina and the contralateral eye. Each line represents one pig.

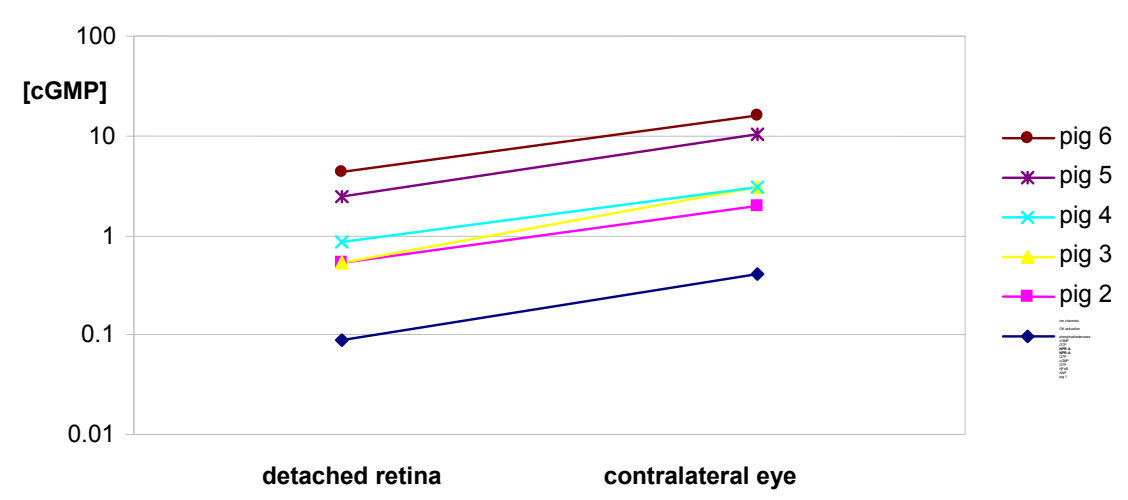

\section{Immunohistochemistry}

We studied cGMP production in retinal cells, following stimulation of soluble guanylyl cyclase (by SNP) or particulate guanylyl cyclase (by ANP) and simultaneous inhibition of cGMP breakdown by PDE's using IBMX. Without blocking phosphodiesterase activity no cGMP expression could be found in any of the retinal cells, in both the detached and healthy retinas. Blocking PDE activity in unstimulated retinas resulted in cGMP immunoreactivity in the inner nuclear layer of the detached as well as the healthy retinas. Addition of $0.1 \mu \mathrm{M}$ ANP, as a stimulator of particulate guanylyl cyclase in the presence PDE inhibition resulted in the appearance of a strong cGMP signal in both the ganglion cells and the inner nuclear layer of the healthy retina. No cGMP signal was visible in the outer nuclear layer of the healthy retina (Figure 2a). In the detached retina, strong cGMP immunoreactivity was visible not only in the ganglion cells and the inner nuclear layer but also in the outer nuclear layer (Figure $2 b, c)$. Figure $2 b$ shows both the nuclei of the cells (Hoechst staining; red signal) and cGMP (green signal) staining of the outer nuclear layer of a detached retina. In Figure $2 \mathrm{c}$ we only show the green signal, showing strong cGMP immunoreactivity in the same retinal wholemount. In both, the detached and healthy retina also the inner plexiform and outer plexiform layer showed cGMP-immunolabeling after incubation with ANP and IBMX. Figure 3 shows the labeling of the outer plexiform layer of a detached retina with Hoechst (Figure 3a) and cGMP (Figure 3b) separately and together (Figure $3 \mathrm{c}$ ) in the same retinal sample. Incubating the retinas in the presence of $100 \mu \mathrm{M} \mathrm{SNP}$, as a stimulator of soluble guanylyl cyclase in combination with PDE inhibition (with IBMX) resulted in cGMP-immuno- 
reactivity in the ganglion cells, the inner nuclear cell layer (figure $4 \mathrm{c}, \mathrm{d}$ ) and the nerve fiber layer of the detached- and healthy retinas (Figure 4a,b). Stimulation with SNP (+ IBMX) did not result in the presence of cGMP immunoreactivity in the photoreceptor cells of the detached or healthy retina.

Figure 2. Photoreceptor layer of a healthy $(\boldsymbol{A})$ or detached $(\boldsymbol{B}, \boldsymbol{C})$ retina after incubation with ANP and IBMX. A,B: Immunolabeling for Hoechst33342 (red) and cGMP (green). C: Same picture as in B, only showing immunolabeling for cGMP (green). Scale bar $=25 \mu m$.
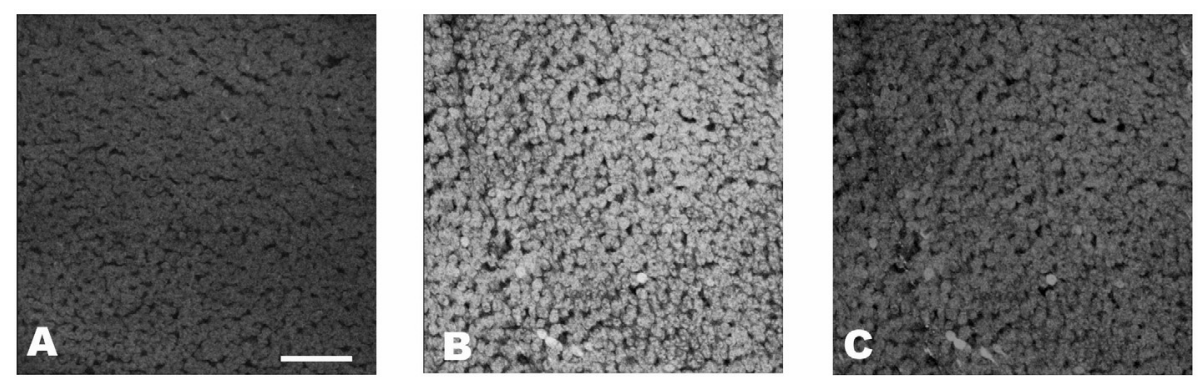

Figure 3. Outer plexiform layer of a detached retina after incubation with ANP and IBMX. A: Immunolabeling for Hoechst33342; B: Immunolabeling for cGMP; C: Immunolabeling for Hoechst33342 (red) and cGMP (green). Scale bar $=20 \mu \mathrm{m}$.
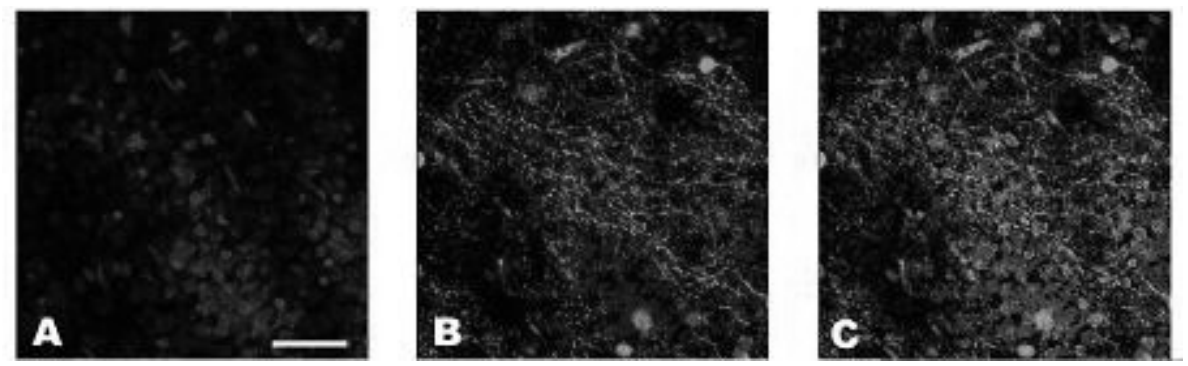


\section{Chapter IX}

Figure 4. $\boldsymbol{A} N F L$, and $\boldsymbol{C} I N L$ of a healthy retina after incubation with $S N P$ and $I B M X . \boldsymbol{B} N F L$, and $\boldsymbol{D} I N L$ of a detached retina after incubation with SNP and IBMX A,B: Immunolabeling for cGMP; C,D: Immunolabeling for Hoechst33342 (red) and $c G M P$ (green). Scale bar $=50 \mu \mathrm{m}$.
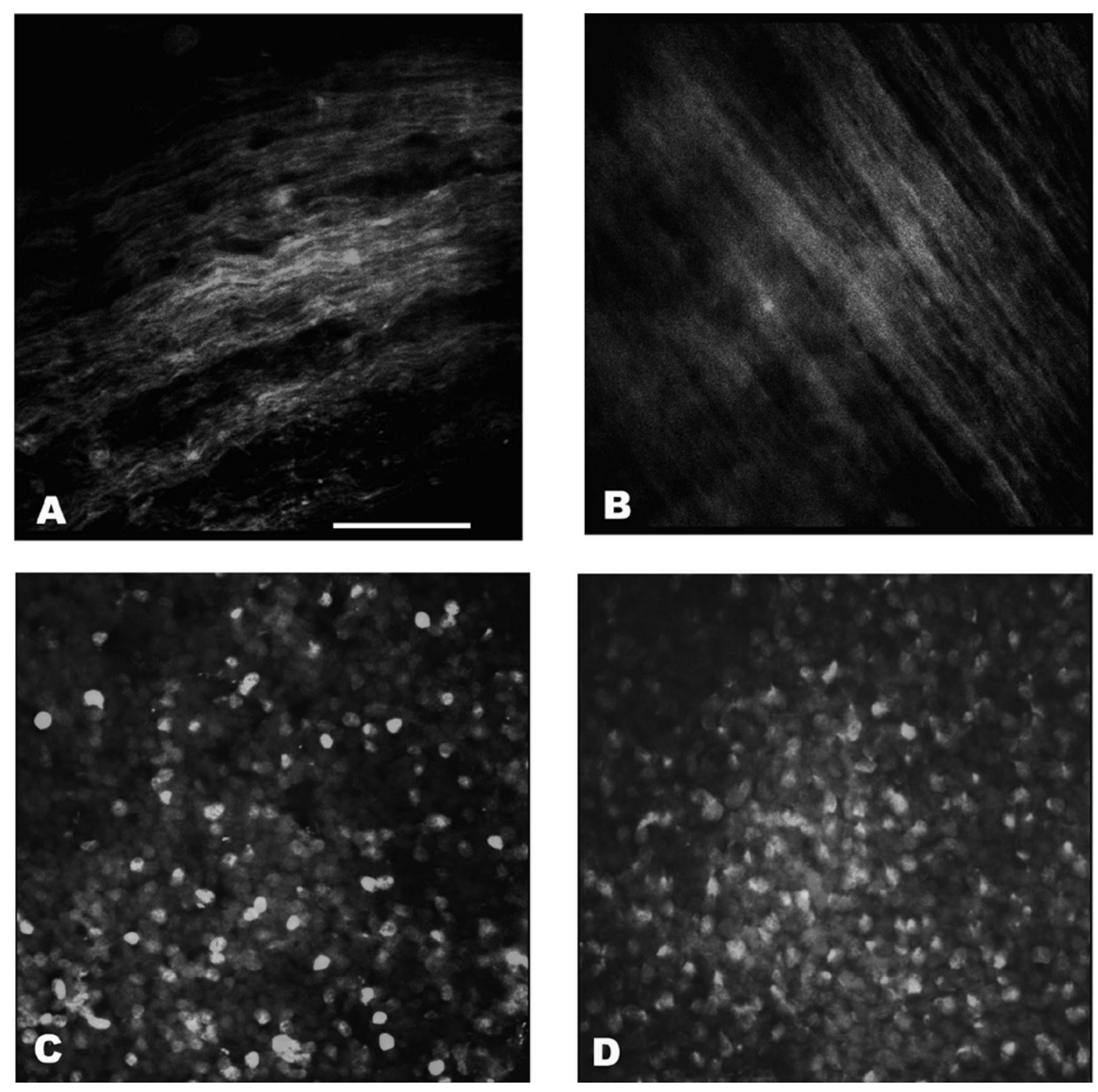

\section{DISCUSSION}

In the current study we demonstrate the presence of cGMP in pig vitreous fluid and showed a significantly lower vitreous cGMP level in pig eyes after retinal detachment, compared to the level of cGMP in contralateral healthy eyes. Our animal study confirms earlier findings in humans in which we showed a significantly lower vitreous cGMP concentration in patients with a RRD compared to controls. ${ }^{17}$ Our findings are also in accordance with earlier findings in a rabbit model that showed that vitreous cGMP levels were almost $60 \%$ lower in eyes with retinal detachment than in control eyes. ${ }^{21}$

In the current study we found a comparable range of vitreous cGMP concentrations in both human and pig eyes with a retinal detachment. The cGMP 
concentration in vitreous of human eyes with a retinal detachment was somewhat lower than the values reported in an earlier study $(6.5 \mathrm{pmol} / \mathrm{ml})$; however this latter value is within the range of our present data. ${ }^{17}$

Cyclic GMP production is catalyzed by either soluble guanylyl cyclase, activated by NO or particulate guanylyl cyclases stimulated by natriuretic peptides. After retinal detachment, the activity of both soluble guanylyl cyclase and particulate guanylyl cyclase could be reduced, since certain populations of retinal cells may have undergone degenerative changes induced by hypoxic or ischemic alterations following the detachment. ${ }^{3,4}$ A decreased production of cGMP by retinal cells may concurrently lead to a lower release into the extracellular space, in this case vitreous fluid.

The cellular concentration of cGMP represents the net balance between synthesis by guanylyl cyclases and breakdown into 5'-cGMP by cyclic nucleotide phosphodiesterases (PDEs). ${ }^{22}$ The decreased cGMP concentration in the vitreous after retinal detachment could also be the result of increased PDE activity. However this is less plausible because no PDE activity could be detected in vitreous fluid, as reported earlier. ${ }^{17}$ After RRD, vitreous passes through a retinal break into the subretinal space and then comes into direct contact with the RPE layer. Cyclic GMP in the vitreous might also be broken down by PDE's located in the RPE cells. This may be plausible since earlier studies have shown the presence of at least PDE2, PDE5 and PDE9 in the RPE cells. ${ }^{23}$

Stimulation of soluble guanylyl cyclase by the NO donor SNP resulted in cGMP expression in the inner pig retina, especially in the ganglion cells and bipolar cell layer. The effect of SNP on cGMP immunoreactivity in the retina was the same as previously shown in other animal studies. ${ }^{11,12}$ Also the finding that in the inner retina, both particulate and soluble guanylyl cyclases can elevate levels of cGMP is in accordance with results shown earlier in the turtle retina. ${ }^{11}$ After stimulation of the particulate guanylyl cyclase with ANP, cGMP could be detected in the outer nuclear layer of the detached retina, where this was not the case in the normal retina. The reason for this difference remains speculative. An explanation might be that cGMP accumulates intracellularly after detachment of the retina. Cyclic GMP accumulation may be caused by a hampered transport from the cells into the extracellular space as a result of hypoxic or ischemic alterations following retinal detachment. Although release of cGMP has not been shown in cultures of photoreceptor cells, earlier experiments have shown that release can occur in RPE cell cultures. ${ }^{24}$

There are several shortcomings of this study. We tried to cut and stain pieces of the left and right retina with the same location in the retina, however this is difficult. This could be of importance because Newsome et al. showed a 


\section{Chapter IX}

variation in cGMP levels in the human retina with the lowest concentration observed in the central (macular) region of the retina. ${ }^{25}$ There is a high variation in vitreous cGMP concentration between the individual pigs. This may be caused by variation in the position in the vitreous cavity at which the sample was obtained. However, in every eye we took the sample from the centre of the vitreous and aspirated almost all vitreous fluid.

Most studies concerning retinal cGMP have focused on its role in phototransduction. ${ }^{26}$ Little is known about the changes in cGMP expression in the retina and the vitreous after retinal detachment. It has been shown that cGMP stimulates subretinal fluid absorption whereas cAMP inhibits this process5. The source of vitreous cGMP is unknown as is the specific role of extracellular vitreous cGMP for the retina.

However, the presence of cGMP in vitreous and its decrease after retinal detachment as found in the current experimental study, and in our previous study in human eyes with RRD may indicate a potential regulatory role in the physiologic responses of the retina after detachment.

\section{ACKNOWLEDGEMENTS}

The authors would like to thank Marc A.M.J. van Zandvoort and Christoph Schmitz for expert help with two-photon laser scanning and spinning disc confocal microscopy. 


\section{Cyclic GMP in the detached pig retina}

\section{LITERATURE}

1 Burton TC. Recovery of visual acuity after retinal detachment involving the macula. Trans Am Ophthalmol Soc. 1982; 80:475-497.

2 Sabates NR, Sabates FN, Sabates R, Ledd KY, Ziemianski MC. Macular changes after retinal detachment surgery. American Journal of Ophthalmology. 1989; 108:22-29.

3 Mervin K, Valter K, Maslim J, Lewis G, Fisher S, Stone J. Limiting photoreceptor death and deconstruction during experimental retinal detachment: the value of oxygen supplementation. American Journal of Ophthalmology. 1999; 128:155-164.

4 Lewis G, Mervin K, Valter K, et al. Limiting the proliferation and reactivity of retinal Muller cells during experimental retinal detachment: the value of oxygen supplementation. Am J Ophthalmol. 1999; 128(2):165-72.

5 Marmor MF, Negi A. Pharmacologic modification of subretinal fluid absorption in the rabbit eye. Arch Ophthalmol. 1986; 104:1674-1677.

6 Mills SC, Massey SL. Differential properties of two gap junctional pathways made by AII amacrine cells. Nature. 1995; 377(6551):734-7.

7 Mikami Y, Hara M, Yasukura T, Uyama M, Minato A, Inagaki C. Atrial natriuretic peptide stimulates $\mathrm{Cl}$ - transport in retinal pigment epithelial cells. Curr Eye Res. 1995; 14, 391-397.

8 Ghiso N, Rohan RM, Amano S, Garland R, Ademis AP. Suppression of hypoxiaassociated vascular endothelial growth factor gene expression by nitric oxide via cGMP. Invest Ophthalmol Vis Sci. 1999; 40(6):1033-9.

9 Kogishi JI, Akimoto M, Mandai M, et al. Nitric oxide as a second messenger in phagocytosis by cultured retinal pigment epithelial cells. Ophthalmic Res. 2000;32:138-142

10 Zhang N, Beuve A, Townes-Anderson E. The nitric oxide-cGMP signaling pathway differentially regulates presynaptic structural plasticity in cone and rod cells. The Journal of Neuroschience. 2005; 25(10):2761-2770.

11 Gotzes S, de Vente J, Muller F. Nitric oxide modulates cGMP levels in neurons of the inner and outer retina in opposite ways. Vis Neurosci 1998; 15:945-55.

12 Blute TA, Velasco P, Eldred WD. Functional localization of soluble guanylate cyclase in turtle retina: modulation of cGMP by nitric oxide donors. Vis Neurosci 1998; 15:485-98.

13 Rollin R, Mediero A, Roldan-Pallares M, Fernandez-Cruz A, Fernandez-Durango R. Natriuretic peptide system in the human retina. Mol Vision. 2004; 10:15-22.

14 Shyjan AW, de Sauvage FJ, Gillett NA, Goeddel DV, Lowe DG. Molecular cloning of a retina-specific membrane guanylyl cyclase. Neuron. 1992; 9:727-37.

15 Ahmad I, Barnstable CJ: Differential laminar expression of particulate and soluble guanylate cyclase genes in rat retina. Exp Eye Res 1993; 56:51-62.

16 Beavo JA. Cyclic nucleotide phosphodiesterases. functional implications of multiple isoforms. Physiol. Rev. 1995; 75;725-748.

17 La Heij EC, Blaauwgeers HG, de Vente J, et al. Decreased levels of cGMP in vitreous and subretinal fluid from eyes with retinal detachment. Br J Ophthalmol. 2003; 87:1409-12.

18 La Heij EC, Hendrikse F, Kessels AGH. Results and complications of temporary silicone oil tamponade in patients with complicated retinal detachments. Retina. 2001; 21:107-114.

19 De Vente J, Markerink-van Ittersum M, van Abeelen J, Emson PC, Axer H, Steinbusch HW. NO-mediated cGMP synthesis in cholinergic neurons in the rat forebrain: effects of lesioning dopaminergic or serotonergic pathways on nNOS and cGMP synthesis. Eur J Neurosci. 2000; 12:507-19.

20 Van Zandvoort M, Engels W, Douma K, Beckers L, Oude Egbrink M, Daemen M, Slaaf DW. Two-photon microscopy for imaging of the (atherosclerotic) vascular wall: a proof of concept study. J Vasc Res. 2004; 41(1):54-63. 


\section{Chapter IX}

21 Dalma-Wiszhaus J, Blumenkranz M, Hartzer M, Hernandez E. Intraocular extracellular cyclic nucleotide concentrations: the influence of vitreous surgery. Graefe's Arch Clin Exp Ophthalmol. 1993; 231:184-186.

22 Francis SH, Corbin JD. Cyclic nucleotide-dependent protein kinases: intracellular receptors for cAMP and cGMP action. Crit Rev Clin Lab Sci 1999; 36:275-328.

23 Diederen RMH, La Heij EC, et al. Selective blockade of Phosphodiesterases Type 2, 5 and 9 results in cGMP accumulation in Retinal Pigment Epithelium Cells. British Journal of Ophthalmology. 2006; Aug 30; [Epub ahead of print].

24 Diederen RMH, La Heij EC, et al. Cyclic GMP synthesis by human retinal pigment epithelial cells is mainly mediated via the particulate guanylyl cyclase pathway. Ophthalmic Research, (In press).

25 Newsome DA, Fletcher RT, Chader GJ. Cyclic nucleotides vary by area in the retina and pigmented epithelium in the human and monkey. Invest Ophthalmol Vis Sci. 1980; 19(8):864-9.

26 Baylor DA. Photoreceptor signals and vision. Investigative Ophthalmology and Visual Science, 1987; 28:34-39. 




\section{CHAPTER X}

\section{General discussion}

Biochemical and clinical factors in

rhegmatogenous retinal detachment

Roselie M.H. Diederen 



\section{MAJOR FINDINGS PRESENTED IN THIS THESIS:}

1. In macula-off as well as macula-on rhegmatogenous retinal detachment, the duration of retinal detachment before surgery is an important preoperative determinant for the post-operative result.

2. Rhegmatogenous retinal detachment is associated with increased levels of vitreous glutamate.

3. Eyes with retinal detachment have increased levels of nitric oxide pathway metabolites in their vitreous fluid, which may reflect a role of nitric oxide in the pathogenesis of this disease.

4. Cultured human retinal pigment epithelium (RPE) cells are capable of producing cGMP and most cGMP is generated following stimulation of the particulate guanylyl cyclase pathway.

5. The presence of inducible nitric oxide synthetase (iNOS) and the ongoing cGMP synthesis by soluble guanylyl cyclase in RPE cells is causally linked and might be part of a regulatory cGMP dependent mechanism integrating the effects of atrial natriuretic peptide and nitric oxide.

6. Phosphodiesterase type 2, 5 and 9 are present in cultured human RPE cells and rat RPE cell layers indicating that these different phosphodiesterase isoforms play a role in controlling cGMP levels in RPE cells.

7. Extracellular cGMP can be detected in pig vitreous fluid and the concentration of vitreous cGMP decreases significantly after experimental retinal detachment.

A retinal detachment, occurring when the retina's photoreceptor layer and the retinal pigment epithelium separate, often causes blindness if left untreated. But even when reattachment surgery is successful, a reattached retina rarely regains normal sensitivity or acuity. ${ }^{1,2}$ In this thesis we were interested in finding clinical and biochemical factors involved in visual and anatomical outcome after rhegmatogenous retinal detachment.

\section{CLINICAL FACTORS INVOLVED IN RHEGMATOGENOUS RETINAL DETACHMENT}

\section{Discussion \& Future directions}

According to our findings, visual acuity outcomes after rhegmatogenous retinal detachment (RRD) with involvement of the macula can be expected to worsen when the duration of macular detachment exceeds 6 days. Based 


\section{Chapter X}

on these data, we propose that the scleral buckling procedure should preferably be done within 7 days after detachment of the macula. In RRD without macular involvement, a longer reported duration of visual field loss before surgery was found to be a statistically significant risk factor associated with a recurrent retinal detachment. According to both these findings described in Chapter 2 and 3, the duration of retinal detachment before surgery is therefore an important pre-operative determinant for the post-operative result.

We noticed that in a large group of patients with retinal detachment the time between the onset of visual field loss as indicated by the patients and the scleral buckling surgery was quite long. For patients with macula-off retinal detachment, the mean duration of macular detachment before surgery was 11.4 days (range 1 day - 6 months). For patients with macula-on retinal detachment the mean duration of visual field loss before surgery was 16.5 days (range 1 day - 12 months). In the current studies we did not score the reason for the delay between the first symptoms noted by the patient and the time of surgery. In the study of Hartz et al. the most important reason for performing immediate emergency surgery was the inability to schedule an operating room the next day. But also patient characteristics influenced how surgery was scheduled. ${ }^{3}$ Future studies might address the reason for delay between the occurrence of retinal detachment and the scleral buckling procedure. Knowing the reasons for delay may provide valuable information that can be used to inform patients as well as medical doctors (general practitioners and ophthalmologists) in order to keep the time between onset of visual field loss and surgery to a minimum.

\section{BIOCHEMICAL FACTORS INVOLVED IN RETINAL DETACHMENT}

\section{D407 Cell Line}

RPE cells play an important role in the pathogenesis of RRD. To study the behavior and function of PRE cells in more detail, in vitro experiments using RPE cell lines may be performed. The spontaneously transformed human RPE cell line D407 is such a cell line. ${ }^{4}$ They have been cloned from a primary culture of human RPE cells and have been sub-cultured more than 300 times. The cells possess epithelial cobblestone morphology. The cytoskeleton of these cells comprises cytokeratins that are characteristic of epithelial cells, together with actin, spectrin and vimentin. The keratins expressed are typical of those of RPE cells. These cells also exhibit phagocytic activity. It has been shown earlier that the D407 cell line retains many of the metabolic and morphologic characteristics of RPE cells in vivo, although there are some minor differences. ${ }^{3}$ 


\section{Discussion \& Future directions}

In our study described in Chapter 4, we report a significantly elevated concentration of glutamate in the vitreous of eyes with RRD compared to controls. This may be due to irreversible damage to the Müller cells, which play a prominent role in the uptake of extracellular glutamate. Müller cells may be damaged because of hypoxia and/or ischemia occurring after retinal detachment, as shown earlier by Lewis et al. ${ }^{5}$

Glutamate toxicity is considered to be caused by an excessive activation of the $N$-methyl-d-aspartate (NMDA)-type glutamate receptor. Binding of glutamate to the NMDA receptor increases the influx of $\mathrm{Ca}^{2}$ through the receptor's associated ion channel. ${ }^{6} \mathrm{Ca}^{2+}$ can stimulate the enzyme nitric oxide synthetase (NOS) to produce nitric oxide (NO). Overproduction of NO can lead to cell death through a variety of mechanisms, e.g. trough DNA damage, apoptosis and decreased energy production by inhibition of mitochondrial function. ${ }^{7}$ Thus the demonstrated elevated vitreous levels of glutamate may be a sign of further damage to the retina, and also as a factor which compromises visual recovery. In addition, we found increased levels of NO pathway metabolites in the vitreous fluid of eyes with retinal detachment, as described in Chapter 5. It has been shown previously that inducible NOS (iNOS) is expressed in Müller cells and RPE cells after cytokine stimulation. ${ }^{8,9}$ Since increased levels of cytokines have been found in eyes with RRD it may be postulated that iNOS is upregulated by these cytokines, leading to elevated levels of NO in the vicinity of the detached retina. ${ }^{10,11}$ In photoreceptors and bipolar cells neuronal NOS (nNOS) is thought to be responsible for producing NO. ${ }^{12}$ Glutamate can stimulate neuronal NOS resulting in increased NO production. Thus the in NO pathway metabolites in eyes with retinal detachment is in agreement with our observation of elevated levels of glutamate in vitreous fluid of RRD patients.

Further research may be aimed at therapeutic agents that block NMDA receptors to prevent the toxic effects of the increased glutamate levels that might lead to cell death after retinal detachment. Experimental studies have previously shown that a variety of agents can be used to prevent the death of retinal neurons (particularly ganglion cells) induced by ischemia. ${ }^{13}$ Systemic treatment with memantine, an NMDA receptor antagonist, was proven to be both safe and effective for reduction of functional loss associated with experimental glaucoma. ${ }^{14}$

Most studies concerning retinal cGMP have focused on its role in phototransduction. Little is known about the changes in cGMP expression in the retina and the vitreous after retinal detachment. It has been shown that cGMP stimulates subretinal fluid absorption whereas cAMP inhibits this process. ${ }^{15,16}$ In Chapter 8, we demonstrate the presence of cGMP in pig vitreous fluid and showed a significantly lower vitreous cGMP level in pig eyes 


\section{Chapter X}

after retinal detachment, compared to the level of cGMP in healthy pig eyes. Our study confirms earlier findings in humans in which we showed a significantly lower vitreous cGMP concentration in patients with a rhegmatogenous retinal detachment compared to controls. ${ }^{17}$ Our findings are also in accordance with earlier findings in a rabbit model that showed that vitreous cGMP levels were almost $60 \%$ lower in eyes with retinal detachment than in rabbit eyes without retinal detachment. ${ }^{18}$ The source of vitreous cGMP is unknown as is the specific regulatory role of extracellular vitreous cGMP for the retina. However, the presence of cGMP in vitreous and its decrease after retinal detachment may indicate a potential regulatory role in the physiologic responses of the retina after detachment.

Hypoxia due to retinal detachment may cause a reduced activity of guanylyl cyclases which produce cGMP. This could lead to a reduced synthesis of cGMP by retinal cells after retinal detachment. We now know that human RPE cells are capable of producing cGMP and most cGMP is generated following stimulation of the particulate guanylyl cyclase pathway (Chapter 6). Previously, it has been demonstrated that NPR-A and NPR-B, both ANP receptors, are present in cultured rabbit RPE cells and in the human and turtle retina. ${ }^{19-22}$ Future research may address the effect of targeted stimulation of RPE cells with ANP after retinal detachment, in order to investigate whether the decrease in cGMP concentration may be prevented.

The major function for PDEs in the cell is to terminate the amplitude and duration of the cyclic nucleotide second messenger signal (Figure 1). ${ }^{23} \mathrm{By}$ knowing the specific PDE families located in retinal cells (Chapter 7) these enzymes could in the future become therapeutic targets in order to limit cGMP breakdown by using selective PDE inhibitors. From the literature we already know that inhibition of PDE5 using Sildenafil would not be favorable. This is due to the fact that Sildenafil, a relatively selective inhibitor for PDE5 also weakly inhibits PDE6, an enzyme involved in the process of phototransduction. Even though the efficacy of PDE6 inhibition is approximately a factor 10 lower than that for PDE $5,{ }^{24}$ a single oral dose of $100 \mathrm{mg}$ sildenafil is sufficient to cause impaired photoreceptor function. ${ }^{25,26}$ Clinically PDE inhibition could be important in retinal detachment as cGMP is not only involved in phototransduction, but also known for its stimulating role in the reabsorption of subretinal fluid by activating the RPE pump. ${ }^{15,16}$

We hope that the experiments, described in this thesis are a first step to an experimental animal model of RRD that could lead to further understanding of the biochemical changes occurring in RRD. This approach can hopefully lead to new diagnostic and therapeutic interventions to prevent poor vision related to RRD. 


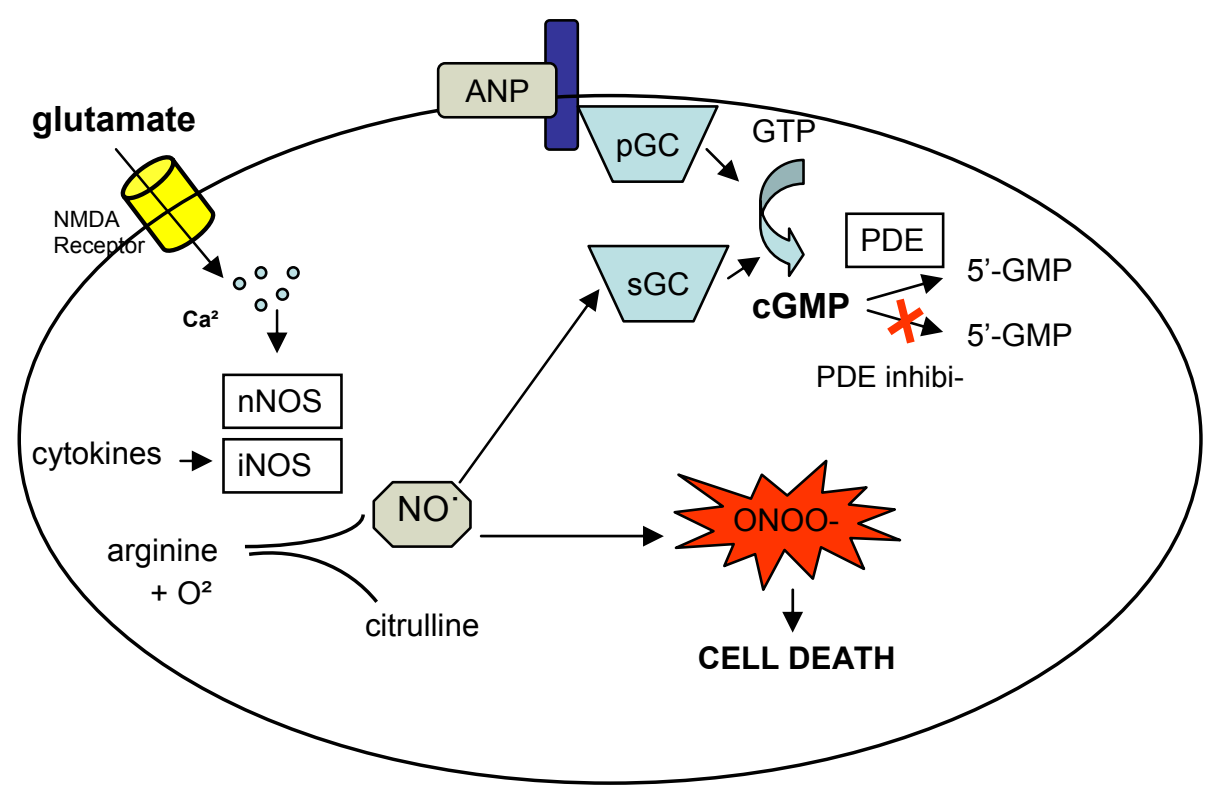

Figure 1. ANP (atrial natriuretic peptide), $p G C$ (particulate guanylyl cyclase), sGC (soluble guanylyl cyclase), iNOS (inducible nitric oxide synthase), nNOS (neuronal nitric oxide synthase), $N O$ (nitric oxide), PDE (phosphodiesterases) 


\section{Chapter X}

\section{LITERATURE}

1 Burton TC. Recovery of visual acuity after retinal detachment involving the macula. Trans Am Ophthalmol Soc. 1982; 80:475-497.

2 Sabates NR, Sabates FN, Sabates R, Ledd KY, Ziemianski MC. Macular changes after retinal detachment surgery. American Journal of Ophthalmology. 1989; 108:22-29.

3 Hartz AJ, Burton TC, Gottlieb MS, McCarty DJ, Williams DF, Prescott A, Klein P. Outcome and cost analysis of scheduled versus emergency scleral buckling surgery. Ophthalmology. 1992; 99:1358-1363.

4 Davis AA, Bernstein PS, Bok D, Turner J, Nachtigal M, Hunt RC. A human retinal pigment epithelial cell line that retains epithelial characteristics after prolonged culture. Invest Ophthalmol Vis Sci. 1995; 36, 955-964.

5 Lewis G, Mervin K, Valter K, et al. Limiting the proliferation and reactivity of retinal Muller cells during experimental retinal detachment: the value of oxygen supplementation. Am J Ophthalmol. 1999; 128(2):165-72.

6 Lipton SA. Failures and Successes of NMDA Receptor Antagonists: Molecular Basis for the Use of Open-Channel Blockers like Memantine in the Treatment of Acute and Chronic Neurologic Insults. Neurorx. 2004; 1(1):101-110.

7 Dawson VL, Dawson TM. Nitric oxide neurotoxicity. J Chem Neuroanat 1996; 10(3-4):179-90.

8 Kelly MEM, Barnes, S. Physilogy and Pathophysiology of Nitric Oxide in the Retina. The Neuroscientist. 1997; 3(6):357-360.

9 Koga T, Zhang WY, Gotoh T, Oyadomari S, Tanihara H, Mori M. Induction of citrullinenitric oxide (NO) cycle enzymes and NO production in immunostimulated rat RPE-J cells. Exp Eye Res. 2003; 76(1):15-21.

10 La Heij EC, Van De Waarenburg MP, Blaauwgeers HG, Kessels AG, De Vente J, Liem AT, Steinbusch H, Hendrikse F. Levels of basic fibroblast growth factor, glutamine synthetase, and interleukin-6 in subretinal fluid from patients with retinal detachment. Am J Ophthalmol. 2001; 132(4):544-50.

11 Kenarova B, Voinov L, Apostolov C, Vladimirova R, Misheva A. Levels of some cytokines in subretinal fluid in proliferative vitreoretinopathy and rhegmatogenous retinal detachment. Eur J Ophthalmol. 1997; 7(1):64-7.

12 Yoshida A, Pozdnyakov N, Dang L, Orselli SM, Reddy VN, Sitaramayya A. Nitric oxide synthesis in retinal photoreceptor cells. Vis Neurosci 1995; 12(3):493-500.

13 Osborne NN, Ugarte M, Chao M, Chidlow G, Bae JH, Wood JP, Nash MS. Neuroprotection in relation to retinal ischemia and relevance to glaucoma. Surv Ophthalmol. 1999; 43 Suppl 1:S102-28.

14 Hare WA, WoldeMussie E, Lai RK, Ton H, Ruiz G, Chun T, Wheeler L. Efficacy and safety of memantine treatment for reduction of changes associated with experimental glaucoma in monkey, I: Functional measures. Invest Ophthalmol Vis Sci. 2004; 45(8):2625-39.

15 Marmor MF, Negi A. Pharmacologic modification of subretinal fluid absorption in the rabbit eye. Arch Ophthalmol. 1986; 104:1674-1677.

16 Marmor MF. Control of subretinal fluid: Experimental and clinical studies. Eye. 1990;4:340-344.

17 La Heij EC, Blaauwgeers HG, de Vente J, Markerink M, Liem AT, Kessels AG, SteinbuschH, HendrikseF. Decreased levels of cGMP in vitreous and subretinal fluid from eyes with retinal detachment. Br J Ophthalmol. 2003; 87:1409-1412.

18 Dalma-Wiszhaus J, Blumenkranz M, Hartzer M, Hernandez E. Intraocular extracellular cyclic nucleotide concentrations: the influence of vitreous surgery. Graefe's Arch Clin Exp Ophthalmol. 1993; 231:184-186.

19 Fujiseki Y, Omori K, Omori K, Mikami Y, Suzukawa J, Okugawa G, Uyama M, Inagaki C. Natriuretic peptide receptors, NPR-A and NPR-B, in cultured rabbit retinal pigment epithelium cells. Jpn J Pharmacol 1999; 79:359-68. 
20 Blute TA, Lee HK, Huffmaster T, Haverkamp S, Eldred WD: Localization of natriuretic peptides and their activation of particulate guanylate cyclase and nitric oxide synthase in the retina. J Comp Neurol. 2000; 424:689-700.

21 Blute TA, Velasco P, Eldred WD. Functional localization of soluble guanylate cyclase in turtle retina: modulation of cGMP by nitric oxide donors. Vis Neurosci. 1998; 15:485-98.

22 Garbers DL, Lowe DG: Guanylyl cyclase receptors. J Biol Chem. 1994; 269:30741-30744.

23 Beavo JA. Cyclic nucleotide phosphodiesterases: functional implications of multiple isoforms. Physiol. Rev. 1995; 75:725-748.

24 Ballard SA, Gingell CJ, Tang K, Turner LA, Price ME, Naylor AM. Effects of Sildenafil on the relaxation of human corpus cavernosum tissue in vitro and on the activities of cycylic nucleotide phosphodiesterase isozymes. J Urol. 1998; 159:2164-71.

25 Vobig MA, Klotz T, Staak M, Bartz-Schmidt KU, Engelman U, Walter P. Retinal sideeffects of Sildenafil. The Lancet. 1999; 353:375.

26 Vobig MA. Retinal side-effects of Sildenafil. The Lancet. 1999; 353:1442. 



\section{SUMMARY}

In this thesis we set out to investigate a number of clinical and biochemical factors that have been implicated in the visual and anatomical outcome after rhegmatogenous retinal detachment (RRD). The questions and hypotheses we addressed in this thesis are outlined in chapter 1.

In chapter 2, we determined the effect of duration of macular detachment (DMD) on post operative visual acuity (VA) in patients with macula-off RRD. In a retrospective, observational case series we studied 202 consecutive patients (202 eyes) with primary, uncomplicated, macula-off retinal detachment, a pre-operative VA $\leq 10 / 100$, a precise history of when macular function was lost, successful re-attachment surgery and a minimal follow up of 3 months. The cumulative mean of the best corrected postoperative VA (LogMAR) as a function of DMD shows a rapid worsening when DMD exceeds 6 days. Our results indicate that the scleral buckling procedure should preferably be done within 7 days of DMD.

In chapter 3, we evaluated risk factors associated with re-detachment and/or a worse visual outcome in patients with RRD without macular involvement following scleral buckling surgery. In a retrospective, observational case series we studied 253 consecutive eyes (248 patients) with primary, macula-on retinal detachment, a precise history of when visual field loss had occurred and a minimal follow up of 6 months. In RRD without macular involvement, a re-detachment and the presence of PVR are indicators for a low visual outcome after retinal detachment surgery. A longer duration of visual field loss before the scleral buckling procedure increases the chance of a retinal redetachment after surgery.

In chapter 4, a possible role for glutamate and other amino acid neurotransmitters during clinical RRD was studied. The study group consisted of 114 vitreous samples of patients with a RRD. The control group included vitreous samples of 52 eyes with an idiopathic macular hole or idiopathic epiretinal membrane and 10 eyes with a traction retinal detachment due to proliferative diabetic retinopathy. Vitreous concentrations of 5 amino acid neurotransmitters were determined by high-pressure liquid chromatography. RRD was associated with a significantly increased vitreous glutamate concentration. Taurine levels were also increased in RRD, whereas no significant difference could be observed for glycine, aspartate and GABA levels when comparing RRD with controls. A correlation was found between increased vitreous glutamate and a lower pre-operative visual acuity. Using visual acuity as a functional parameter in this study, we could not demonstrate a correlation between vitreous glutamate, or any of the other tested amino acid neurotransmitters and visual outcome. 
In chapter 5, we hypothesized that in RRD, the production of NO pathway metabolites might be upregulated. Using high-pressure liquid chromatography citrulline, arginine and nitrite were measured in vitreous fluid of 93 eyes with RRD, 9 eyes with a traction retinal detachment due to proliferative diabetic retinopathy, and in 49 control samples of vitreous fluid from eyes without retinal detachment. The mean vitreous concentrations of citrulline and arginine were significantly increased in eyes with RRD or in eyes with a traction retinal detachment as compared to control eyes. The mean concentration of nitrite was elevated in vitreous fluid of RRD patients as compared to controls although this was not statistically significant.

In chapter 6, we quantified cGMP synthesis by RPE cells and investigated the role of soluble and particulate guanylyl cyclase in its production. Cyclic GMP expression was evaluated in the presence of a non-selective phosphodiesterase inhibitor. Stimulation of the particulate guanylyl cyclase in RPE cells with ANP resulted in high intra and extracellular cGMP levels. Stimulation of the soluble guanylyl cyclase by SNP resulted in a slight elevation of cGMP levels compared to controls. These experiments show that cultured human RPE cells are capable of producing cGMP and that most cGMP is generated following stimulation of the particulate guanylyl cyclase pathway.

In chapter 7, we studied cGMP synthesis after inhibition of NOS, inhibition of soluble guanylyl cyclase or inhibition of particulate guanylyl cyclase. Furthermore, we showed NADPH-diaphorase activity and the presence of $\beta-1$ and $\alpha-2$ subunits of soluble guanylyl cyclase, inducible NOS, and ANP in cultured human RPE cells. The results show an important role for ANP in the cGMP synthesis in RPE cells and indicate that there are interacting signaling pathways using cGMP as a second messenger in cultured human RPE cells. The presence of inducible NOS and the ongoing cGMP synthesis by soluble guanylyl cyclase in RPE cells is causally linked and might be part of a regulatory cGMP dependent mechanism integrating the effects of ANP and NO.

In chapter 8, we investigated which PDE's are involved in regulating cGMP breakdown in RPE cells. In the absence of PDE inhibitors cGMP levels in cultured RPE cells are very low. In the presence of Bay60-7550 as a selective PDE2 inhibitor, sildenafil as a selective PDE5 inhibitor or Sch51866 as a selective PDE9 inhibitor the cGMP content strongly increased after stimulation of the particulate guanylyl cyclase. Furthermore messenger RNA of PDE2, PDE5 and PDE9 was detected in all cultured human RPE cells and in rat RPE cell layers in vivo.

In chapter 9, we studied cGMP expression in pig retinas and pig vitreous fluid after creating an experimental retinal detachment. We could detect 
cGMP in these vitreous samples and showed a significantly lower vitreous cGMP level in pig eyes after retinal detachment compared to the level of cGMP in healthy pig eyes. Comparing the existence of cGMP immunoreactivity between the retinas with and without experimental retinal detachment only shows a difference after stimulation of the particulate guanylyl cyclase with ANP. Under this condition, cGMP could be detected in the outer nuclear layer of the detached retina, where this was not the case in the normal retina.

In chapter 10 we discuss the findings presented in the thesis and point out directions for further research in this area. 


\section{SAMENVATTING}

In Hoofdstuk 2 heb ik het effect beschreven van de duur dat de macula los ligt op de post-operatieve visus bij patiënten met een netvliesloslating waarbij de macula betrokken was. In een retrospectieve studie hebben we 202 patiënten bestudeerd met een primaire, ongecompliceerde netvliesloslating met macula-af, een pre-operatieve visus $\leq 10 / 100$, een gedetailleerde anamnese over wanneer de visus grotendeels weg viel, een succesvolle netvlies operatie en een minimale follow-up van 3 maanden. Het cumulatieve gemiddelde van de best gecorrigeerde post-operatieve visus als functie van de duur dat de macula los ligt, laat een verslechtering zien wanneer de duur 6 dagen overschrijdt. Onze resultaten indiceren dat de cerclage plombe operatie het beste gedaan kan worden binnen 7 dagen na het ontstaan van de macula loslating.

In Hoofdstuk 3 hebben we de risicofactoren geëvalueerd die geassocieerd zijn met een recidief loslating en/of een slechte visus na een cerclage plombe operatie bij patiënten met een netvliesloslating zonder betrokkenheid van de macula. In een retrospectieve studie hebben we 253 ogen ( 248 patiënten) bestudeerd met een primaire, ongecompliceerde netvliesloslating met maculaaan, een pre-operatieve visus $\geq 80 / 100$, een gedetailleerde anamnese en een minimale follow-up van 6 maanden. Bij een netvliesloslating zonder betrokkenheid van de macula blijken een recidief en de pre-operatieve aanwezigheid van PVR indicatoren voor een slechte visuele prognose na de operatie. Het langer bestaan van het gezichtsveldverlies voor de operatie verhoogt de kans op een recidief loslating van de retina post-operatief.

In Hoofdstuk 4 hebben we de concentraties van glutamaat en andere aminozuur-neurotransmitters bestudeerd in glasvocht van ogen met een netvliesloslating. De studie groep bestond uit 114 glasvochtmonsters van patiënten met een netvliesloslating. De controle groep bestond uit 52 glasvochtmonsters van ogen met een macula gat of macula-pucker en 10 ogen met een tractie ablatio ten gevolge van proliferatieve diabetische retinopathie. De concentraties van 5 aminozuren in het glasvocht werden bepaald met behulp van high-pressure liquid chromatography (HPLC). Een netvliesloslating bleek geassocieerd met een significant hogere concentratie glutamaat in het glasvocht. Ook de concentratie van taurine was verhoogd. Bij glycine, aspartaat en GABA werden geen verhoogde concentraties gevonden. Ook vonden we een correlatie tussen een verhoogde concentratie glutamaat in het glasvocht en een lagere pre-operatieve visus. We konden echter geen correlatie aantonen tussen de concentratie glutamaat in het glasvocht en de visus na de cerclage plombe operatie.

Hoofdstuk 5 beschrijft de studie die ik heb uitgevoerd naar de productie van NO pathway metabolieten in glasvocht van patiënten met een netvlieslosla- 
ting. Met behulp van HPLC werden de concentraties van citrulline, arginine and nitriet gemeten in glasvocht van 93 ogen met een netvliesloslating, 10 ogen met een tractie ablatio ten gevolge van proliferatieve diabetische retinopathie en in 49 controle monsters van ogen zonder netvliesloslating. De gemiddelde concentratie van citrulline en arginine was significant hoger in ogen met een netvliesloslating of een tractie ablatio dan de concentratie in de controle monsters. De gemiddelde concentratie nitriet was verhoogd in glasvocht van patiënten met een netvliesloslating maar deze verhoging was niet significant.

In Hoofdstuk 6 hebben we de cGMP productie door RPE cellen bepaald, evenals de rol van de oplosbare en membraan gebonden cyclases hierin. De cGMP productie werd bepaald in de aanwezigheid van een niet specifieke PDE remmer. Stimulatie van het membraan gebonden cyclase (pGC) met ANP resulteerde in hoge intra- en extracellulaire cGMP waarden. Stimulatie van het oplosbare cyclase (sGC) met SNP resulteerde in licht verhoogde cGMP waarden ten opzichte van de controle situatie zonder SNP. Deze experimenten laten zien dat humane RPE cellen in staat zijn cGMP te produceren en dat dit vooral gebeurt na stimulatie van pGC.

In Hoofdstuk 7 hebben we de cGMP productie bestudeerd in RPE cellen na remming van NOS, sGC of pGC. Verder hebben we NADPH-diaphorase activiteit en de aanwezigheid van de $\beta-1$ en $\alpha-2$ subunits van sGC, iNOS en ANP aangetoond. De resultaten onderstrepen de rol van ANP in de cGMP productie en laten zien dat er twee autocriene wegen zijn die de cGMP synthese aansturen in gekweekte humane RPE cellen. De aanwezigheid van iNOS en de continue cGMP productie door sGC in RPE cellen is met elkaar verbonden en zou een onderdeel kunnen zijn van het cGMP regel mechanisme dat de effecten van ANP en NO combineert.

In Hoofdstuk 8 hebben we onderzocht welke PDE's betrokken zijn bij de afbraak van cGMP in RPE cellen. In de afwezigheid van PDE remmers is het cGMP niveau in gekweekte RPE cellen laag. In de aanwezigheid van Bay607550 als een selectieve PDE2 remmer, sildenafil als een selectieve PDE5 remmer of Sch51866 als een selectieve PDE9 remmer is de hoeveelheid cGMP sterk verhoogd, vooral na simultane stimulatie van pGC. Verder hebben we mRNA van PDE2, PDE5 en PDE9 aangetoond in gekweekte humane RPE cellen en RPE cellagen in vivo van de rat.

In Hoofdstuk 9 beschrijf ik onze studie naar de cGMP expressie in varkens retina's en glasvochtmonsters na het creëren van een experimentele netvliesloslating. We hebben cGMP aangetoond in de glasvocht monsters en vonden significant lagere waarden in glasvocht van varkensogen na een netvliesloslating in vergelijking met gezonde varkensogen. Wanneer we de aanwezigheid van cGMP in de retina vergelijken tussen ogen met en zonder netvlies- 
loslating zien we alleen verschil na stimulatie van pGC met ANP. In deze conditie kon cGMP aangekleurd worden in de buitenste kern laag van de losse retina en niet in dezelfde laag van de normale gezonde retina.

In Hoofdstuk 10 vat ik de belangrijkste bevindingen van mijn promotie onderzoek samen en bediscussieer ik deze. Verder bespreek ik mogelijke richtingen voor toekomstig onderzoek. 


\section{CURRICULUM VITAE}

Roselie Diederen was born on March 25rst 1977 in Heerlen, The Netherlands. After she graduated for secondary school, VWO, at St,- Janscollege in Hoensbroek in 1995 she started her medical training at Maastricht University. She received her doctoral diploma in medicine in 1999. After a research internship at the department of Dermatology (Academic Hospital Maastricht), an elective internship in Pediatrics at New South Wales hospital in Newcastle (Australia) and an elective internship in Ophthalmology (Academic Hospital Maastricht) she received her medical doctor degree in 2002. Thereafter she started her Ph.D. project on retinal detachment at the department of Ophthalmology at the Academic Hospital Maastricht and the department of Psychiatry and Neuropsychology at the Maastricht University, which is part of the European Graduate School of Neuroscience (EURON). The author received a grant from the Dutch Scientific Organization (NOW) for a working visit with Prof. B. Winkler at the Eye Research Institute at the Oakland University in Rochester (Michigan, USA). Several conferences were visited, including the 2004, 2005 and 2006 Annual Meeting from the Association for Research in Vision and Ophthalmology (ARVO), for which she received two travel grants form the Universiteitsfonds Limburg/SWOL. The results of her PhD research are described in this thesis. In April 2007 she will start her residency in Ophthalmology at the VU University Medical Center in Amsterdam, headed by Prof. dr. PJ Ringens and Prof. dr. BC Polak. 


\section{CURRICULUM VITAE}

Roselie Diederen werd geboren op 25 maart 1977 in Heerlen. Na het behalen van het eindexamen VWO aan het Sint Janscollege in Hoensbroek in 1995, startte zij met de studie geneeskunde aan de Universiteit Maastricht. Zij behaalde haar doctoraal diploma geneeskunde in 1999. Na een wetenschapsstage bij de afdeling dermatologie (Academisch Ziekenhuis Maastricht), een keuze co-schap kindergeneeskunde in het New South Wales hospital in Newcastle (Australië) en een keuze co-schap oogheelkunde (Academisch Ziekenhuis Maastricht), behaalde ze in 2002 haar arts diploma. Vervolgens is zij begonnen met haar promotie onderzoek naar netvliesloslating bij de afdelingen Oogheelkunde van het Academisch Ziekenhuis Maastricht en Psychiatrie en Neuropsychologie aan de universiteit Maastricht, onderdeel van the European Graduate School of Neuroscience (EURON). De auteur verkreeg een beurs van de Nederlandse Wetenschappelijke Organisatie (NWO) voor een werkbezoek in het kader van haar promotie onderzoek bij Prof. B. Winkler in het Eye Research Institute aan de Oakland University in Rochester (Michigan, USA). Verschillende congressen werden bezocht waaronder drie maal de Annual Meeting from the Association for Research in Vision and Ophthalmology (ARVO). Hiervoor ontving ze onder meer subsidies van het Universiteitsfonds Limburg/SWOL. De resultaten van haar promotie onderzoek zijn te lezen in dit proefschrift. In april 2007 start de auteur met de opleiding oogheelkunde van het VU Medisch Centrum in Amsterdam, bij opleiders Prof. dr. P.J. Ringens en Prof. dr. B.C. Polak. 


\section{DANKWOORD}

Bij het voltooien van mijn onderzoek heb ik hulp gekregen van velen. Bij dezen wil ik dan ook iedereen bedanken die op enigerwijs heeft bijgedragen bij het tot stand komen van dit proefschrift. In dit dankwoord wil ik graag een aantal mensen in het bijzonder bedanken.

Allereerst mijn beide co-promotoren dr. Ellen La Heij en dr. Jan de Vente. Ellen, zonder jou had ik hier niet gestaan. Bedankt voor je hulp, maar vooral voor het vertrouwen en de vrijheid die jij me tijdens dit onderzoek gegeven hebt. Je stond me altijd bij met raad en daad. Ik vind het bijzonder hoe jij mij, ondanks je drukke schema in de kliniek zo goed begeleid hebt. Ellen, ik heb veel van je geleerd, bedankt! Jan, bedankt voor jouw enthousiasme voor mijn onderwerp en vooral voor cGMP. Jij wist mij altijd te motiveren en inspireren bij het bedenken en uitvoeren van de experimenten. Ik kon, ook nadat je met pensioen bent gegaan altijd op je rekenen. Jan, bedankt voor alles!

Veel dank ben ik ook verschuldigd aan mijn promotor Prof. dr. F. Hendrikse. Bedankt voor je steun en vertrouwen gedurende de afgelopen 4 jaar. Tevens wil ik je langs deze weg bedanken voor je hulp bij de afronding van dit project.

Prof. dr. A. Kijlstra, beste Aize, ontzettend bedankt voor je advies en sturing tijdens mijn onderzoek. Vooral tijdens het schrijven van mijn artikelen ben jij van onschatbare waarde geweest. Volgens mij heb ik nooit langer dan een dag op een antwoord van jouw hoeven wachten.

Prof. dr. H. Steinbusch, bedankt dat ik op jouw afdeling in alle vrijheid mijn onderzoek heb mogen uitvoeren.

Suzanne, hartelijk dank voor onze plezierige samenwerking. Ook al werkte we beide aan een ander onderwerp. Veel succes bij je volgende project.

Prof. B. Winkler a special word of thanks goes to you. Dear Barry and colleagues (Marry and Cathy) from the Eye Research Institute (Oakland University, Rochester, Michigan, USA), great thanks for the valuable and enjoyable time I spent in the United States. Not only our work in the lab, but also our trips (to the opera e.a.) made my visit to Rochester a great experience.

Dr. F. Kessels, beste Fons, bedankt voor je hulp bij de statistiek van mijn onderzoek. Het was fijn dat je altijd op korte termijn "even" tijd voor me hebt willen maken. 
Marjanne Markerink-van Ittersum, Hellen Steinbusch en Marjo van de Waarenburg, zonder jullie hulp op het lab was het nooit gelukt. Vele malen dank.

Ellen Timmermans, Sandra Haverman, Marjan Janssen, Akke Spauwen en Mirese Willems, bedankt voor de geweldige secretariële ondersteuning.

Nicolle Senden, ik vond het leuk om mee te mogen helpen aan de EURON $\mathrm{PhD}$-dagen in Maastricht.

(Ex) collega's bij basale neurowetenschappen, ik heb een hele gezellige en leerzame tijd gehad bij jullie op de afdeling. Ik wil jullie graag bedanken voor alle leuke momenten in het lab en in de stad (vooral met carnaval).

Arts-assistenten oogheelkunde, ook als "buitenbeetje" hebben jullie mij al die jaren betrokken bij de gebeurtenissen op de afdeling. Ik vond het altijd erg gezellig om met jullie naar alle refereeravonden, etentjes en recepties te gaan. Ik wens jullie erg veel succes met jullie opleiding en we zullen elkaar in de toekomst gelukkig regelmatig blijven tegen komen.

Evi, mede dankzij jou ging ik iedere dag met plezier naar mijn werk. We hebben de afgelopen vier jaar samen erg veel gelachen op onze kamer. Maar gelukkig werd er tussendoor ook hard gewerkt en hebben we elkaar altijd goed kunnen steunen en motiveren. Ik wens je heel veel succes bij het afronden van jouw promotie!

Esther, zusje, wat er ook gebeurd jij laat mij altijd lachen. Ik vind het fijn dat jij mijn paranimf wilt zijn. Ik ben trots op je.

Pap en mam, bij iedere beslissing die ik neem, geven jullie mij de steun en het vertrouwen dat ik nodig heb. Ook bij het voltooien van dit proefschrift zijn jullie van onschatbare waarde geweest.

David, super bedankt voor alle liefde, hulp en interesse. 


\section{PUBLICATIONS AND PRESENTATIONS}

\section{Journal articles}

Dieudonné SC, La Heij EC, Diederen RMH, Kessels AGH, Liem ATA, Kijlstra A, Hendrikse F. High TGF- $\beta 2$ levels during primary retinal detachment may protect against proliferative vitreoretinopathy. Invest Ophthalmol Vis Sci. 2004; 45(11):4113-8.

La Heij EC, Dieudonné SC, Mooy CM, Diederen RMH, Liem ATA, Van Suylen RJ, Hendrikse F. Analysis of the internal Limiting Membrane peeled with infracyanine green. Am J of Ophthal. 2005; 140(6):1123-5.

Diederen RMH, La Heij EC, Deutz NEP, Kessels AGH, Van Eijk HMH, Hendrikse F. Increased nitric oxide (NO) pathway metabolites in the vitreous fluid of patients with rhegmatogenous retinal detachment or diabetic traction retinal detachment. Graefes Arch Clin Exp Ophthalmol. 2006; 224:683-688.

Diederen RMH, Starnes CA, Winkler BS. Reexamining the hyperglycemic pseudohypoxia hypothesis of diabetic oculopathy. Invest Ophthalmol Vis Sci. 2006; 47(6):2726-31.

Diederen RMH, La Heij EC, Deutz NEP, Kijlstra A, Kessels AGH, Van Eijk HMH, Liem ATA, Dieudonné S, Hendrikse F. Increased glutamate levels in the vitreous of patients with retinal detachment. Exp Eye Res. 2006; 83(1):45-50.

Diederen RMH, La Heij EC, Markerink-van Ittersum M, Kijlstra A, Hendrikse F, De Vente J. Cyclic GMP synthesis by human retinal pigment epithelial cells is mainly mediated via the particulate guanylyl cyclase pathway.

Ophthalmic Res. 2007; 39:55-59.

Diederen RMH, La Heij EC, Markerink-van Ittersum M, Kijlstra A, Hendrikse F, De Vente J. Selective blockade of Phosphodiesterases Type 2, 5 and 9 results in cGMP accumulation in Retinal Pigment Epithelium Cells. Br J Ophthalmol (in press)

Diederen RMH, La Heij EC, Kessels AGH, Goezinne F, Liem ATA, Hendrikse F. The effect of duration of macular detachment on visual recovery after macula-off Rhegmatogenous Retinal Detachment. Ophthalmology (in press)

Dieudonné SC, La Heij EC, Diederen RMH, Kessels AGH, Liem ATA, Kijlstra A, Hendrikse F. VEGF-PEDF Balance prior to PVR Development. Ophthalmic Res. (in press)

\section{Submitted}

Diederen RMH, La Heij EC, Kessels AGH, Goezinne F, Liem ATA, Kijlstra A, Hendrikse F. Pre-operative factors influencing visual outcome and anatomic success after retinal detachment without macular involvement. 
Diederen RMH, La Heij EC, Markerink-van Ittersum M, Hendrikse F, De Vente J. Two autocrine pathways to regulate cGMP synthesis in cultured human RPE cells.

Diederen RMH, La Heij EC, Lemmens MAM, Kijlstra A, De Vente J, Hendrikse F. Cyclic GMP in the pig vitreous and retina after experimental retinal detachment.

\section{Abstracts (most relevant)}

Diederen RMH, La Heij EC, Liem ATA, Hendrikse F. Scleral buckling surgery after macula-off retinal detachment; worse visual outcome after more than six days. Annual meeting ARVO, May 1 - 5, 2006. Fort Lauderdale, Florida, USA (poster)

Diederen RMH, La Heij EC, Liem ATA, Hendrikse F. Effect van de duur dat de macula los ligt op het visus resultaat na cerclage plombe chirurgie bij patienten met een rhegmatogene ablatie retinae. De 201e Vergadering Nederlands Oogheelkundig Gezelschap (NOG), 22 - 24 Maart 2006. Groningen, The Netherlands (oral presentation)

Diederen RMH, La Heij EC, Deutz NEP, Hendrikse F. Glutamate and Nitric oxide in vitreous of patients with retinal detachment. September 2005. Department of Ophthalmology, University Clinic Aachen, Aachen, Germany. (oral presentation)

Diederen RMH, La Heij EC, De Vente J, Markerink-van Ittersum M, Kijlstra A, Hendrikse F. Cyclic GMP metabolism and PDE expression in Retinal Pigment Epithelial cells. Annual meeting ARVO, May 1 - 5, 2005. Fort Lauderdale, Florida, USA. (poster)

Diederen RMH, La Heij EC, De Vente J, Markerink-van Ittersum M, Kijlstra A, Hendrikse F. Cyclic GMP metabolism in Retinal Pigment Epithelial cells. 9th EURON PhD student meeting, 8 - 9 September 2005, Liège, Belgium. (poster)

Diederen RMH, La Heij EC, De Vente J, Markerink-van Ittersum M, Kijlstra A, Hendrikse F. Cyclic GMP and NOS expression in Retinal Pigment Epithelial Cells. Annual meeting ARVO, April 30 - May 4, 2004. Fort Lauderdale, Florida, USA. (poster)

Diederen RMH, La Heij EC, Liem ATA, Hendrikse F. Glutamaat concentratie in glasvocht van patienten met een ablatio retinae. De 199e Vergadering Nederlands Oogheelkundig Gezelschap (NOG), 24 - 26 Maart 2004. Amsterdam, The Netherlands. (oral presentation)

Diederen RMH, La Heij EC, Deutz NEP, Liem ATA, Hendrikse F. Glutamate concentrations in vitreous of patients with retinal detachment. Annual meeting EVER, September, 2003. Allicante, Spain (poster) 